Keywords: International Union of Crystallography; Executive Committee.

Supporting information: this article has supporting information at journals.iucr.org/a

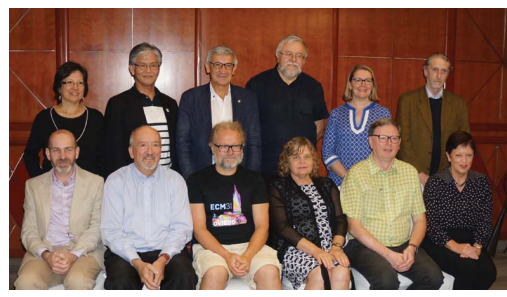

(C) 2019 International Union of Crystallography

\section{Twenty-Fourth General Assembly and International Congress of Crystallography}

The Twenty-Fourth General Assembly and International Congress of Crystallography were held at the Hyderabad International Convention Centre, Hyderabad, India, 21-28 August 2017, by invitation of the Indian National Science Academy. A report, including a detailed report of the General Assembly, will be published. The General Assembly and Congress were attended by 1748 participants from 73 countries. The Eleventh Ewald Medal and Prize were accepted by Professor T. Blundell at the Opening Ceremony. The fourth Gjønnes Medal in Electron Crystallography was awarded to Professor R. Henderson and to Professor N. Unwin. There were three Plenary Lectures, 40 Keynote Lectures, 119 Microsymposia and Open Commission Meetings. An easy-to-use mobile app and attendee website were available to serve as the platform for the real-time Scientific Programme. A commercial exhibition comprising 58 companies and booksellers was organized. The General Assembly met on the evenings of Tuesday 22 August, Wednesday 23 August and Saturday 26 August. Applications for membership from Albania and Kosovo, Bangladesh, Singapore and Tunisia (all category I) were accepted. The change in names for the Adhering Body of the Regional Committee of Crystallographers from Malaysia, Thailand and Vietnam was accepted. The Minutes of the Twenty-Third General Assembly in 2014 were approved. The General Assembly received the triennial financial report, the report of the IYCr Project Manager and the reports of the Executive Committee, the Commissions, the Scientific Associates and Regional Associates, and the Union Representatives on Other Bodies since the Twenty-Third General Assembly in 2014. New officers of the Union, Chairs and members of Commissions and Union Representatives were elected; the full list of these people will be given as an Appendix to the Report of the Twenty-Fourth General Assembly and Congress. The Commission on Crystallography of Materials was approved. Reports of the Chair of the Sub-committee on the Union Calendar, of the Chair of the Committee for the Maintenance of the CIF Standard, of the Diffraction Data Deposition Working Group and of the Editor of the IUCr Newsletter were received. The General Assembly approved the recommendation that the unit contribution remain unchanged at CHF 1000 for the years 2018-2020 inclusive. It reaffirmed its decision to hold the Twenty-Fifth General Assembly and Congress in Prague, Czech Republic, in 2020. It also accepted an invitation from the Society of Crystallographers in Australia and New Zealand to hold the Twenty-Sixth General Assembly and Congress in Melbourne, Australia, in 2023. The Executive Committee met for several days before and most days during the Congress, mainly to deal with matters directly related to the business of the General Assembly and the work of the Commissions.

\section{Other meetings}

The IUCr sponsored the following meetings held during 2017:

XVI Intensive Teaching School in X-ray Structure Analysis, Durham, UK, 25 March 2 April 2017.

4th School on Crystal Structure Determination from Diffraction Data; Application on Powder Samples, Hammamet, Tunisia, 7-9 April 2017.

RapiData 2017, Stanford, USA, 16-21 April 2017.

Understanding Biology through Structure, Santa Fe, USA, 13-17 May 2017.

Modern Trends in Mathematical Crystallography - 2nd Manila International Workshop on Mathematical Crystallography, Manila, Philippines, 20-24 May 2017.

6th International School on Biological Crystallization, Granada, Spain, 29 May 2 June 2017. 
To.Sca.Lake 2017: Total Scattering for Nanotechnology on the Como Lake, Como, Italy, 29 May - 2 June 2017.

6th ALMA Conference Painting as a Story and 2nd CrysAC

Workshop, Brno, Czech Republic, 31 May - 3 June 2017.

Integrative Structural Biology (50th Erice School), Erice, Italy, 2-11 June 2017.

Shanghai International Crystallographic School Working with Bilbao Crystallographic Server, Shanghai, People's Republic of China, 11-17 June 2017.

Zürich School of Crystallography 2017: Bring Your Own Crystals, Zürich, Switzerland, 11-23 June 2017.

School on Charge Density and MoPro, Mexico City, Mexico, 12-15 June 2017.

Mineral Fibres: Crystal Chemistry, Chemical-Physical Properties, Biological Interaction and Toxicity, Modena, Italy, 17-21 June 2017.

4th European Crystallography School (ECS4): HighThroughput Structure Analysis - From Routine Chemical Problems to Advanced Applications, Warsaw, Poland, 2-7 July 2017.

International School on Fundamental Crystallography and Workshop on Structural Phase Transitions: Satellite School of the 24th IUCr Congress 2017, Odisha, India, 30 August 4 September 2017.

AIC International Crystallography School 2017, Pavia, Italy, 3-6 September 2017.

International Autumn School on Fundamental and Electron Crystallogrpahy, Sofia, Bulgaria, 8-13 October 2017.

IX School of the Argentinian Association of Crystallography, Bahia Blanca, Argentina, 6-10 November 2017.

Macromolecular Crystallography School 2017; Structural Biology to Enhance High Impact Research in Health and Disease, Montevideo, Uruguay, 13-23 November 2017.

\section{Executive Committee}

The membership of the Executive Committee, including new members elected at the General Assembly in 2017, is as follows: President: Professor S. Lidin (Sweden); VicePresident: Dr H. A. Dabkowska (Canada); General Secretary and Treasurer: Professor L. Van Meervelt (Belgium); Immediate Past President: Professor M. L. Hackert (USA); ordinary members: Professor W. Depmeier (Germany), Professor G. C. Diaz de Delgado (Venezuela), Professor S. Garcia-Granda (Spain), Professor R. Kuzel (Czech Republic), Professor J. L. Martin (Australia), Professor M. Takata (Japan).

\section{Publications}

Volume 73 of Acta Crystallographica, Volume 50 of Journal of Applied Crystallography $(J A C)$, Volume 24 of Journal of Synchrotron Radiation (JSR) and Volume 4 of IUCrJ were published.

\section{Adhering Bodies}

A list of Adhering Bodies of the Union, with names and addresses of the Secretaries of the National Committees for Crystallography, will be published as Appendix D to the Report of the Twenty-Fourth General Assembly and International Congress of Crystallography.

\section{Work of the Commissions \\ 6.1. Commission on Journals}

6.1.1. IUCrJ

IUCrJ had an excellent year in 2017, with a record number of papers published and further establishing itself within the wider scientific communities that use the results obtained from diffraction methods. Impressions from authors, readers, referees and commentators are very positive with a number of papers receiving high downloads in line with high-impact publications.

The journal reached an impact factor of 5.8 in 2017. All submissions undergo preliminary screening by a panel consisting of the Main Editors (Ted Baker, Richard Catlow, Gautam Desiraju, Sine Larsen, John Spence, and, since the start of 2018, Sriram Subramaniam) and the Editor-in-chief (Samar Hasnain), and this has helped to provide a rapid and efficient review process. Preliminary screening is generally complete within $72 \mathrm{~h}$, and any articles that do not meet the journal's requirement for broad scientific significance are usually transferred, with the agreement of the authors, to another IUCr journal. Such transfers are seamless and do not require any further work by the authors.

The six issues of $I U C r J$ published in 2017 featured papers from a wide variety of areas including biology, chemistry, crystal engineering, cryo-electron microscopy (cryo-EM), materials, physics and free electron lasers (FELs). In addition, a number of key papers were captured from the IUCr 2017 Congress, with some of the articles published ahead of the Congress. The number of articles submitted to the journal was 133; a total of 93 papers were published with an average turnaround time of 15 weeks. Articles have been highlighted by a number of different methods, with 12 articles highlighted via in-depth commentaries.

A total of 23 papers were published in the biology and medicine section of IUCrJ, representing approximately $25 \%$ of the total papers published. In addition, papers in several other sections, notably neutron and synchrotron science and technology and physics and FEL science and technology, described applications in structural biology or medicine. It is evident that the biological sciences are a major source of highimpact crystallographic publications, and it is important that this momentum should be maintained. Most of the papers published in this section combined multiple structural approaches, or utilized emerging technologies such as serial crystallography, FEL-based methods or high-resolution cryoEM. With a new cryo-EM section being established in 2018, some papers that currently appear in the Biology and Medicine section will go to cryo-EM, but this will undoubtedly 
boost the overall structural biology profile of the journal in a very beneficial way. Highlights of the biology and medicine section during 2017 include an outstanding review by Professor Sir Tom Blundell, describing the contributions of crystallography to the development of new medicines, and a number of papers using serial crystallography or related approaches that showed that the long-held goal of being able to 'see' each individual step in an enzymatic reaction is now coming within reach.

The chemistry and crystal engineering section of the journal continued to make progress in 2017. There were 36 submissions of which 31 articles were voted for review in 2017 and four were directed successfully to Acta Cryst. B or C. Of these, 22 were accepted for publication, with four rejected and five still in review at the end of the year. These numbers are satisfying. This section continues to pull its weight and is contributing to the impact factor of 5.8. At the present time, one would hope to see more submissions, especially in the MOF and COF area, and also more citations to papers already published. It is of note that within the crystal engineering community, $I U C r J$ is perceived to be a better journal than competitors like Crystal Growth and Design and CrystEngComm. Certain papers in journals like J. Am. Chem. Soc. and Angew. Chem. Int. Ed. are declined for having too high a 'crystallographic content'. We should attempt some strategy to attract such papers to IUCrJ rather than see them diverted to journals like Chem. Eur. J. or Dalton Trans. The present Co-editors of the Chemistry and Crystal Engineering section of the journal are M. Eddaoudi, C. Lecomte, P. Lightfoot, L. R. MacGillivray and C.-Y. Su.

The other sections of the journal, covering materials and computation, neutron and synchrotron science and technology, and physics and free electron laser science and technology have published 14 , eight and 16 papers, respectively, in 2017, and have illustrated the rapid advances that are being made in these fields.

As mentioned above, a major new development at the start of 2018 has been the launch of a section of the journal dedicated to cryo-EM. Sriram Subramaniam is the Main Editor for this section, and he, together with Werner Kühlbrandt and four new Co-editors - Esther Bullitt, Lori Passmore, Stefan Raunser and Fei Sun - aim to attract high-quality papers and champion IUCrJ as the natural home for cryo-EM results and breakthroughs in instrumentation and methods developments.

We hope that you will consider publishing in $I U C r J$ and, by doing so, help to further establish the journal as one of the mainstream comprehensive science journals.

D. Argyriou, E. N. Baker, G. R. Desiraju, C. R. A. Catlow and J. C. H. Spence, Editors

\subsubsection{Acta Crystallographica Section A}

In 2017 we continued to offer rapid review and publication of potentially high-impact papers in the Advances section of the journal. Five research articles and one short communication were published under the Advances banner: A general algo- rithm for generating isotropy subgroups in superspace, by Harold T. Stokes and Branton J. Campbell, with a commentary To superspace and beyond by Mark S. Senn; A projectionbased reformulation of the coincident site lattice for arbitrary bicrystals at finite temperature by B. Runnels, with a commentary Approximating coincidence - turning a new page for bicrystallography by Srikanth Patala; Three-dimensional single-cell imaging with $X$-ray waveguides in the holographic regime, by Martin Krenkel, Mareike Toepperwien, Frauke Alves and Tim Salditt, with a commentary Introducing the holo-TIE approach to cellular imaging by Ian Robinson; Highresolution $X$-ray diffraction with no sample preparation, by G. M. Hansford, S. M. R. Turner, P. Degryse and A. J. Shortland; Z-module defects in crystals, by Abdullah Sirindil, Marianne Quiquandon and Denis Gratias; and A firstprototype multi-determinant $X$-ray constrained wavefunction approach: the $X$-ray constrained extremely localized molecular orbital valence bond method, by Alessandro Genoni. The article by Graeme Hansford et al. featured in a news item on the IUCr web page (Pioneering $X$-ray technique to analyse ancient artefacts), which was timed to coincide with a press release from the University of Leicester. Authors of Advances clearly appreciate the efforts made to highlight their articles (often with accompanying commentaries or news items, promotion in social media and/or being featured on the cover), and several authors continue to send us good articles for consideration. An analysis of the performance of Advances papers over the last three years has shown that they are downloaded and cited at a consistently higher level than average for the journal.

The number of papers published in 2017 was down on previous years, but this is partly owing to our increasing tendency to encourage authors who had previously been publishing frequent but rather incremental pieces of research to consider combining these into one longer article describing the whole body of work and its possible significance in more detail. We also require authors to explain the wider significance of their work, and work with them on improving titles, keywords and abstracts to increase the likelihood that their paper will be found by search engines.

The 2016 impact factor that was announced in 2017 saw a boost from its usual level of around 2.3 to 5.7, mainly because of two highly cited articles on computer programs (SHELXT and $O L E X 2)$ published back in 2015. The high impact factor, which should persist for another year, might be attracting new authors to consider publishing in Acta A. However, we do not feel that the impact factor is a good reflection of the value of Acta $A$ as a publication - as we publish a high proportion of articles on innovative new techniques and methods, we see that there is often a delay in uptake of these new ideas by the wider community that means that these papers are often highly cited a few years later, outside the impact-factor calculation window.

A lead article Quasicrystals: What do we know? What do we want to know? What can we know? by Walter Steurer was published at the end of 2017 as part of the January 2018 issue, and has already generated a lot of interest. 
Looking forward, we are planning a special issue based around selected papers from the Aperiodic18 conference. We discussed a special issue on electron microscopy (but combined this with a similar activity in Acta B, with Acta B taking the lead).

Finally, I would like to thank all the Co-editors for their hard work during the year, and welcome Laure Bourgeois from Monash University, who joined the Editorial Board in September.

\section{S. J. L. Billinge, Editor}

\subsubsection{Acta Crystallographica Section B}

Acta Crystallographica Section $B$ continues to publish six issues per year and in 2017 achieved the highest numbers of submissions (175), published papers (134) and pages (1199) in recent years, in part because of the publication of two Special Issues. These were on Halogen bonding (Guest Editors: Mate Erdelyi and Pierangelo Metrangolo) and on Charge density, photocrystallography and time-resolved crystallography: a tribute to Professor Philip Coppens (Guest Editors: Claude Lecomte, Jason Benedict and Yu-Sheng Chen). We are most grateful to these Guest Editors for their insight and hard work in bringing about these Special Issues.

We note that publishing such a large number of articles has a direct effect on the average publication time, and while Special Issues have many advantages they need to be planned and implemented carefully. We also note that the rejection rate in 2017 (34\%) falls within the long-term range for the journal of $28-40 \%$ and feel there is no need for specific action. The average length of a paper (9.8 pages) has fallen back slightly, reversing a trend towards longer papers. The number of open-access papers is still very low and we propose that the advantages of making papers open access should be spelt out more strongly, notably at the article's proof stage.

The journal's impact factor reached 2.9 in 2015, in part due to the effects of a small number of highly cited Feature Articles. As these articles moved out of the citation window it fell back to 2.2, but with the inclusion of some very highly cited articles published in 2016 we anticipate major increases to $>6.0$ for 2017 and 2018. While we wish to take full advantage of this increase in impact factor to promote the journal and attract high-quality submissions, we also want to avoid dependency on such small numbers of articles. To this end, we regularly solicit invited articles from prominent scientists such as Keynote Lecturers at IUCr Congresses and Regional Associate Meetings. Our analysis suggests that Invited Articles have higher impact than Special Issues and, while we intend to continue with both, there will be a strong focus on the former. We have broadened the range of authors we approach for Invited Articles and will maintain and use an active list of potential authors and topics.

We wish to express our deep thanks to Dave Billing, Elena Boldyreva, Nadezhda Bolotina, Francesca Fabbiani, T. N. Guru Row, Chris Howard and Alan Pinkerton who retired from the Editorial Board at or before the Hyderabad IUCr
Congress: their many contributions to the journal are most appreciated. We welcome to the Board Stefan Adams, Joke Hadermann, C. M. Reddy and Piero Macchi, and we look forward to working with them. Further appointments will be announced later this year. We would like to express our thanks to the Chester staff, especially Jill Bradshaw and Amanda Berry, for all their support.

\section{A. J. Blake, M. de Boissieu and A. Nangia, Editors}

\subsubsection{Acta Crystallographica Section C}

Tony Linden retired as Main Editor of Acta Crystallographica Section $C$ in August 2017 having served in the role for nine years. His contribution to the journal over this period has been enormous and it is appropriate to record the thanks of the co-Main Editors, Paul Raithby, Larry Falvello and Jonathan White, the editorial team at the IUCr Chester office, the Acta $C$ Co-editors and the crystallographic community at large to him for his sterling efforts. Tony has led the development of the journal with the introduction of special issues and of feature articles, and by the setting up of a $60+$ member Review Board to ensure that high-quality reviews are received within a reasonable time. This success has been reflected in the metrics for the journal. The impact factor for 2016 leapt to 4.1 from 0.48 for 2015 and a further increase is expected in 2017. This increase can be attributed to multiple citations for the SHELXL and PLATON feature articles. The number of submissions in 2017 has shown a modest increase to 367 from 335 in 2016, and is moving towards the target of 400 in future years. The rejection rate in 2017 has remained steady at $47 \%$. During 2017 there has been a pleasing increase in the number of papers that include a significant amount of chemistry in addition to the core crystallography, and that tell a chemical story. Further evidence for the trend of including a more detailed discussion of chemical and crystallographic data is the increase in the average page length of each paper. In 2017 this increased to an average of 6.7 pages per article, which shows a marked increase on the average of 4.5 pages per article only four years ago. This indicates that our aim to attract more members of the chemistry community to the journal readership is working. We should add that papers where the crystallography is sound but where there is no chemical story are being recommended for transfer to Acta E, and this process continues to work smoothly.

We are conscious that the benefit of the increased impact factor through the large number of citations from the SHELX and PLATON papers has a limited life span, and we are planning further high-profile articles to maintain the high impact of the journal. To this end, during 2017, following up the success of the feature articles on SHELXL and PLATON, the journal published a feature article by Richard Cooper, (the late) Howard Flack and David Watkin entitled $H U G$ and SQUEEZE: using CRYSTALS to incorporate resonant scattering in the SQUEEZE structure-factor contributions to determine absolute structure, describing methods for enhancing the success of absolute structure determination. We hope that feature articles on $O L E X 2$, from Horst Puschmann, and 
CrysAlis, from Mathias Meyer, will appear towards the end of 2018.

During 2017, the journal published one special issue, on NMR Crystallography, that contained two topical reviews. We thank the two guest editors, David Bryce (University of Ottawa, Canada) and Francis Taulelle (KU Leuven, Belgium), for coordinating a substantial issue, bringing together traditional crystallography with the results from solid-state NMR spectroscopy, to provide very powerful complementary tools for structure determination. A special issue on an important area of inorganic chemistry, polyoxometalates, will be published in 2018. The issue was commissioned by Larry Falvello and we are grateful to the two guest editors, José Ramón Galán-Mascarós (Institute of Chemical Research of Catalonia, ICIQ, Spain) and Ulrich Kortz (Jacobs University, Germany) for all the work that they have put in to make this important issue a success.

In 2017 we have further strengthened our team of Co-editors with the addition of Helena Shepherd (University of Kent, UK), David Turner (Monash University, Australia) and Ian Williams (Hong Kong University, Hong Kong). We look forward to working with them in the coming years. Teresa Duarte and Uli Englert have recently retired from the Co-editors team and we would like to thank them for all their hard work and support that they have given to the journal. We are conscious that with the increasing chemistry component in the papers submitted we need Co-editors and review board members with expertise beyond crystallography and have recently conducted a survey to assess the additional expertise already present among our editorial and review teams. We will use these data to better match submissions with editors and referees.

L. R. Falvello, P. R. Raithby and J. White, Editors

\subsubsection{Acta Crystallographica Section D}

Challenges continue for Acta $D$. The impact factor has declined slightly to 2.1 but remains within the historic range of 2 to 3. In spite of the obvious flaws of the impact factor as a measure of journal relevance and quality, it unfortunately continues to influence the choice of venue for authors. The number of submissions has stabilized, but ideally should be higher in the longer term.

There are nonetheless positive developments. The change of scope to cover a wider range of structural biology is yielding fruit: a special June issue contained a number of excellent contributions arising from the 2016 CCP-EM Spring Symposium. This is fitting given the enthusiasm with which many macromolecular crystallographers have embraced the new opportunities for structural biology provided by the rapidly improving instruments and methods for cryo-EM. Acta $D$ was also chosen as the home for the 2017 Publication guidelines for structural modelling of small-angle scattering data from biomolecules in solution: an update. Since these guidelines were published in August, they have already been viewed over 2000 times and cited ten times.
A highly successful CCP4 Study Weekend, also from 2016, provided a two-part special issue, spread over February and March. These proceedings are always a valued snapshot of the progress in our field.

The number of authors choosing the paid-for open-access option continues to increase, from the already high rate of $45 \%$ in 2016 to $52 \%$ in 2017 .

I am pleased to welcome three new Co-editors to our editorial board: Gino Cingolani, Bostjan Kobe and Markus Rudolph. Their appointments help to consolidate our coverage in geography and expertise.

In spite of some recent hiccups in the computer systems, electronic submissions continue to work well for authors, reviewers and editors. Thanks to the hard work of Louise Jones and Simon Glynn in the Chester Office, under the supervision of Executive Managing Editor Peter Strickland and Editor-in-chief Samar Hasnain, the journal operation runs smoothly and the publication quality is very high.

\section{R. J. Read, Editor}

\subsubsection{Acta Crystallographica Section E}

In January we received the analysis of the progress and performance of Acta Cryst. E in the form of a report by the Acta $E$ advisory board.

The overall appreciation was positive, and we are encouraged to continue working towards inclusion of the journal in the Science Citation Index Expanded. The journal was included in the Emerging Sources Citation Index (ESCI) when this was launched in November 2015. Other remarks and suggestions given in the advisory board report cover the following points:

(a) Over the period 2015-2016 there appears to be little obvious difference in quality between Acta E and Acta C judging from citation count statistics alone.

(b) The scope of the journal should be enlarged to cover inorganic, extended structures and materials, especially engaging not only crystallographers but chemists in the fields of magnetism, asymmetric catalysis or other topical subjects.

(c) Suggestions were made concerning the replacement of retiring Main Editors: Bill Harrison and Matthias Weil, who retired in September 2017 after the Hyderabad Congress. The Editor-in-chief interviewed a number of candidates and Elena Boldyreva (Russia; high-pressure crystallography) and Chiara Massera (Italy; organic molecular crystallography) were appointed and joined the two remaining Main Editors, Helen Stoeckli-Evans (Switzerland; crystallography of coordination compounds and organic/natural products) and Luc Van Meervelt (Belgium; biological and organic crystallography), in September 2017. This wide range of specialities will, we hope, encourage more authors to consider publishing in Acta Cryst. E.

(d) The possibility of publishing Topical Reviews was also suggested and a first collection of invited papers on Weak interactions in crystals: an integrated approach should appear in early 2018, edited by Chiara Massera. 
(e) Other comments concerned approaching chemists and biochemists who work in topical fields of research and for whom X-ray crystallography is indispensable for structure elucidation to encourage them to consider publishing their work in Acta Cryst. E. During the year the Managing Editor has attended various meetings to carry out this task.

In the last year the quality of papers has increased, and the range of structures has been much broader. Many papers now report two or more structures, discuss complementary techniques and include extra tables and figures to illustrate their results. We are increasingly receiving papers describing measurements using synchrotron radiation, powder diffraction analyses and Hirshfeld surface analyses.

There were 551 submissions (542 in 2016), and 449 openaccess publications (450 in 2016) from 63 countries. The number of pages published increased from 1874 in 2016 to 1986 in 2017, showing that authors are taking the opportunity of a full Crystallographic Communication to enhance the discussion of the underlying science in their papers. The average publication time remains less than one month, thanks to the efforts of our Co-editors.

The top five countries for Acta E were, as in 2016, the USA (15\%; 62 papers), India ( $9 \% ; 39$ papers), Germany $(7 \% ; 31$ papers), China ( $6 \% ; 27$ papers) and Japan $(6 \% ; 25$ papers $)$.

As always, we are extremely grateful to our Co-editors for the excellent work they do and cannot thank them enough. We have been particularly fortunate to recruit a number of new Co-editors to join the journal's hard-working team that now numbers 36, including the four joint Main Editors. We also gratefully acknowledge the work of a number of Main and Co-editors who, having achieved nine years of tireless service to the journal, retired after the Hyderabad Congress. As always, we are extremely grateful for the excellent support that we receive from the staff in Chester, particularly Gillian Holmes, Sean Conway and Mike Hoyland, for their constant help and support, and to Peter Strickland for his sound advice and expert guidance.

E. Boldyreva, C. Massera, H. Stoeckli-Evans and L. Van Meervelt, Editors

\subsubsection{Acta Crystallographica Section F}

Acta Crystallographica $F$ is profiled as a home for short and rapid structural biology communications, welcoming manuscripts covering a range of techniques, including crystallography, cryo-electron microscopy, NMR spectroscopy, SAXS and computational approaches. Preliminary results such as crystallization notes will now only be accepted if the system studied is novel and the method also has new aspects useful for researchers working on other systems. As a result, the rejection rate is up to about $40 \%$ compared with a few years ago, and the cited half-life has increased significantly. The impact factor has also been increasing, and hopefully it will get above 1.0 sooner rather than later. On a negative note, 2017 has seen the lowest number of published papers for some years, suggesting that more efforts are needed to attract potential authors. Fortunately, the data from the first four months of 2018 suggest that the number of papers is on the rise again. Thanks to the efficient work of the Co-editors and Chester staff, the average publication time is well under three months, which will hopefully attract even more high-quality structure communications. The average length of manuscripts has also increased somewhat, and this may be related to the increase in manuscript quality.

In 2017 six new Co-editors were recruited (Maria Romao, Matthew Bowler, Alok Mitra, Steven Sheriff, Gordon Joyce and Kyeong Kyu Kim) and a new Section Editor (undersigned). Together with the longer-serving Co-editors, the team of editors should be sufficient for 2018 and hopefully beyond. However, the gender balance of the Editorial Board could be improved.

The strengths of the journal include the fast but high-quality scientific and technical editing, its standing in the crystallographic community and goodwill by virtue of it being a scientific society journal. However, the impact of the journal and its familiarity to non-crystallographic structural biology communities need to be increased further.

It will be important to continue to grow the journal in terms of quantity and quality of papers, but also to maintain the philosophy of short and rapid communications in order to distinguish it from Acta Cryst. D and IUCrJ. To achieve this, special issues on interesting topics are being pursued. An issue on protein/carbohydrate structures is underway and more special issues will hopefully follow. Inaugural articles from the new Co-editors and more topical reviews are also planned.

M. van Raaij, Editor

\subsubsection{Journal of Applied Crystallography}

One major change to the Editorial Board of Journal of Applied Crystallography in 2017 was Anke Kaysser-Pyzalla stepping down as a Main Editor, after ten years at the helm. Under Anke's leadership there was a significant rise in the number of submissions to the journal, which was achieved while maintaining the range and quality of scientific content. She also guided the journal into the all-electronic age. Anke was succeeded by Garry McIntyre in the current three-strong group of Main Editors. No changes have been made to the board of Co-editors since 2015.

Journal of Applied Crystallography, in common with other IUCr journals, has now been online-only since 2014. It is probably too early to read great significance into the publication statistics of the past three years compared to earlier years, nor specifically into the numbers of submissions and of published papers being lower in 2017 than in the four previous years. One clear change, however, is the increase in the average number of pages per paper; being online only imposes a lower cost premium on the total number of pages. It is also pleasing to see that the number of open-access pages in this latest three-year period is three times that of the preceding three-year period when the paper version was still available. The fraction of each type of article has remained fairly stable 
over the past six years, but we should encourage more feature and lead articles. Such articles on subjects that are emerging could attract a new readership.

As befits the vision of the journal, the category Research Papers dominates. Amongst the other categories, the category Computer Programs leads by a significant margin, in part as a result of active encouragement by the Editorial Board, in part because of the increasing need for user-friendly, broadly applicable and robust data-collection and data-analysis tools for researchers without extensive training in crystallography. This is not the only journal category in which computer programs are published; full descriptions of the underlying algorithms plus the programs may appear as Research Papers.

Techniques, instrumentation and applications to specific materials continue to dominate in Research Papers. Growing or emerging topics include application of various crystallographic techniques to cultural heritage, total scattering and application of three-dimensional printing to develop crystallographic apparatus. The scope in the Notes for Authors appears to be quite appropriate and well defined, with just a small proportion of the submissions being transferred to another IUCr journal and an overall withdrawal rate of $8-9 \%$ over the past three years.

Virtual special issues, which collect together selected fulllength research papers associated with particular conferences or solicited on a relevant and topical technical theme, are proving to be quite popular and successful to judge by their articles drawing significantly more citations than articles in regular issues published just before or after. The most recent of these are: CCP-FEL: a collection of computer programs for FEL research (August 2016 with 17 articles), Small-angle scattering (December 2016 with 12 articles, all open access) and High-resolution X-ray diffraction and imaging (June 2017 with 17 articles, all open access). The next special issue will be on Advanced neutron scattering instrumentation (June 2018 with about 20 articles).

The latest impact factor of 2.617, published in 2017 for 2016, is lower than in the recent past, but does not reflect a general decline; the higher impact factors are largely due to the sporadic publication of articles on computer programs that draw high and obligatory citations. The recognized integrity of the journal's Computer Program papers is largely a result of the separate, non-blind but independent reviews required for the software itself, in addition to the usual blind reviews of the submitted paper. As noted above, we encourage such publications, but they should be just one part of the overall portfolio.

Overall, Journal of Applied Crystallography has made a smooth and successful transition to the all-electronic era, thanks in no small part to the dedication and professionalism of our Co-editors and reviewers. The format offers a costeffective open-access option, with free access to selected articles to attract a new readership.

Andrew J. Allen, Janos Hajdu and Garry J. Mclntyre, Editors

\subsubsection{Journal of Synchrotron Radiation}

164 papers were accepted in 2017 compared with 174 in 2016. The rejection rate decreased to $25 \%$ from $28 \%$, and publication times rose to 5.6 months (from 5.0).

The number of pages published was down compared with 2016, i.e. 1300 pages published in 2017 compared with 1563 in 2016. Both years saw one special issue published: papers from the PhotonDiag2015 workshop in 2016 and papers from the 9th International Workshop on X-ray Radiation Damage to Biological Crystalline Samples in 2017. The drop in page numbers in 2017 was most likely due to the 2016 special issue being larger and also to an unusually high number of pages published in 2016. The special issue on Radiation damage, a recurring series that has been published in $J S R$ every two years since 2002, formed part of the January 2017 issue. The guest editors were Elspeth Garman and Martin Weik, and the issue featured nine special-issue papers totalling 94 pages.

$J S R$ is continually looking to publish such themed issues of selected papers from workshops or meetings because as well as providing an important service to the synchrotron radiation community they are a good way for the journal to expand into new areas and to attract new authors and readers. Two special issues are expected in 2018 (from the PhotonDiag2017 and Q2XAFS2017 workshops) and one is already in the pipeline for 2019 (XFELs).

At the 24th Congress and General Assembly of the IUCr held in Hyderabad, India, in August, two long-standing Main Editors retired: Gene Ice and Friso van der Veen. As replacement, Ingolf Lindau was appointed as Main Editor; Ingolf is based at Stanford University, USA, and was one of the founding fathers of the Stanford Synchrotron Radiation Light Source in 1972 and the Director for the MAX-Laboratory in Lund, Sweden, 1991-1997.

The Facility Information pages continued in 2017. These provide an opportunity for facilities to communicate important news and updates to the international community of synchrotron radiation users. In 2017, facility pages were provided by the Advanced Photon Source, Paul Scherrer Institute and MAX IV, the latter upgrading their package in 2017 from two pages to the full six pages per year.

We thank the readers of $J S R$ for their continued interest and support, the authors for publishing in our journal, and the Co-editors for their great services to the journal and to the community.

Y. Amemiya, M. Eriksson, I. Lindau and I. Schlichting, Editors

\subsection{Commission on International Tables}

International Tables for Crystallography is a book series published by the IUCr in conjunction with Wiley. Eight volumes designated $\mathrm{A}$ (and A1) through $\mathrm{G}$ are currently in print, a ninth $(\mathrm{H}$, on powder diffraction) is expected to appear during 2018, and a tenth (I, on X-ray absorption spectroscopy and related techniques) is well underway. Printed volumes can be purchased individually; online access is by subscription to 
the entire series. A new, considerably revised edition of the low-cost, printed Brief Teaching Edition of Vol. A (SpaceGroup Symmetry) is expected to be available towards the end of 2018.

More than half the income from International Tables is now coming from the online subscriptions. Some printed volumes, however, continue to sell well; just over 200 copies of Vol. A (space-group tables) were sold in 2017. It seems likely that it, the related Vol. E (tables for the subperiodic rod and layer groups), and perhaps the related Vol. A1 (symmetry relations between space groups) will continue in print. The viability as printed books of the other volumes is being reviewed regularly.

The possibility of making individual articles available prior to publication of the full volume was discussed before and during the 2017 Congress in Hyderabad. The idea was received enthusiastically by editors of volumes covering fields that are changing rapidly but there are still details to be worked out; furthermore, development work would need to be done in Chester. Strategies for getting articles indexed in places like PubMed so that the articles would be directly searchable and citable are being pursued actively because such indexing is seen as very important to the recruiting of expert authors.

Descriptions of activities during 2017 for the individual volumes follow:

Volume A (Space-Group Symmetry; most recent online edition is dated 2016; editor Mois Aroyo). The 6th edition of Vol. A (ITA6) appeared at the very end of 2016 so that there was little activity during 2017. There were discussions with users of ITA6 and the authors of the chapter on space-group determination (ch. 1.6) about the possibility of including the so-called 'diffraction symbols' (also known as 'extinction symbols') in the tables of the reflection conditions.

Symmetry Database server of the Online Edition of International Tables (updated continuously; editor Mois Aroyo). Development continued through 2017. The newly designed user-oriented general menu page facilitates the access to the different databases and programs. There are help pages that explain the crystallographic items and the functionality of the tools. The Symmetry Database now gives access to: (i) Crystallographic point-group data including generators, general and special Wyckoff positions (Wyckoff letter, multiplicity, coordinate triplets and site-symmetry groups). Different types of notation are used for the presentation of the symmetry operations: as $x y z$-based coordinate triplets, in matrix form, by geometric symbols (indicating the type and order of the operations, and the orientation of the corresponding symmetry elements) and by Seitz symbols. Computer tools for coordinate transformations of the crystallographic data are also available. An interactive tool permits the visualization of the symmetry elements of the crystallographic point groups. (ii) The online-accessible space-group data have been extended to include the online determination of the sitesymmetry groups of any point of the special Wyckoff positions, the geometric interpretation of the symmetry operations and their Seitz symbols. The normalizers of the space groups including Euclidean, chirality-preserving and affine ones are also shown.

Brief Teaching Edition of Volume A (current edition is dated 2010; editor Mois Aroyo) (BTE). During 2017 material for the new edition was written and reviewed. Part 1 of BTE follows closely the introductory part of ITA6 but will be more accessible to those who are new to the field; the text has been reduced and more illustrative examples have been added. The chapter on subperiodic groups has been extended to describe the applications of layer- and rod-group descriptions of twodimensional structural units. Material in Part 2 includes brief guides to the tables of space groups (Vol. A), of the maximal subgroups and minimal supergroups (Vol. A1), and of the subperiodic groups (Vol. E). Magnetic groups are also discussed briefly. Some pages of the new BTE will be printed in colour. The material for all seven chapters of Part I and of the guides of Part 2 of BTE are ready for typesetting; publication by the end of 2018 is anticipated. It is hoped that this printed volume will not only be a guide to the space-group tables of Vol. A but will also demonstrate the breadth of modern crystallography.

Volume A1 (Symmetry Relations Between Space Groups; most recent online edition is dated 2011; editor Ulrich Müller). The expansion of Vol. A1 to cover the frieze, rod, and layer groups has been discussed. A search for a second editor has been initiated.

Volume B (Reciprocal Space; most recent online edition is dated 2010; editors Gervais Chapuis \& Michal Dušek). The information about incommensurate structures is being moved from Vol. C to Vol. B; it is fortunate that Ted Janssen completed his expert contribution on that subject before his passing. Articles on the solution of structures based on electron diffraction data and on the three-dimensional delta pair distribution function (three-dimensional-PDF) method are being written.

Volume C (Mathematical, Physical and Chemical Tables; online edition is dated 2006; editor Richard Welberry). Of the promised articles for this very major revision $75 \%$ have now been submitted or are close to being submitted. Some of these have already been reviewed and finalized. The articles outstanding are in varying degrees of preparedness. It is anticipated that typesetting will begin in the first half of 2019.

Volume D (Physical Properties of Crystals; most recent online edition is dated 2013; editor was André Authier, who has since retired). Finding a new editor is proving difficult.

Volume E (Subperiodic Groups; most recent online edition is dated 2010; editor Danny Litvin). The Seitz symbols in the print and online version of the second edition are not the kind that were later approved by the IUCr. Modification of these symbols in the online edition will be made during 2018. There have been discussions about how this volume might be developed further and a search for a second editor has begun.

Volume F (Crystallography of Biological Macromolecules; most recent online edition is dated 2012; editors Liang Tong, Michael Rossmann \& Eddy Arnold). Given the many technological advances in crystallography over the past few years (such as cryo-EM, free-electron laser sources and serial crys- 
tallography) it is timely and important to produce a new edition. For this effort Liang Tong joined the editorial team in November 2017. The second (i.e. 2012) edition of Vol. F contains 96 chapters; significant updates (primarily by the original authors) are planned for the majority of them. New chapters will describe recent advances. The chapters on electron microscopy from the section on Other Experimental Techniques in the second edition will be moved to a new section that will cover the recent revolution in this technology. The existing chapters will be updated and new chapters will be written. Possible authors have been identified.

Volume $G$ (Definition and Exchange of Crystallographic Data; online edition is dated 2006; editors Brian McMahon \& James Hester). The Volume $G$ editors met at the IUCr Congress in Hyderabad and resolved many of the outstanding issues around the overall approach and construction of the volume. Authors for most of the dictionary-related chapters are in the process of writing or updating chapters; two chapters have already been submitted for review. Some delays have occurred due to ongoing enhancement of the standards describing the dictionaries, as well as the appearance of new dictionaries suitable for incorporation into the volume.

Volume H (Powder Diffraction; new volume; editors Henk Schenk, Chris Gilmore \& Jim Kaduk). Proofs for almost twothirds of the chapters have been corrected. Publication in 2018 is expected.

Volume I (X-ray Absorption Spectroscopy and Related Techniques; new volume; editors Chris Chantler, Federico Boscherini \& Bruce Bunker). Most chapters have gone under review; a range of chapters are being revised and $20 \%$ have been accepted. Because individual chapters are shorter than in other volumes of the series some 150 experts have contributed to the project. Publication is scheduled for 2019.

Further information about the volumes can be found at the home page of the Commission, http://www.iucr.org/resources/ commissions/international-tables. The 'Guided Tour' available at http:/it.iucr.org/services/guidedtour/ is highly recommended because it shows what is available electronically. Access to the Tables of Contents of all the volumes is free, as are sample pages (including author lists and prefaces); see the homepages for the individual volumes (e.g., http://it.iucr.org/ $\mathrm{A} /$ ).

This series very much depends on the expertise and experience of the staff in Chester, and especially Nicola Ashcroft. Laying out the pages and making sure the English usage is standard are just the beginning. The numerous links in the electronic editions need to be inserted and maintained. New formats require development work. Editors and authors depend on the advice about how things have been done in the past and what might be done differently in the future. Finally, the staff in Chester are the people who interact directly with the publisher. This work largely goes on in the background, but without it the series could not continue. The staff in Chester deserve our heartfelt thanks.

\section{P. Brock, Chair}

\subsection{Commission on Aperiodic Crystals}

The new membership of the Commission (CAC) for the present triennium was approved by the General Assembly; the Commission wishes to thank its outgoing Chair, U. Grimm, for his many years of service for the promotion of aperiodic crystals.

The Commission wish to pay special tribute to Ted Janssen who passed away on 29 September 2017 at the age of 81 . He was a pioneer in the symmetry description of aperiodic crystals; his contribution to the activities of the community was always greatly valued.

The Commission has continued to promote actively aperiodic crystallography in 2017 via the organization of meetings, workshops and educational activities worldwide. Thus different workshops were organized in 2017.

Concerning education, the CAC supported the 9th Workshop on Structural Analysis of Aperiodic Crystals in Bayreuth, Germany, 23-26 March 2017 (http://aperiodic.uni-bayreuth. de/workshop_2017/). This four-day workshop was organized by the Special Interest Group on Aperiodic Crystals (AK 16) of the German Crystallographic Association (DGK), with local organizers Andreas Schönleber and Sander van Smaalen. It provided to a public of (mainly) young scientists an overview of the methods of structural analysis of incommensurately modulated crystals and composite crystals.

The series of ad hoc workshops on JANA2006 continued with the 32nd ad hoc Workshop on Basics of JANA2006 and modulated structures, 19-21 April 2017, Institute of Physics, Czech Republic.

One workshop on the mathematics of aperiodic crystals was also organized in 2017 by M. Baake: Workshop on Aperiodic Order: Enumeration Problems, Dynamics, and Topology, Bielefeld University, Bielefeld, Germany, 24-28 May 2017.

To develop the connection between structure and properties, the second workshop Open Space Between Aperiodic Order and Strong Electronic Correlations took place in Annecy (France), 19-22 June 2017. This international workshop aimed to explore the frontiers between aperiodic order and strongly correlated electron systems, and brought together specialists of the two communities to explore the open space between aperiodic order and strong electronic correlations to promote the exchange of ideas.

Another important event in 2017 was of course the 24th Congress and General Assembly of the International Union of Crystallography, Hyderabad, India, 21-28 August 2017. The Congress had a good focus on aperiodic crystals, with five Microsymposia and one Keynote Lecture directly related to aperiodic crystals. The CAC would like to acknowledge the excellent work of the Programme Committee and the constructive and fruitful collaboration with many other Commissions, and we are looking forward to continuing this synergistic approach in the future.

The most important upcoming meeting for the Commission is Aperiodic 2018 (https://register.extension.iastate.edu/ aperiodic2018), to be held in Ames, Iowa, USA, 8-13 July 2018. The meeting is being organized by A. Goldman, $\mathrm{P}$. Thiel 
and G. Borgstahl, with the Commission acting as its Scientific Programme Committee. Other upcoming activities include the 31th European Crystallographic meeting (ECM31), Oviedo, Spain, 22-27 August 2018, and the 14th International Conference on Quasicrystals (ICQ14), Kranjska Gora, Slovenia, 26-31 May 2019, organized by Janez Dolinšek. Our central educational activity will be the fourth edition of the International School on Aperiodic Crystals held in Cabourg, France, in September 2019. It follows on from the successful schools in Carqueiranne, France, in 2010, in Bayreuth, Germany, in 2013 and in Antwerpen, Belgium, in 2016. The objective is to provide an overview of aperiodic order, of the basics of the mathematical description of both modulated structures and quasicrystals, of physical properties and chemical understanding of aperiodic crystals, as well as a working knowledge of structural analysis of aperiodic crystals.

O. Pérez, Chair

\subsection{Commission on Biological Macromolecules}

The aim of the Commission on Biological Macromolecules (CBM) is to support macromolecular crystallography worldwide through scientific exchange, training, and the promotion of policies that encourage the generation and dissemination of knowledge and technologies.

Standards for data to be provided to reviewers of macromolecular structures: the CBM has continued to work with the American, Asian and European Crystallographic Associations, as well as the Worldwide Protein Data Bank Partnership to define essential information for assessing macromolecular structures both before and after PDB deposition. It was agreed that reviewers should receive (1) coordinates, (2) structure factors, (3) the PDB validation report, and (4) omit map images for any ligands or unusual structural elements.

The availability of diffraction data: the CBM coordinated its discussions with the IUCr Diffraction Data Deposition Working Group (DDDWG) and worked with the DDDWG Data Committee to evaluate the practicalities of depositing raw diffraction images, the primary data for macromolecular $\mathrm{X}$-ray diffraction experiments. The CBM submitted to the Executive Committee a White Paper entitled Proposed mechanisms for making diffraction experiments available. During 2017, already close to 4000 diffraction data sets have been submitted to the two most popular servers.

Recently, the CBM initiated discussions on the PDB deposition process and standards for interpreting experimental electron density maps. The ultimate goal is to define standards for deposited models that more optimally account for disorder within structures.

Meetings, workshops and other outreach activities: the CBM has recommended that the IUCr supports a number of meetings and workshops that teach or publicize macromolecular crystallography.

W. Minor, Chair
6.5. Commission on Quantum Crystallography (formerly known as the Commission on Charge, Spin and Momentum Densities)

As in the previous period, the Commission has been active in 2017 in the organization of meetings, schools and workshops. Moreover, after long discussion, the Commission proposed to the IUCr General Assembly a change of name (Quantum Crystallography instead of Charge, Spin and Momentum Density), to better reflect the present momentum. The new name was unanimously approved at the General Assembly in Hyderabad.

One of the first meetings with the new name is the Cecam discussion meeting Quantum Crystallography: Current Developments and Future Perspectives, organized in Nancy (France) on 19-20 June 2018 by Alessandro Genoni and Simon Grabowsky. This discussion has enabled the basis to be set for a better definition of the field, integrating the previous research on charge and spin density, in position or in momentum space, with the new methodologies that enable refinement of density matrices and calculation of X-ray restrained wavefunctions. Moreover, a perspective paper was later prepared by all participants for Chemistry, a European Journal, which is currently in the press.

At the IUCr General Assembly in Hyderabad, the field was represented by the Keynote Lectures of Professor Dietmar Stalke (Applications of Charge Density in Chemistry) and Juri Grin (Application of Charge Density in Materials Science). Moreover, seven Microsymposia were organized, either standalone or in cooperation with other Commissions. One of these was dedicated to the memory of Robert F. Stewart, who died in 2015. Unfortunately, a few weeks before the IUCr meeting, Philip Coppens also passed away, so the Microsymposium was a way to remember these two fathers of the field of charge density determination, who gave enormous service to the community for more than 50 years.

The rest of the activities of the new Commission dealt with the organization of the forthcoming meetings in 2018: the first Erice School on Quantum Crystallography (June 2018), the XIX Sagamore Meeting (Canada, July 2018) and the sessions at the European Crystallographic Meeting (Oviedo, August 2018).

Concerning the Commission projects, the ongoing projects on Round-Robin Test on Charge Density Determination Using Synchrotron and Home-Laboratory Radiation Sources (led by Dr J. Overgaard, University of Aarhus, Denmark and Professor E. Espinosa, University of Lorraine, France) and Electron Distribution in Metals, Measured by QCBED Techniques and X-ray Diffraction (led by Professor P. Nakashima, Monash University, Australia) were concluded, but final reports are not ready yet. A new project was initiated which deals with the new Commission name, Establishing Quantum Crystallography (led by P. Macchi, University of Bern) and is expected to be concluded by the end of the ongoing term. In the meantime, some review and perspective articles on the subject have already appeared, 
and a scientific commentary will shortly appear in Acta Cryst. Section B.

P. Macchi, Chair of the Commission on Charge Spin and Momentum Density (2014-2017) and J.-M. Gillet, Chair of the Commission on Quantum Crystallography

6.6. Commission on Crystal Growth and Characterization of Materials

The activities of the Commission (the CCGCM) in 2017 were dominated by the Twenty-Fourth Congress and General Assembly of the International Union of Crystallography, Hyderabad, India.

In 2017 the members of the Commission collaborated actively but mostly via the internet. However, in August, at the IUCr Congress in Hyderabad, there was an official Open Meeting of the Commission on 25 August and some of us had the opportunity to meet in person and exchange opinions about the future of crystal growth around the world. Several Commission members/consultants were present at the meeting: Geetha Balakrishnan, Abel Moreno, Hanna Dabkowska, Joseph Ng and Andrea Zappettini.

I reported about the meeting I had, as Commission Chair, with the Executive Committee (EC) on 21 August. One of the points discussed was the Commission composition to be presented for approval at the General Assembly. The composition of the Commission that was approved by the EC mainly reflected the results of the ballot by our Commission members, and during the General Assembly on 26 August this composition was approved.

\section{A. Zappettini, Chair}

\subsection{Commission on Crystallographic Computing}

The main activities of the Commission on Crystallographic Computing in 2017 were the Computing School in Bangalore (15-20 August 2017) and the IUCr Congress in Hyderabad (20-28 August 2017), https://www.iucr.org/ resources/commissions/crystallographic-computing/schools/ bangalore2017 and https://www.iucr2017.org.

The local organizer of the Computing School was B. Gopal (Bangalore). Members of the Programme Committee were P. Mercier, A. van der Lee, G. Murshudov and H. R. Powell. The school was attended by 86 participants and teachers with a majority of participants from India. The programme consisted of Plenary Lectures and, as intended, there was plenty of room for tutorials and discussions. As the Commission covers most aspects of crystallography in its broadest sense, this was also reflected in the programme of the Computing School. Topics included biological, chemical and materials science, and techniques included crystallographic statistics, X-ray and electron diffraction, single-crystal and powder experiments, and X-ray free electron lasers. Teachers were E. Dodson, M. R. N. Murthy, T. Terwilliger, G. Murshudov, K. Diederichs, J. Parkhurst, V. Favre-Nicolin, S. Panjikar, H. Powell, P.
Mercier, R. Cooper, M. Mendenhall, C. Cuocci, S. Billinge, L. Palatinus, T. White and S. Mande.

At the IUCr Congress in Hyderabad, the Commission was represented at the International Programme Committee by P. McArdle. Only one Microsymposium was co-organized by the Commission. In addition, there was a Crystallographic Software Fayre (organizers: M. Lutz, C. Millan Nebot). In 36 tutorial sessions, new developments in crystallographic software were presented.

The next major activity of the Commission will be the Computing School in 2020 in the Czech Republic as a satellite meeting to the Prague Congress. Initial planning has started.

\section{Lutz, Chair}

\subsection{Commission on Crystallographic Nomenclature}

The members of this Commission (the $\mathrm{CCN}$ ) are the Editors of the Union's journals, the Editors of the volumes of International Tables, the Chair of the IUCr/OUP Book Series Committee, the Chair of the Teaching Commission, the Chair of the Committee for the Maintenance of the Crystallographic Information File Standard, and both the IUCr President and General Secretary. The total number of members and appointed consultants is $c a$. 50. While ways to reduce the size of the $\mathrm{CCN}$ have been considered, the importance of all members is recognized. In the case of a matter needing the vote of the whole Commission, a Working Group composed of members representing all important viewpoints would be asked to prepare a report to be circulated to the $\mathrm{CCN}$ in advance of the vote.

(1) The Commission's web page invites crystallographers to bring nomenclature problems to the attention of any Commission member. No such matter arose during 2017.

(2) Online Dictionary of Crystallography (ODC). The Editor is Gervais Chapuis. The CCN is responsible for maintaining the ODC, which was established in 2006 as a wiki and continues to be run as such, i.e. as a website of definitions that qualified members of the crystallographic community can add to or modify. Snapshots of the ODC were published in paperback form in 2014 and 2017 (i.e. on the occasion of the two most recent IUCr Congresses).

The ODC has not generated much activity. It still contains only 307 definitions, with only 18 having been added in the last year. During that time only a few authors created new entries or revised or extended existing definitions.

Statistics on page views (see http://reference.iucr.org/ dictionary/Special:PopularPages) suggest that the ODC is an important resource. The 50th most viewed page (WignerSeitz cell) has been visited more than 23000 times (although many of these may be the result of robots following the embedded hyperglossary links in journal articles). In any event there is a consensus that the dictionary should be expanded greatly - at least as long as some other group of people does the work.

The ODC was discussed in Hyderabad within the CCN and with the Executive Committee (EC). There is anecdotal 
evidence that some in the scientific community view the ODC as more authoritative than it, as a wiki, can be. The CCN decided that a paragraph should be put on the main web page of the ODC explaining that it should not be viewed as authoritative; rather, if there is any conflict between a definition in the ODC and a definition in one of the volumes of International Tables then the latter takes precedence. Text for such a paragraph is being written.

The CCN recommended to the EC that each of the Commissions be asked to appoint a representative responsible for contributing and reviewing definitions in their Commission's areas of interest. The activity of the Commission on XAFS is a model. During development of their new Vol. I of International Tables, that Commission has contributed 17 new definitions and one synonym to the ODC.

During the Hyderabad meetings of the $\mathrm{CCN}$ it was suggested that there should be an entry in the ODC for every term found in the indices of standard crystallography texts. That plan is excellent but experience suggests that finding crystallographers to write the definitions will be difficult.

An important problem with the ODC is that people interested in definitions often have very strong opinions about what is correct and are often willing to argue at length. During 2017 A. M. Glazer and C. P. Brock attempted, in response to several very specific requests, to modify the definition of 'crystal' to include a description more accessible to nonexperts (especially students). That effort was eventually abandoned because it seemed that reaching a consensus would require too much time and energy.

The ODC would almost certainly prosper under the leadership of a crystallographer having broad knowledge, a talent for producing clear and concise definitions, a serious interest in the project, and plenty of time to devote to it. The ability to inspire others to contribute to the ODC and to guide a group to consensus would also be necessary. No such person has yet been identified.

During 2017 93\% of the entries were modified in some way. Some changes were made for stylistic consistency, some substantive revisions were made, and contributed translations of terms into various languages (e.g. German and Japanese) were added. Brian McMahon of the Chester office has done a great deal to maintain the ODC.

There are also technical questions regarding searches. In the past, there was a separate entry in the ODC for isometry, but it is now given as a synonym under Euclidean mapping. A Google search for the latter, but not for the former, turns up the entry in the ODC. The staff in Chester are considering more powerful search engines for the journals; that project would also benefit the ODC.

(3) During the Hyderabad Congress, Massimo Nespolo was appointed a consultant to the Commission. We appreciate his expertise and active interest in the ODC, and are very grateful he is willing to serve. We are also pleased that Mike Glazer continues as a consultant.

\section{P. Brock, Chair}

\subsection{Commission on Crystallographic Teaching}

The Commission on Crystallographic Teaching (CCT) has had some new faces join our group since the Hyderabad Congress and General Assembly in August 2017. At that time, due to scheduling conflicts and professional duties, the Chair gave the Commission's Triennial Report to and met with the Executive Committee synchronously online using Zoom. At that time, the slate of candidates to be approved for CCT membership was discussed and finalized. The timetable for review of applications and suggestions for streamlining the current procedures were also discussed.

The CCT is large, with nine regular members and 13 member consultants. We are proud of our international, subdiscipline, gender and age diversity. We held our first meeting as the newly constituted CCT synchronously online across 17 time zones using Zoom on 26 October 2017. Our plan is to have such meetings three to four times annually. The Commission members selected Toyin Asojo as our Vice Chair. Toyin has expressed interest in serving as Chair when the current Chair's term expires in 2020.

Since its constitution, the CCT has reviewed two rounds of applications for IUCr support. We have worked together to develop and, at last, utilize rubrics for application review. The Commission members now share rubrics, a tip sheet, evaluation forms, applications, and all supporting documentation on Google Drive. A few members instead have opted to receive documents and comment via e-mail. The shared folder facilitates very efficient and effective application review. During a two-week timeframe towards the end of the application period, CCT members are reminded to access the folder and review ALL applications received during the application period. In this way, applications are more thoughtfully considered and discussed in context. Missing materials are more easily identified. This process then gives the CCT Chair two weeks to draft all letters of support prior to the due date. The letters are then forwarded to the IUCr and enter the next level review. At this same time, copies of each letter are also sent to the corresponding applicant for their files. Our rubrics, tip sheet and evaluation form are available upon request.

Social media and web resources. Since the 2017 Congress and General Assembly in Hyderabad, the CCT has continued its efforts to reach out to the crystallographic community, the scientific community, and the community at large using social media. The Commission Facebook page has been extremely active (http://www.facebook.com/ IuCrCommissionOnCrystallographicTeaching), now with 1135 'likes' and 1131 'follows'. Our Twitter feed (@IUCrTeach) has 150 followers. We are also planning to review our web pages on the IUCr website, examining resources for utility and audience, reorganizing content as appropriate, and updating information. The new CCT has assigned certain of its members to share posting responsibilities to our social media to keep our followers informed and engaged, as well as regularly review and refresh our web resources.

We plan to explore with the IUCr how to transfer ownership of these social media sites/feeds from individuals, so that 
when the Commission membership and Chair change content is not lost. In addition, we hope to reactivate a quarterly newsletter with a global outlook.

Given the current IUCr rules concerning appointments to the International Programme Committees, the CCT has recently nominated Diego Lamas as its representative to the IPC for the Prague Congress and General Assembly in 2020. Toyin Asojo will serve as our alternate. Diego has been active with the Commission over the years. As noted earlier, the CCT recently selected Toyin as its Vice Chair (and Chair apparent when the current Chair term ends).

Several members of the CCT would like the IUCr to reconsider the current rule that disallows an individual who has been on an IPC to serve again for at least two Congresses. They feel that this disrupts continuity, and that prior experience is very helpful. Others who have served on an IPC have noted that things went smoothly when they served and, as someone who has served in this capacity, the current CCT Chair would concur with that sentiment. It also helps if an IPC representative has previously organized sessions or Microsymposia at international crystallography meetings.

We note that with the current rule in place, an individual will likely serve only once, as almost three triennia will pass before they would be eligible again. The individual will likely have served out their 6-9 years on a Commission and, after nearly a decade, would likely have moved on in their career. The IUCr may be limiting its options by excluding such people, who readily give of their time, energy and experience. The rule might be altered to state that preference would be given to those who have not served for at least one (or two) Congresses.

\section{K. A. Kantardjieff, Chair}

\subsection{Commission on Crystallography in Art and Cultural} Heritage

The Commission (CrysAC) continues to pursue the mission of spreading the crystallographic knowledge related to artworks and ancient materials. 2017, the year in which the 24th Congress and General Assembly of the International Union of Crystallography was organized in Hyderabad, was a special year in CrysAC activities.

(1) Conferences, sessions, lectures

(a) The 2nd workshop organized by the Commission of Crystallography in Art and Cultural Heritage entitled Applied Crystallography in the Study of Pigment Degradation was organized in Brno (Czech Republic) on 31 May 2017, in conjunction with the 6th interdisciplinary ALMA Conference. The event was attended by about 110 participants from European countries. The programme of the workshop was as follows:

Gilberto Artioli, Michele Secco, Ivana Angelini, Leslie Rainer and Kiernan Graves (University of Padova, Italy, and
Getty Conservation Institute, USA): Roman Pigments from Pompeii and Herculaneum: Crystallographic Notes on the Yellow to Red Colour Change; Giovanni Cavallo (University of Applied Sciences and Arts of Southern Switzerland): Heat Treatment of Goethite-Based Raw Materials During Prehistory; Katrien Keune (University of Amsterdam, The Netherlands): Zinc Soap Degradation Phenomena in Oil Paintings: Formation and Structure; Alessa A. Gambardella, Kokkie Schnetz, Roel van Elsas, Marine Cotte, Wout de Nolf, Pieter Iedema and Katrien Keune (Rijksmuseum Amsterdam, University of Amsterdam, Vrije University in Amsterdam, The Netherlands, and European Synchrotron Radiation Facility, Grenoble, France): Ultramarine Degradation: Toward Understanding the Mechanism and Identifying Markers; Silvie Švarcová, Zdeňka Čermáková, Eva Kočí, Janka Hradilová, Petr Bezdička and David Hradil [ALMA Laboratory (Institute of Inorganic Chemistry of the CAS, v.v.i., and Academy of Fine Arts in Prague), Czech Republic]: Colour Changes of Pigments vs. the Crystal Structure; Costanza Miliani (Institute of Molecular Science and Technology in Perugia, Italy): Multiscale Study of the Degradation of Chrome Yellow in Oil Paintings; Koen Janssens, Frederik Vanmeert, Ermanno Avranovich, Steven De Meyer, Gert Nuyts, Marc Vermeulen, Jana Sanyova and Letizia Monico (University of Antwerp, KIK-IRPA Brussels, Belgium, and Institute of Molecular Science and Technology in Perugia, Italy): Multimodal Investigation of $\mathrm{Pb}$ - and As-Based Pigment Transformations; and Alicja Rafalska-Łasocha, Marta Grzesiak-Nowak, Zofia Kaszowska and Wiesław Łasocha (Jagiellonian University, Jan Matejko Academy of Fine Arts and Jerzy Haber Institute of Catalysis and Surface Chemistry PAS, Krakow, Poland): Physicochemical Study of Cadmium Yellow from Historic Pigments' Collections.

(b) CrysAC was a co-organizer of the scientific international conference 6th ALMA Conference in Brno, 1-2 June 2017 (P. Bezdička, G. Artioli, A. Rafalska-Lasocha and Koen Janssens). The programme of the conference is available at https://www.alma-lab.cz/userfiles/files/ALMA2017_final_ programme.pdf.

(c) The CrysAC Commission actively participated in organization of the 24th Congress and General Assembly of the International Union of Crystallography. Gilberto Artioli and Alicja Rafalska-Lasocha, as members of the International Programme Committee, were actively involved in the proposal and organization of: Plenary Lecture Crystallography in Art and Cultural Heritage, delivered by Giacomo Chiari; Keynote Lecture Indian Geometric Patterns, Compared to Persian and Moroccan Styles by Jean Marc Castera; and four Microsymposia connected with the investigations of objects of cultural heritage (each with a related poster session):

(i) MS-047: Crystalline Materials Characterization with Combined Techniques (Chairs: Koen Janssen and Alejandro Ayala): On Site Analysis of Paintings by Using Portable Instruments, Izumi Nakai; Getting More for Less: Adaptive X-ray Fluorescence Sampling for Imaging, Marc Walton; Combining Elemental and Compound Specific Techniques for 
the Material Analysis in Cultural Heritage, Manfred Schreiner; Disordered Zeolite Solved by Combining Electron Diffraction, HRTEM and XRPD, M. Ola Cichocka; Crystallochemical Characterization of Polyoxometalate New Minerals, Marcelo B. Andrade; Tailoring Molecular Multiferroic Compounds: Neutron Studies on Formate Frameworks, Laura Canadillas-Delgado; Scanning Transmission Electron Microscopy Assessment of a Metalorganic Framework Compound, Peter Moeck.

(ii) MS-071: Crystallographic Patterns in Art and Cultural Heritage (Chairs: Louise De Las Penas and Rima Ajlouni): The Different Tiling of 12-Fold Rosettes in Moroccan Geometric Art, Youssef Aboufadil; Quantitative Classification of Periodic Grey-Level Patterns by Geometric AIC, Peter Moeck; Crystallographic Patterns in Philippine Indigenous Fabrics, Louise Antonette De Las Penas; A Generalized Structural Model for Generating Quasi-Periodic Formations, Rima Ajlouni.

(iii) MS-104: Synchrotron Measurement in Conservation and Cultural Heritage (Microsymposium prepared by Eric Dooryhee; Chairs: Alison Jeanine Edwards and Gilberto Artioli): Synchrotron-Based Micro-Analyses of Artistic Materials at ID21, ESRF, Marine Cotte; Deciphering Ceramic Workshops Practices in Classical Athens, Apurva Mehta; $\mu$ XRD for the Identification of Pigments in CrossSections of Paintings, Bernadette Fruehmann; Using Neutron Tomography to Examine Guitar Strings, Alison Jeanine Edwards.

(iv) MS-114: Crystallography and Cultural Heritage: From Microsampling to Noninvasive Techniques (Chairs: Manfred Schreiner and Serge Cohen): Multimodal Investigation of $\mathrm{Pb}$ - and As-Based Pigment Degradation, Koen Janssens; X-ray Powder Diffraction Structural Studies of Lithol Red Pigments, Wieslaw Lasocha; Red/Yellow Pigments in Pompeii and Herculaneum: Which is Which? Gilberto Artioli; Potential of Forensic Analysis of Multicomponent Samples, Marek Kotrly; Comprehensive Studies of Cultural Heritage Objects in NRC Kurchatov Institute, Roman Senin; Characterization of Ancient Harappan Faience Bangles, Gilberto Artioli; $\mu \mathrm{XRD}$ for the Identification of Pigments in Cross-Sections of Paintings, Bernadette Fruehmann; In situ and Time-Lapse XRD as Tools for Atmospheric Corrosion Research, Rita Wiesinger; On the Grounds of Icons from National Museum in Krakow, Alicja Rafalska-Lasocha; Verifying the Reliability of Historical Sources Through an Archaeometric Study, Simona Quartieri.

(d) The Crys AC Commission in co-operation with Professor Bernardo Cesare (UNIPD) was involved in the preparation of an exhibition Beauty Hidden in Rocks, which accompanied the 24th Congress of IUCr. The IUCr also prepared some beautiful postcards, which were distributed during the Congress, representing the exhibited photographs in a smaller format. The exhibition of the colourful large-format posters met with considerable success.

(e) The IUCr Executive Committee and General Assembly took into due consideration our proposals and the proposals of the National Committees concerning the membership of the
Commission. For the 2017-2020 term the Crys AC Commission is officially composed of:

CrysAC members: Gilberto Artioli (Italy) Chair, Petr Bezdicka (Czech Republic), Miguel Delgado (Venezuela), Koen Janssens (Belgium), Izumi Nakai (Japan), Fermin Otalora (Spain), Patrick Ravines (US), Elena Tereschenko (Russia).

CrysAC consultants: C. Abad-Zapatero (USA), J. M. Castera (France), E. Dooryhée (USA), E. Makovicky (Denmark), S. Mande (India), S. Quartieri (Italy), A. Rafalska-Lasocha (Poland), A. Thalal (Morocco), A. Zürn (Switzerland).

(f) Members, consultants of CrysAC and participants of the 24th Congress of the IUCr interested in investigations of objects of cultural heritage met in Hyderabad and discussed future Crys AC activities.

(g) The CrysAC Commission (Alicja Rafalska-Lasocha, Gilberto Artioli, Petr Bezdicka, Koen Janssens) is a coorganizer of the 7th meeting X-ray and Other Techniques in Investigation of the Objects of Cultural Heritage, which will be held in Krakow on 17-19 May 2018. More information is available at http://www.biurokarier.chemia.uj.edu.pl/conf/ $\mathrm{x}$-ray18.

(h) The CrysAC Commission is also an organizer of the 3rd CrysAC Workshop on Recent Advances in the Investigation of Ancient Mortars and Binders, which will be held on 20 May 2018, before the 42nd International Symposium on Archaeometry (ISA 2018) in Mérida, Yucatán, Mexico, 20-26 May 2018.

Celerino Abad-Zapatero continued collaboration with $\mathrm{Mr}$ Painton Cowen to incorporate scientific content into the 'Rose Window' site (http://therosewindow.com/TheRoseWindow2/ Rose-numbers.htm).

\section{(2) Papers}

Istvan Hargittai (2017). Generalizing crystallography: a tribute to Alan A. Mackay at 90. Structural Chemistry, 28, $1-16$.

Makovicky, E. (2017). On the Kond style of Islamic tiling: a study in practical Islamic geometry. Rendiconti Lincei, 28(1), 35-51.

Makovicky, E. \& Makovicky, N. M. (2017). Nonperiodic Octagonal Patterns from a Jali Screen in the Mausoleum of Muhammad Ghaus in Gwalior and Their Periodic Relatives. Nexus Network Journal, 19(1), 101-120.

A. Rafalska-Łasocha, M. Grzesiak-Nowak, P. Goszczycki, K. Ostrowska \& W. Łasocha (2017). X-ray powder diffraction data for three red azo pigments: sodium, barium, and ammonium lithol salts. Powder Diffraction, 32, 187-192.

(3) Special journal issue: Alan L. Mackay and Generalized Crystallography, edited by I. Hargittai, Structural Chemistry, Special Issue, February 2017 (Vol. 28, No. 1).

(4) Crys AC website: The Commission is responsible for updating the CrysAC website: http://www.iucr.org/resources/ commissions/crysac.

Gilberto Artioli, Chair and Alicja Rafalska-Lasocha, PastSecretary 


\subsection{Commission on Crystallography of Materials}

Our Commission was formally approved during the meeting of the General Assembly of the IUCr in Hyderabad (August 2017), with the ad interim Commission having been approved at the meeting of the Executive Committee of the IUCr in Boston (July 2012). This is in many ways a unique Commission that covers a crystallographic topic that has not been covered by other IUCr Commissions.

(1) Activities

The 26th International Conference on High Pressure Science and Technology (AIRAPT 26) joint with the 8th Asian Conference on High Pressure Research (ACHPR 8) and the 19th China High Pressure Research (CHPC 19); Beijing, China, 19-23 August 2017; http://www.airapt26.org/.

Two sessions at World Economic Forum in Dalian, China (June 2017).

International conference on Carbon for Energy Storage and Environment Protection: CESEP'17, Lyon, France, 23-26 October 2017, http://cesep2017.univ-lyon1.fr/en.

International Conference on Nanotechnology: Ideas, Innovations and Initiatives, Roorkee, India, 6-8 December 2017. Indian Institute of Technology (IIT), Roorkee, https:// www.iitr.ac.in/icn3i2017/.

5th International Symposium on Enhanced Electrochemical Capacitors (ISEECap2017), Jena, Germany, 10-14 July 2017, https://www.iseecap2017.com/.

Advances and Applications in Carbon Related Nanomaterials: From Pure to Doped Structures Including Heteroatom Layers (HeteroNanoCarb-2017), Benasque (Aragon), Spain, 11-15 December 2017, http://heteronanocarb.org/.

7th International Conference on Smart Engineering of New Materials, SENM 2017, Lodz, Poland, 27-29 June 2017, http:// senm.semtherm.eu/.

Workshop on Computational Materials Discovery, Poitiers, France, 11-13 January 2017.

Workshop on Computational Materials Discovery, Shanghai, China, 16-20 June 2017.

(2) Plenary, Keynote and Invited Lectures

Artem Oganov: Computational Materials Discovery, Inorganic Chemistry and Materials conference-school, Novosibirsk, Russia, 25 May 2017; Computational Materials Discovery (Distinguished Lecture), Hong Kong Polytechnic University, 80th Anniversary, 2 June 2017; New Materials Discovery (Keynote Lecture), 26th International Conference on High Pressure Science and Technology (AIRAPT 26), Beijing, China, 19-23 August 2017; The NaCl Structure Type in Solid State Chemistry and Crystallography, IUCr Congress, Hyderabad, India, 22 August 2017; Computational Materials Discovery Science of the Future, Nizhny Novgorod, Russia, 12 September 2017; How to Discover New Materials on the Computer? TEDx Lecture, Industries of the Future, Sochi, Russia, 16 October 2017.

Y. Gogotsi: Plenary Lecture, Africa Energy Materials 2017 Conference, 28-31 March, South Africa; Keynote Lectures, Symposium H03, Properties and Applications of 2-Dimensional Layered Materials 2, European MRS Meeting,
Strasbourg, 23-24 May 2017; Computational Materials Discovery (Distinguished Lecture), Hong Kong Polytechnic University, 80th Anniversary, 2 June 2017; Computational Materials Discovery, Inorganic Chemistry and Materials conference-school, Novosibirsk, Russia, 25 May 2017.

(3) Popular science talks

Artem Oganov: Puzzles of Crystallography, Pryamaya Rech Lectorium, Moscow, Russia, 10-12 March 2017; High Pressure Chemistry, Pryamaya Rech Lectorium, Moscow, Russia, 12 March 2017; Predictive Crystallography: Novel Materials and Chemical Phenomena, Popular Science Center Arkhe, Moscow, Russia, 23 March 2017; Computational Materials Discovery, Open Lesson Youth Forum, Yaroslavl, Russia, 1 September 2017; Mysteries of Crystallography (three lectures), Day of Moscow, Russia, 9 September 2017; Computational Materials Discovery (three lectures), Day of Moscow, Russia, 10 September 2017; Computational Materials Discovery: Yesterday, Today, and Tomorrow, ITMO University, St Petersburg, Russia, 27 October 2017; Islands of Stability in the World of Nanoparticles, 2nd Panarmenian Scientific Forum, Yerevan, Armenia, 6 November 2017; From Dream to Reality, or How to Make Materials of the Future, National Academy of Sciences, Minsk, Belorussia, 10 November 2017.

Y. Gogotsi: Seminar and Workshop at Shinshu University, Japan, 19-25 February 2017; Invited Lecture, 2D Carbides and Nitrides of Transition Metals - An Emerging Family of Energy Storage Materials, Gordon Conference on Nanomaterials for Applications in Energy Technology, 25 February - 2 March 2017, Ventura Beach, USA; two Seminars at Jilin University, Changchun, China, 2-18 March 2017; Seminar, University of Johannesburg, South Africa, 24 March 2017; CSIR, Materials Science and Manufacturing Division Council for Scientific and Industrial Research, Pretoria, South Africa, 27 March 2017; Seminar, University of Pretoria, South Africa, 28 March 2017; Plenary Lecture, International Forum on Graphene 2017, Shenzhen, China, 7 April 2017; Lithium Ions in Layered Twodimensional Transition Metal Carbides: MAX Phases and Mxenes, 231st ECS Meeting in New Orleans, USA, 28 May 1 June 2017; Much Ado About Nearly Nothing: Nanotech and the Future of Energy, World Science Festival, New York, USA, 3 June 2017; Brain Ukraine, Kiev, Ukraine, 7 June 2017; Invited Seminar, Tsinghua University, Chemical Engineering Department, Beijing, China, 16 June 2017; Invited Seminar and Discussion, Beijing University of Chemical Technology, Materials Science Department, Beijing, China, 17 June 2017; 9th International Conference on Materials for Advanced Technologies (ICMAT 2017), Singapore, 18-23 June 2017; Invited Seminar, Jilin University, Changchun, China, 25-28 June 2017; Seminar, Materials Architecturing Research Center, Korea Institute of Science and Technology (KIST), Seoul, South Korea, 31 July 2017; Seminar, National NanoFab Center, NNFC, Daejeon, South Korea, 3 August 2017; Seminar, Sungkyunkwan University (SKKU), School of Chemical Engineering, South Korea, 4 August 2017; Freestanding Carbon Composite Electrodes for Electrochemical Capacitors, 5th International Symposium on Enhanced Elec- 
trochemical Capacitors (ISEECap), Jena, Germany, 10-14 July 2017; 2D Ordered Double Transition Metal Carbides (MXenes), Conference on Advances in Functional Materials, UCLA, USA, 14-17 August 2017; Organic-Inorganic Hybrid Materials for Electrochemical Energy Storage in Symposium B.7, Advances in Electrochemical Energy Storage, International Materials Research Congress, Cancun, Mexico, 19 August - 23 August 2017; Synthesis, Structure and Properties of Two-dimensional Carbides and Nitrides (MXenes), ACS Nano Editors' Symposium, Suzhou, China, 25-26 August 2017; 2D Metal Carbides and Nitrides (MXenes) for Energy Storage and Beyond, 7th International Conference on Nanoscience and Technology, China 2017 (China Nano), Beijing, China, 2930 August 2017; ACS Nano Editors' Symposium, Peking University, Beijing, China, 1 September 2017.

C. Q. Jin: public lecture on High Pressure Materials, Open Day of IOPCAS, Beijing, China, 20 May 2017.

(4) Books

Nanomaterials Handbook (2nd edition), edited by Y. Gogotsi, was published by CRC Press. Nanodiamonds: Advanced Material Analysis, Properties and Applications, edited by J.-C. Arnault, was published by Elsevier and included ch. 15: Nanodiamonds in composites: polymer chemistry and tribology by I. Neitzel, V. N. Mochalin \& Y. Gogotsi.

(4) Other news

Artem R. Oganov was elected as a member of Academia Europaea and appointed as a member of the Russian Presidential Council for Science and Education.

Chongqing Jin, Chair

\subsection{Commission on Electron Crystallography (CEC)}

The main event of 2017 was the Twenty-Fourth Congress and General Assembly of the International Union of Crystallography (August 2017, Hyderabad, India). One of the major parts of the Congress was electron crystallography in both physical and the biological sciences. There were several sessions and Keynote talks related to electron diffraction, imaging and their uses for structure characterization. The Gjønnes Medal in Electron Crystallography was awarded to Richard Henderson and Nigel Unwin. Subsequently, Richard Henderson and co-workers were awarded a Nobel Prize for their pioneering work in the field of cryo-electron crystallography. Our community is very proud of this achievement and, in our view, the Gjønnes Medal has become even more prestigious after being awarded to a future Nobel Prize winner.

The CEC meeting also took place at the Congress (minutes of the meeting were communicated to the members and consultants of the CEC). Several decisions with regard to the future structure of the CEC were made: (1) Chairs of the special group of interest on electron crystallography of the European Crystallography Association will automatically become consultants of the CEC; (2) a Vice-Chair should be chosen (elected) in order to become the leading candidate in the next election for the Chair's position. This continuity will enable better functioning of the CEC.

It has long been recognized that the interactions between $\mathrm{X}$-ray and electron crystallography in the USA are weak. To start to remedy this, the CEC consultant L. D. Marks has initiated discussions between the Microscopy Society of America (MSA) and the American Crystallographic Association (ACA), also with the partial involvement of the US National Committee on Crystallography, which represents American crystallographers in the IUCr through the National Academy of Sciences. As the first step, the MSA is partially sponsoring a workshop on Cryo Electron Microscopy at the next ACA meeting in Toronto in June 2018.

The terms of reference of the CEC are: to strengthen links and interactions among electron crystallographers, and to promote a common language; to promote the presence at IUCr meetings of scientists working in the field of electron crystallography; to promote the publication of electron crystallography papers in the journals of the IUCr; to encourage the development and dissemination of mathematical and theoretical methods, software and databases for the solution of electron crystallographic problems; to promote the use of precise measurements based upon electron scattering; to promote and organize symposia of interest to electron crystallographers during IUCr Congresses and meetings of Regional Associates, in cooperation with other Commissions of the Union; and to promote and organize meetings, workshops and schools in electron crystallography, particularly targeting post-graduate students and young scientists.

Following the tradition of the CEC, the emphasis of the CEC function is on teaching and spreading the science of electron crystallography. In 2017 the following international schools on electron crystallography took place (where Commission members/consultants were involved as organizers or lecturers). Names of members/consultants of the CEC as well as geographical location of the event are provided. It should be noted that there were more schools on electron crystallography than are listed here, as the current list contains only those events in which CEC members/consultants were directly involved.

(1) Karla Balzuweit has reported that at the Annual Meeting of the Brazilian Society of Microscopy and Microanalysis in Búzios, Rio de Janeiro, Brazil, 4-7 June 2017 (http://www.eventus.com.br/csbmm2017/), courses on Electron Diffraction and Electron Back Scattered Diffraction (EBSD) as well as symposia on Electron Diffraction Mapping in Materials Characterization in SEM and TEM took place.

(2) Lukas Palatinus and Damien Jacob have organized and participated in the electron diffraction session of the Quantitative Electron Microscopy European School in 2017 (QEM2017; Balaruc-les-Bains, France), 21 May - 2 June, 2017. The school was attended by 98 students and 33 lecturers (https://qem2017.sciencesconf.org/).

(3) In 2017, the CEC (Joke Hadermann) organized together with the Commission on Mathematical and Theoretical 
Crystallography in Sofia, Bulgaria an International Autumn School on Fundamental and Electron Crystallography (IASFEC), 8-13 October 2017 (http://www.crystallography.fr/ mathcryst/sofia2017.php).

(4) Joke Hadermann was also involved in the organization of the biannual EMAT Workshop on Transmission Electron Microscopy, 12 June - 23 June, University of Antwerp, Belgium, where she gave classes on electron diffraction (http:// ematworkshop.uantwerpen.be/).

(5) Prior to the IUCr Congress in Hyderabad, India, on 21 August 2017, the CEC organized (sponsored by Nanomegas Company) a workshop on Electron Diffraction for Materials Science and Pharmaceutical Applications, in which several of the CEC consultants were involved (https://www.iucr2017.org/ program/onsite-events/iucr-workshops/).

(6) Xiaodong Zou and colleagues organized an International Symposium on Cryo-EM - Past and Future Challenges, 9 December 2017, Stockholm, Sweden. The symposium was in connection with the Nobel Prize in Chemistry 2017, and brought together world-leading experts, academic researchers, and industrial scientists to discuss ideas for further advancement in this exciting and rapidly evolving field. The speakers include pioneers in cryo-EM and microED, present/former collaborators of the Nobel Laureates, as well as young researchers in the field. There were 120 participants from ten countries.

(7) The K. H. Kuo school in 2017 was held in Xi' An, China on 30 May - 2 June 2017. Xiaoadong Zou attended the school and gave a talk.

(8) At the 2017 American Crystallography Association meeting in New Orleans, USA, Jim Ciston and Olaf Borkiewicz organized a symposium on Electron Diffraction of SolidState Materials. This symposium focused on the application of the electron diffraction techniques as well as on the successes, challenges and needs for the management, processing and visualization of large data streams resulting from these expanding capabilities. The list of the speakers at this event included several consultants of the CEC. There were 30-40 participants.

(9) Gianluigi Botton was involved in the organization of the 9th Advanced Electron Microscopy School and a one-day Advanced Microscopy Methods for Materials Research at the Canadian Centre for Electron Microscopy, McMaster University (Hamilton, Canada). The workshop had over 100 international participants.

Plans for 2018

(1) In June 2018, the biggest European international school on electron crystallography (in Erice, Italy) will take place. This school is organized by Lukas Palatinus, Andy Stewart and Joke Hadermann. Many of the members/ consultants of the CEC will give lectures at this school. Such a school is organized by the CEC once every seven years.

(2) The CEC Chair has issued a letter of support to the IUCr for the 2018 Kuo School in Haozhou, China.

L. Meshi, Chair

\subsection{Commission on High Pressure}

The main event in 2017 was the 24th Congress and General Assembly of the IUCr at Hyderabad, India, 21-28 August, which had 1748 attendees from 73 countries. The Commission was represented on the Programme Committee by Professor Andrzej Katrusiak.

The following Keynote Lecture and Microsymposia were sponsored fully or partly by the Commission:

Keynote Lecture: Progress in High-Pressure Methodology and Applications, presented by Jon Eggert, Lawrence Livermore National Laboratory, USA. Another Keynote Lecture had a strong high-pressure component: High Pressure Science: the Emerging Role of X-ray Absorption Spectroscopies, presented by Sakura Pascarelli, ESRF, France.

MS023: Synchrotron and XFEL for Materials at Ambient and Extreme Conditions (Chairs: Yasuo Ohishi and John Tse). MS060: XAS at Extreme Conditions (Chair: Giuliana Aquilanti). MS078: Advances in High Pressure Crystallographic Methods (Chairs: Goutam Dev Mukherjee and Kamil Dziubek). MS119: Interactions in Solids Under Stress (Chairs: Boris Zakharov and Shanti Deemyad).

Two Microsymposia sponsored by other Commissions with a significant high-pressure component were: MS086: Accurate High Resolution Diffraction Studies at High Pressure (Chairs: Krzysztof Wozniak and Nicola Casati). MS123: Magnetic Structures at Extreme Conditions (Chairs: Oleksander Prokhnenko and Konstantin Kamenev).

The new Commission members and consultants present in Hyderabad (Haozhe Liu, Boris Zakharov, Narcizo Marques De Souza-Neto, Jean-Paul Itie, Andrzej Katrusiak and Kamil Filip Dziubek) held a closed lunch meeting during the Congress. We discussed the future activities, mission and challenges of the High Pressure Commission, with discussion topics including: potential locations and voting guidelines for the future IUCr High Pressure Workshop; the Commission's own website update and maintenance issues (Boris Zakharov and Kamil Dziubek will follow up); and the interaction with the IUCr management and website issues.

Update for the format mission for depositing highpressure crystallographic diffraction data from various highpressure techniques. This project was led by Kamil Dziubek, who represented the Commission at ECM-29 in 2015.

The role of the High Pressure Commission in this multidisciplinary and dynamically evolving field is to facilitate and enable the efficient exchange of new ideas and cutting-edge developments worldwide. The main activities available to the Commission to achieve these goals are annual workshops on high-pressure crystallography. The Commission also helps to shape a strong high-pressure programme at the triennial IUCr Congresses. In addition, Commission members and consultants are involved in organizing summer schools for highpressure crystallography, and in other dedicated meetings for high-pressure science and techniques. Two major conferences organized by current and previous Chairs of this Commission in 2017: 
Haozhe Liu co-chaired the 26th International Conference on High Pressure Science and Technology (AIRAPT-26), which was held at Beijing, China, 19-23 August, and which reached a record high of 983 attendees. The Bridgman Gold Medal Award winner was Mikhail Eremets (Max Planck Institute for Chemistry, Germany) and the Jamieson Award winner was Philip Dalladay-Simpson (HPSTAR, China). Some previous and current Commission members and consultants participated in AIRAPT-26, and many of the participants travelled to Hyderabad straight after the conference.

Andrzej Katrusiak chaired the 55th European HighPressure Research Group Meeting (EHPRG-55), which was held at Poznan, Poland, 3-8 September and had 220 attendees from 26 counties.

The Commission chose next year's workshop location as Honolulu, USA, scheduled for 29 July - 2 August 2018. The Chair of the Local Organizing Committee will be Professor Przemek Dera, who successfully led the local organizing committee in gaining multiple funding support, which did not include the IUCr because of the strict application window limitation for young scientists' travel awards. A hands-on training event for high-pressure single crystal data acquisition using laboratory based XRD equipment and analysis procedures was planned. We expect more than 100 attendees at this workshop.

H. Liu, Chair

\subsection{Commission on Inorganic and Mineral Structures}

Members and consultants of the Commission (CIMS) discussed various issues via e-mail. Other forms of communication were by occasional meetings or conferences or by using the website. The latter is kindly maintained by $\mathrm{M}$. Nespolo (http://www.crystallography.fr/cims/).

The Commission on Structural Chemistry (CSC) and CIMS maintained their links. P. Mercier is now the liaison person representing the CSC in CIMS and vice versa.

CIMS also maintains strong links with the new IUCr Commission on NMR Crystallography and Related Methods. J. Rocha is the liaison person and also a consultant for that Commission.

P. Mercier continues to act as liaison officer of CIMS with the IUCr Newsletter.

Strong links exist between CIMS and the European Crystallographic Association: O. Yakubovich (a CIMS member) was a member of the Executive Committee; the Secretary of the Special Interest Group SIG-05 was O. Siidra, the Chairman, S. Krivovichev, is a CIMS consultant and the ViceChairman, F. Hatert, is a CIMS member (ECA -SIG5, http:// sig5.ecanews.org/).

There are very good relationships between CIMS and the European Mineralogical Union (EMU, http://eurominunion. org/); R. Oberti (EMU Past-President) is a member of CIMS and also Commissioning Editor of the EMU Notes in Miner- alogy and Co-editor of the volume The Contribution of Mineralogy to Cultural Heritage to be printed in 2018, while the volume Mineralogical Crystallography, co-edited by $\mathrm{J}$. Majzlan, Sergey Krivovichev (CIMS consultant) and J. Plášil, was published in 2017.

M. Nespolo is the book-review Editor for the IUCr journals.

Giovanni Ferraris was Editor of a special section Mineral Phases and Synthetic Analogues in Earth and Materials Science, published in issue No. 4 (2017) of the Rendiconti Lincei (Springer), and La Luce fra Scienza e Cultura (Light between Science and Culture), issue No. 26 (2017) of Quaderni dell'Accademia delle Scienze di Torino to celebrate the UNESCO International Year of Light 2015.

C. Ling is the President of the Society of Crystallographers in Australia and New Zealand (SCANZ) and the Secretary of the Asia-Oceania Neutron Scattering Association (AONSA).

P. Mercier has been Chair of the Canadian National Committee for Crystallography since August 2015.

R. Oberti is Chair of the Committee on the participation of the CNR (Consiglio Nazionale delle Ricerche) to the IUCr.

R. Oberti was a member of the scientific committee of the 46th Congress of the Italian Association of Crystallography (AIC; Perugia, 26-29 June 2017) and convener of the session Crystallography for Cutting-Edge Mineral Sciences.

G. Ferraris and R. Oberti are organizing the meeting Two Hundred Years of Mixed Crystals, May 2018, at the Accademia delle Scienze di Torino.

J. Rocha is involved in the organization of SMARTER 6, taking place in Ljubljana, Slovenia, 2-6 September 2018 (https://smarter6.ki.si/index.php/committees/).

A special issue of Acta Crystallographica Section B on Mineralogical Crystallography was in preparation during 2017. The Guest Editors for this special issue are Sergey Krivovichev, Stuart Mills and Janusz Lipkowski. As indicated by Peter Strickland in an e-mail to the Guest Editors, following the IUCr 2017 Congress, 'the IUCr Executive Committee asked that the Editors of the special issue be put in contact with the Commission on Inorganic and Mineral Structures, as the Commission may be able to help e.g. with suggestions on how best to publicize the special issue to the community'. This has been accomplished, and new suggestions for possible co-authors emerged from the interactions between the Guest Editors and CIMS through its Chair.

P. Mercier participated as an Invited Speaker and was a member of the Programme Committee for the 2017 IUCr Crystallographic Computing School, 15-20 August 2017, in Bangalore, India.

Several new members and consultants were appointed to CIMS at IUCr 2017, while others' mandates were extended.

J. Rocha terminated his mandate as Chair and P. Mercier was appointed as the new Chair after the Congress. J. Rocha continues as a consultant to ensure a smooth transition in the role of Chair. Members terminating office were Professor Tim J. White (Singapore) and Olga V. Yakubovich (Russia). New persons appointed as members were Dr Marie Colmont (France), Professor Dr Massimo Nespolo (France), Professor Volker Kahlenberg (Austria) and Professor Natalia 
V. Zubkova (Russia). New persons appointed as consultants were Dr Isabella Pignatelli (France) and Professor Raúl Carbonio (Argentina).

CIMS was involved in the following meetings held in 2017:

J. Rocha was involved in the organization of SMARTER5 meeting in Bayreuth, which was for the first time a satellite meeting of the 30th Meeting of the European Crystallographic Association (http://www.smarter5.uni-bayreuth.de/de/index. html). This event was promoted jointly by CIMS and the Commission on NMR Crystallography and Related Methods.

CIMS was involved in the preparation of the $2017 \mathrm{IUCr}$ Congress in Hyderabad. In particular, CIMS members and consultants chaired the Microsymposia MS 7 Topology and Symmetry of Modular Structures (I. Pignatelli, S. V. Krivovichev) and MS 52 Minerals/Gems in Industrial Applications (P. Mercier). M. Nespolo gave the Keynote Lecture Crystal Rationale for the Formation of Twinned Crystals.

R. Oberti was a member of the scientific committee of the 2017 EMU School Mineral Fibres: Crystal-Chemistry, Chemical Physical Properties, Biological Interactions and Toxicity, held in Modena, 19-23 June 2017 (http://emu2017. unimore.it/). The school received support from the IUCr after CIMS sponsorship.

CIMS supported the application for funding from the IUCr of the following meetings held in 2018:

Sixth SMARTER Crystallography Conference, to be held 2-6 September 2018, at the Faculty of Chemistry and Chemical Technology, University of Ljubljana, Slovenia.

The 4D Workshop: Deep-Time Data-Driven Discovery and the Evolution of the Earth, to be held 4-6 June 2018 at the Carnegie Institution for Science in Washington DC, USA (https://www.4d-workshop.net/).

CIMS provided 'moral' support to the application for funding by the IUCr from the Gordon Research Conference 2018: Crystal Engineering, held on 24-29 June 2018, at the Jordan Hotel at Sunday River, Newry, Maine, USA.

P. Mercier, Chair

\subsection{Commission on Magnetic Structures}

At the IUCr Congress in Hyderabad in August 2017, Maxim Avdeev (Australia), Maria Teresa Fernandez-Diaz (France), Ovidiu Garlea (USA), Margarida Henriques (Czech Republic), Andrew Wills (UK) and Oksana Zaharko (Switzerland) were elected as new voting members of the Commission, while Andrea Cornea (Italy), Daniel Litvin (USA), Vaclav Petricek (Czech Republic), Alexander Pirogov (Russia), Vladimir Pomjakushin (Switzerland) and Wieslawa Sikora (Poland) stepped down from the voting membership after many years of service. This rather large turnover came two terms after the formation of the Commission (Madrid, 2011) as was expected. The voting membership of the Commission also includes Branton Campbell (Chair, USA), Manuel Perez-Mato (Spain), Juan Rodriguez-Carvajal (France) and Taku Sato (Japan).
Mois Aroyo (Spain) continues to serve as a consultant to the Commission, and is now joined by Danny Litvin (USA), Alexander Pirogov (Russia) and Wielslawa Sikora (Poland), who were previously voting members and who are helping to maintain continuity during a time of significant transition, as well as Javier Campo (Spain) who notably brings expertise in molecular magnetism to the Commission. We express appreciation to Harold Stokes (USA), who has stepped down as a consultant to the Commission, but who continues to be involved in its activities.

The Commission held an online meeting on 14 February 2017, with Branton Campbell, Andrea Cornia, Danny Litvin, Manuel Perez-Mato, Vaclav Petricek, Alexander Pirogov, Vladimir Pomjakushin and Taku Sato participating. The primary focus of the meeting was promoting the upcoming Congress in Hyderabad, which being an unusual location for the magnetic structure community, required special effort; we identified a significant list of regional and topical interest groups around the world to whom various Commission members made contact via mailing lists and direct e-mails; we also decided to advertise to all members of the IUCr WDC who list magnetic or magnetism as profile keywords. The Commission further discussed potential sponsorship or other supporting involvement in a variety of meetings planned for the next two years. On the technical side, we discussed the possibility of creating an international standard for magnetic space-group symbols. An international standard could assist new researchers in understanding the symmetries present within and the physical property tensors allowed by each magnetic space group. Examples of avoidable misunderstandings in recent literature were highlighted. There is no general agreement about the form that such symbols might take, but we agreed to explore the issue in detail during the coming year.

Another online Commission meeting was held on 25 April 2017 to discuss Commission priorities and changes to the voting membership in the coming term. The key priorities are education/outreach, software/data infrastructure development, standards (e.g. magCIF) and diversity (gender, geographic and topical).

In mid-July, Branton Campbell and Harold Stokes formulated an initial proposal for an international standard for magnetic space-group symbols. This led to some lively debate. Many are enthusiastic about the potential for the proposal, and feel that the short-term trauma and confusion surrounding a new standard are outweighed by the long-term benefits, while others are either satisfied with the status quo (the historical OG and BNS symbols) or feel that the costs outweigh the benefits. The critical issue to assess is how severe the deficiencies in the current systems really are. More discussion will follow.

The Commission held an informal face-to-face meeting in Hyderabad on 26 August 2017, with Margarida Henriques, Juan Rodriguez Carvajal (represented by Oscar Fabelo), Taku Sato and Branton Campbell participating. Regarding education/outreach, we discussed (1) immediate efforts to organize an International School of Crystallography on 
magnetic structure in Erice in 2019, (2) the possibility of a four-day workshop somewhere in Asia, and (3) a satellite workshop at the IUCr Congress in Prague in 2020. Regarding software development, we discussed concrete plans to assist the developers of a variety of software packages to implement the new magCIF standard. Regarding standards, we discussed recent (reflection data) and pending (rotational analogs) efforts of the magCIF working group to extend the magCIF dictionary, and the ongoing possibility of a new volume of the International Tables. We have already committed to prepare an introduction to magCIF in Volume G. Also in Hyderabad, the IUCr Executive Committee commended the Commission for its activity and diversity, and formally suggested (1) active support of the next Congress, (2) a Commission-generated review article on magnetic crystallography, and (3) a journal article on the outcomes of the magCIF project.

We conducted a two-part online meeting on 10 November 2017 and 4 December 2017, in which all voting members and nearly all consultants of the Commission participated. We identified nine upcoming international meetings or schools with opportunities to sponsor, organize or otherwise support sessions on high-quality magnetic structure research. We also discussed potential avenues of funding for young-scientist bursary grants at the International School of Crystallography in Erice in 2019. We briefly touched on the matter of an international standard for MSG symbols; it was suggested that a proper list of magnetic Hall-style symbols, which define the origin, may be a more pressing issue. Our efforts to assist software developers in adopting the magCIF standard have been quite active this year; notably, the Bilbao Crystallographic Server, including its database of magnetic structures, has been updated to the new standard. Perhaps we could encourage specific journals to require a magCIF file when submitting a magnetic structure. Juan reminded us that magnetic superspace groups have not been fully classified, and that this classification should be straightforward.

We also had a very engaging discussion of active feature developments in JANA, FullProf, TOPAS, GSAS2, the Bilbao Crystallographic Server, the ISOTROPY Suite, SARAH and $M O D Y$. There is a lot happening and an increasing need for programs to communicate with one another. For example, $S A R A H$, FullProf and $J A N A$ have been refining internally generated symmetry-mode (representational analysis) models for years; FullProf can now import and directly refine magnetic symmetry-mode models from external tools like ISODISTORT; and the user can self-program such a model in TOPAS. GSAS2 also has a beta feature for importing nonmagnetic symmetry-mode models. The need to communicate such models between packages has reached a critical stage. Work on the representational-analysis CIF dictionary, which the Commission has been discussing since 2011, will begin in the new year. Alexander suggested that when comparing experimentally indistinguishable models, the determination of the correct magnetic structure would be helped by a userfriendly software tool for calculating the exchange Hamiltonian of each model. Manu recommended a general utility for manually creating both commensurate and incommensurate magCIF files. Oksana made a strong case for better support of single-crystal neutron diffraction in mainstream refinement packages; the capabilities exist, though more user-friendly interfaces and tutorial materials are badly needed; while the powder-diffraction community is much larger, the singlecrystal community does need support; improved support for polarized experiments is also justified. This led to an interesting general discussion of funding for single-crystal and powder software development and various administrative models. There are very few people in the world who understand the fine details of diffraction modelling well enough to do the programming. Large new facilities could play a leadership role in supporting this effort, both through longterm staff positions and though one-to-three-year grant competitions in which the deliverables are specific software capabilities. Max asked how much the Commission really knows about the needs of software users, and suggested establishing formal channels for soliciting feedback and delivering responses (e.g. mailing list archives, wiki site, SLACK channel); workshop results are often repeated while an online response to a question persists.

The Commission supports a variety of scientific meetings each year through formal sponsorship, direct meeting organization, featured lecture presentations, workshop tutorials, the organization and chairing of conference sessions, and the presentation of lecture courses. Highlights from 2017 include the following:

Shanghai International Crystallographic School: working with the Bilbao Crystallographic Server, Shanghai, China, 1117 June 2017 (Mois Aroyo, Luis Elcoro).

International Conference on Neutron Scattering, Daejeon, Korea, 9-13 July 2017 (Max Avdeev, Maria Teresa FernandezDiaz, Alexander Pirogov, Juan Rodriguez-Carvajal).

ISODISTORT Workshop on Symmetry-Mode Analysis of Nuclear and Magnetic Structures, 19 August 2017, Banaras Hindu University, Varanasi, India (Branton Campbell).

XXIV IUCr Congress, Hyderabad, India, 21-28 August 2017. All Commission members and consultants participated in the organization. Session Chairs included Margarida Henriques, Taku Sato and Branton Campbell.

First International Conference on Intellectually Intensive Technologies in Energetics, Ekaterinburg, Russia, 20 September 2017 (Alexander Pirogov, invited lecture on Structure and Magnetic Neutron Diffraction).

School on Neutron Diffraction Data Treatment using the FullProf Suite, Grenoble, France, 16-20 October 2017 (MariaTeresa Fernandez-Diaz, Juan Rodriguez-Carvajal).

Hokkaido University Graduate School of Engineering, Intensive Course on Condensed Matter Research Using Neutron Scattering, Sapporo, Japan, 7-9 November 2017 (Taku Sato).

Ural Federal University, lecture course on Magnetic Neutron Diffraction, Ekaterinburg, Russia, NovemberDecember 2017 (Alexander Pirogov).

B. J. Campbell, Chair 
6.16. Commission on Mathematical and Theoretical Crystallography

Most of the communications among the members and consultants of the Commission (MaThCryst) took place via e-mail. In addition, some of the members and consultants present at the IUCr Congress in Hyderabad (IUCr 2017) met during an Open Commission Meeting (OCM) on 26 August 2017, where the outgoing Chair M. I. Aroyo presented a brief account of the activities of the Commission and introduced the new Chair of the Commission, Dhananjai Pandey. D. Pandey lauded the rich contributions of M. I. Aroyo, the outgoing Chair, and M. Nespolo, the founder Chair, in raising the level of activities of MaThCryst. During the OCM, several suggestions related to possible topics, venue and funding of future schools/workshops, outreach activities, publication of review articles in IUCr journals and special thematic issues, and publication of teaching pamphlets were made. The activities of the MaThCryst Commission for 2017 can be grouped into three parts and a brief summary of each one of these is presented below.

(1) 24th IUCr Congress and General Assembly 2017

The Commission actively participated in the organization of the 24th Congress and General Assembly of the IUCr held in Hyderabad, India, 20-29 August 2017, with L. Suescun as member representative of MaThCryst on the International Programme Committee (IPC) of the Congress. Thanks to his successful negotiations, one Keynote Lecture and two Microsymposia (MS-035 Crystal-Structure Relationships and their Applications and MS-026 A Bridge between Two Worlds: Graphs as Standard Descriptors) sponsored by the Commission and five more co-sponsored Microsymposia (MS-007 Topology and Symmetry of Modular Structures, MS-017 Extending the Boundaries of Crystallography, MS071 Crystallographic Patterns in Art and Cultural Heritage, MS-103 Methods for Characterizing Commensurate and Incommensurate Magnetic Structures and MS-115 Polymorphism and Structural Transformations in Crystalline Materials) were held at the Congress. Even in the cosponsored Microsymposia, at least one member/consultant of MaThCryst served as Chair/Co-chair. All these Microsymposia were well attended and witnessed lively discussions after the talks.

The Commission also organized a satellite event of the 24th IUCr Congress, namely the International School on Fundamental Crystallography and Workshop on Structural Phase Transitions, 30 August - 4 September 2017, at Rourkela, India, with D. Pradhan, member of the Commission, as the local organizer and M. I. Aroyo, M. Nespolo and D. Pandey as members of the IPC. The speakers included one member of the Commission (L. Suescun) and four consultants (M. I. Aroyo, M. Nespolo, B. Souvignier and D. K. Pradhan). This second school followed the one coordinated by D. Pandey at Varanasi, India, in 2014. There were 72 participants and the event was financially supported by IUCr, like the previous one (http://www.crystallography.fr/mathcryst/satelliteIUCr2017. php).

\section{(2) Organization of schools/workshops}

The following six workshops/schools were organized by MaThCryst. The details of each one of these are given at the Commission's and the events' home pages.

(i) The Second Philippine Workshop on Mathematical Crystallography with L. De Las Peñas as the main local organizer and MaThCryst coordinator was held in Manila, 2025 May 2017. The speakers were L. De Las Peñas, J. G. Eon (Rio de Janeiro, Brazil), M. Nespolo (Université de Lorraine, France), E. Schulte (Northeastern University, Boston, USA), S. Hyde (Australian National University), M. I. Aroyo (University of the Basque Country, Spain), D. Frettloeh (Bielefeld University, Germany), S. Akiyama (Tsukuba University, Japan) and M. Senechal (Smith College, Northampton, USA). There were 65 participants, including 14 members of the local organizing committee (LOC). The event was financially supported by the IUCr (http:// www.crystallography.fr/mathcryst/manila2017.php).

(ii) Shanghai International Crystallographic School Working With The Bilbao Crystallographic Server was held at Shanghai University, 11-17 June 2017, with MaThCryst coordinator M. I. Aroyo (University of Basque Country, Spain), and local organizers A. Stroppa and Wei Ren. There were 88 participants and the speakers were M. I. Aroyo, I. Errea (both from UPV/EHU, Spain), M. Nespolo, A. Stroppa (CNRSSPIN, Italy) and Q. Zhu (University of Nevada, USA). The school was financially supported by the IUCr (http://www. crystallography.fr/mathcryst/shanghai2017.php).

(iii) The International Autumn School on Fundamental and Electron Crystallography was held at Sofia, Bulgaria, 8-13 October 2017, with MaThCryst coordinators J. Hadermann (University of Antwerp) and M. I. Aroyo and local organizer D. Karashanova (Bulgaria). The speakers included M. Nespolo, M. I. Aroyo, J. Hadermann (all members or consultants of the Commission) and B. Ranguelov (BAS, Bulgaria). There were 48 participants including speakers and 12 LOC members, and the school was financially supported by the IUCr (http://www.crystallography.fr/mathcryst/sofia2017. php).

(iv) The International School on Topological Methods in Materials Science 2017 was held in Beijing, China, 13-15 October 2017, with MaThCryst coordinator and main speaker V. A. Blatov (Samara University, Commission member). There were 20 participants (http://www.crystallography.fr/ mathcryst/beijing2017.php).

(v) and (vi) Training courses on Symmetry and Group Theory (ongoing series in Japan); fifth course 6-10 March 2017, sixth course 31 July - 4 August 2017, both at KEK Tsukuba, MaThCryst coordinator and lecturer: M. Nespolo. There were 45 participants. (See https://www.iucr.org/gallery/ 2017/5th-tsukuba-training-course and https://www.iucr.org/ gallery/2017/6th-tsukuba-training-course for photographs.)

(3) Contributions by members/consultants in 2017.

M. I. Aroyo co-chaired (with M. Loquias) MS017 Extending the Boundaries of Crystallography, chaired a Keynote session and delivered an invited talk at MS110 Phase Transitions in Alloys and Molecular Solids at IUCr 2017, and delivered an 
invited lecture course on Crystallography Online: from Fundamentals to Applications of the Bilbao Crystallographic Server, Max-Planck Institute for Solid-State Research, Stuttgart, 6-8 February 2017. M. Nespolo delivered a Keynote talk at IUCr 2017. D. Pandey delivered an invited talk at MS035 Crystal Structure Relationships and their applications at IUCr 2017, was elected as Chair of the MaThCryst Commission by the 24th General Assembly and continues as a Co-editor of $J$. Appl. Cryst. L. Suescun acted as a member of the Consejo Consultivo of the Latin American Crystallographic Association (LACA), lecturing on Symmetry and the Use of the International Tables for Crystallography (https://www. openlabcr2017.com/residents/). Ma. Louise Antoinette N. De Las Peñas co-chaired and made an oral presentation at the Microsymposium on Crystallography in Art and Cultural Heritage at IUCr 2017. S. Hyde delivered an invited talk in MS-017: Extending the Boundaries of Crystallography at IUCr 2017, and co-organized and delivered a lecture at the International PhD School on Geometry and Topology in Contemporary Materials Science-2017 at Niels Bohr Institute. B. Souvignier co-chaired MS-026: A Bridge Between Two Worlds: Graphs as Standard Descriptors at IUCr 2017. K. Momma co-chaired MS-115: Polymorphism and Structural Transformations in Crystalline Materials at IUCr 2017.

D. Pandey, Chair

\subsection{Commission on Neutron Scattering}

The Commission (CNS) promotes the use of neutron scattering by encouraging the publication of information on the capabilities of neutron sources and instrumentation and by supporting symposia, schools and workshops that educate researchers on the unique information that can be provided by neutron scattering. Several members of the Commission are actively involved in developing neutron sources and new neutron-scattering technologies and methods.

The construction of the European Spallation Neutron Source is underway in Sweden, which is projected to produce the first neutrons in 2019, and plans to start a user programme with eight instruments in 2023 and to be fully operational with 22 instruments in 2029. The Chinese Spallation Neutron Source (CSNS), which is expected to be operational in 2018, is progressing. The operation of the Spallation Neutron Source (SNS) in the USA is continuing. The beam power for J-PARC/ MLF in Japan has been recovered and operation is continuing. Several new neutron scattering instruments were also brought into user programmes at neutron-scattering facilities across the world.

Commission members were also involved in organizing several meetings that took place in 2017 , including various annual meetings of regional crystallographic associations. A notable neutron conference in 2017 was the 11th International Conference on Neutron Scattering (ICNS2017), which was held in Daejeon, South Korea. A total of 758 scientists, engineers and aspiring students from 36 countries participated in this conference, contributing to 682 oral and poster presentations covering a wide range of topics, with six Plenary Lectures and a tour of the HANARO reactor. In addition to large facilities, compact neutron source projects are being established and constructed in various countries. In Europe, Forschungszentrum Jülich is conducting a high-brilliance neutron sources project and held the 3rd Workshop on High Brilliance Neutron Sources 2017 (HBS 2017) at Unkel, Germany. In India, a special Theme Meeting on Neutron Scattering was organized in Mumbai on 19 August 2017 to review the ongoing programme and future plans in this area in India.

Several neutron schools at many facilities were supported by Commission members. In the Asia-Oceania region, the 9th AONSA Neutron School/2nd Neutron and Muon School was jointly held at J-PARC in Japan with 49 students from 13 countries.

Commission members were also involved in planning activities for several important neutron conferences in 2018.

\section{T. Ishigaki, Chair}

\subsection{Commission on NMR Crystallography and Related} Methods

In this reporting period, our Commission entered its second triennium. A new list of members of the Commission was approved by the General Assembly of the IUCr at the 24th Congress in Hyderabad, India. As the Commission's existence is becoming better known in the NMR and diffraction communities, we are seeing increased interest in our various activities.

In early 2017, David Bryce (University of Ottawa, Canada) and Francis Taulelle (KU Leuven, Belgium) guest-edited a themed issue of Acta Crystallographica Section C on NMR crystallography. The 23 papers in the issue capture the growing breadth of NMR crystallography in the interrogation of the crystalline state of matter. One year on, the citation metrics for articles in the issue are reported to be roughly three times the average for papers in that journal, indicating the heightened interest in the subject.

We continue to strengthen our ties with the American Crystallographic Association. The 2017 annual meeting of the ACA in New Orleans, USA (26-30 May 2017) featured a first-of-a-kind half-day session on NMR crystallography, co-chaired by Tomislav Friscic and Manish Mehta. Five speakers formed a compelling and complementary set to present a good cross section of a growing field. They were James Harper (University of Central Florida, USA), Mhialis Arhangelskis (McGill University, Canada), Leonard Mueller (University of California, Riverside, USA), Kenneth Harris (Cardiff University, UK) and Darren Brouwer (Redeemer University, Canada). In short, the session exceeded everyone's expectations. The participants felt a certain momentum coming out of the meeting, as well as a certain relevance to the crystallography community. The session's attendance of 
approximately 50 was strong, relative to the meeting size of 500 , and the science presented was of the highest quality. At the New Orleans meeting, plans were laid for a similar session at the 2018 meeting of the ACA in Toronto, Canada. This collaboration between our Commission and the ACA may serve as a model for connections with other regional crystallographic associations.

The 24th Congress of the IUCr in Hyderabad, India, featured a Microsymposium on NMR Crystallography, featuring six leading practitioners in the field. Held on 23 August, it came on the heels of a successful Keynote Lecture by David Bryce on 22 August. (That Keynote had over 60 members in the audience.) Both the Keynote and Microsymposium were the first of their kind at an IUCr Congress. At its peak, the Microsymposium had nearly 60 members in the audience. While an emerging discipline, NMR crystallography is broad in its scope, ranging from technique development to applications in a variety of areas. The six presentations reflected this breadth in an impressive way. The talks were broadly accessible to the mixed audience. The presentations were of a complementary nature and gave a good feel for the questions that are being addressed and the tools employed to tackle those questions. P. K. Madhu gave an excellent overview of cutting edge NMR capabilities and their potential application to crystallography, while Yusuke Nishiyama showed what can be accomplished with proton chemical shift tensors. Sachin Chaudhari, having completed a postdoc with Lyndon Emsley in Lyon, spoke about the utility of dynamic nuclear polarization, while James Harper spoke about the possibility of determining crystal structures using NMR data alone. Gerd Buntkowski and Jurgen Senker spoke about powerful applications of NMR crystallography in the study of enzymes and polymer additives, respectively. In all, this was a highly successful Microsymposium, which made a valuable addition to the overall scientific program.

F. Taulelle, Chair, and M. Mehta

\subsection{Commission on Powder Diffraction (CPD)}

Commission activities during 2017 were mainly limited to activities related to the IUCr Congress in Hyderabad, where, as is often the case during this meeting, powder diffraction related research was well represented in many parts of the formal programme. Leading up to the meeting there was a fairly active discussion among Commission members regarding the Commission membership for the next triennium. This resulted in the list of names presented to the IUCr Executive Committee, and subsequently following due process the membership as approved by the General Assembly. During the latter stages, the new Chair of the CPD was invited onto the International Programme Committee of the PCCr2 meeting in Accra, Ghana, now scheduled for 28 January to 2 February 2019. Regarding other smaller meetings, the Commission reviewed a number of requests for support from meetings and supported these when appropriate, mostly based on the meetings containing a significant and identifiable powder diffraction component in its programme.

Unfortunately, the ongoing health issues of the outgoing Chair somewhat limited the other activities of the Commission. In terms of projects, most significant was that production of Volume $\mathrm{H}$ of International Tables for Crystallography continued.

Following a significant changing of the guard in terms of membership of the CPD, it is the intention and hope that the Commission will go into the next triennium with renewed energy and fresh ideas.

D. Billing, Chair

\subsection{Commission on Small Angle Scattering}

For 2017, the business of the SAS Commission (CSAS) was conducted principally via e-mail and during personal meetings at national and international conferences. There was good engagement from many of the CSAS members and consultants. What follows is a summary of highlights of activities for calendar year 2017.

Brief overview of CSAS interactions with IUCr Executive Committee and SAS community: Preparation of annual and triennial reports; support for the IUCr Congress (e.g. nominating a representative for the International Programme Committee and contributing suggestions for the programme via that nominee); support for the triennial Guinier Prize; recommending conferences to the IUCr for support for early-career scientists and under-represented countries; and contributions to IUCr Newsletter/website, e.g. a report on the Guinier Prize winner and general interest stories.

Jill Trewhella, outgoing Chair of the Commission, met with the IUCr Executive Committee (EC) to report on Commission activities and present the slate of members and consultants as specified in the 2017 report. The EC emphasized the importance of geographical, cultural and gender diversity in Commission membership and IUCr activities generally. The EC requested just one adjustment to the member/consultant nomination slate - to exchange a consultant with a member to bring greater gender balance to the membership group. The slate to be presented to the General Assembly was thus:

Members: U-Ser Jeng, Chair, soft matter, Asia Pacific (member since 2011); David Baboneau, materials, Europe (member since 2011); Kristina Djinovic Carugo, biology, Europe; Elliot Gilbert, soft matter, Asia Pacific (currently a consultant); Duncan McGillivray, soft matter, Asia Pacific (member since 2014); Jan Ilavsky, materials, North America (National Committee nominee); Eleonora Shtykova, biology, Eastern Europe/Northern Asia (National Committee nominee); Masaaki Sugiyama, soft matter, Asia Pacific (National Committee nominee).

Consultants: Andrew Allen, materials, North America; Javier Pérez, biology, Europe (National Committee nominee); Daniel Clemens, materials, Europe; Pete Jemian, materials, North America. 
The outgoing Chair, Jill Trewhella, chaired an Open Meeting of the Commission on 23 August 2017 in Hyderabad, India. Attendees included current and nominated incoming members and consultants: Jill Trewhella (Chair), U-Ser Jeng (incoming Chair), Andrew Allen, Kristina Djinovic Carugo, Jan Ilavsky, Pete Jemian, Toshiji Kanaya, Duncan McGillivray, Dmitri Svergun; J. Mitchell Guss from the IUCr Executive Committee; Stephen Burley, Sameer Velankar, Genji Kurisu, John Westbrook from the worldwide Protein Data Bank (wwPDB); and additional interested parties including $\mathrm{Cy}$ Jeffries and Al Kikhney (SASBDB EMBL), and Frank Gabel (ILL, CEA, CNRS). The brief outcomes include those listed below:

2020 IUCr Congress (IUCr 2020): CSAS will nominate two members for the International Programme Committee (IPC), considering diversity in the nomination. [Note: the SAS Commission consultant Dr Andrew Allen (preferred) and Professor Semra Ide were proposed to the IUCr 2020 Chair as the SAS IPC candidates on 1 March 2018].

Review paper for IUCrJ: The importance of high-quality work being published in IUCr journals was emphasized. An opportunity exists to produce a review paper for IUCrJ highlighting the state of the art in SAS and advances in the triennial period. CSAS could consider recruiting an individual or small group to propose topics and potential authors.

Organization of SAS2018 (Pete Jemian, Jan Ilavsky) is well underway and a comprehensive web page is available (http:// sas2018.anl.gov/). In addition to the Guinier Prize, Anton Paar has again committed to funding the Kratky Prize and sponsorship is being sought for additional prizes.

2018 Guinier Prize. Following normal protocol, a selection committee for the 2018 Guinier Prize will be made up of CSAS representatives (member Kristina Djinovic Carugo and consultant Iris Torriani were nominated for the committee on 22 February 2018) and SAS2018 organizers (in an approximately 2:3 ratio). Advertisement for the prize will be posted on the SAS2018 web page and the CSAS web page, and also distributed via the SAS list server. The Chair highlighted that the prize is highly competitive, and that nominations need to be substantial. The call for nominations should go out during January 2018 for receipt of nominations by about 30 April 2018 for winner selection by July 2018. With this timing, it is hoped to maximize the probability of the winner's attendance at SAS2018 to deliver a Plenary Lecture.

$S A S 2024$. Details of the bid process for SAS2024 are available on the SAS 2018 web page. Three CSAS representatives will join former and future SAS organizers in reviewing the bids and requesting any necessary/desirable additional information before posting on the web page prior to their presentation at SAS2018. After the vote at the meeting the evaluation committee will select the winning bid taking into account the quality of the bids, geographical representation in the field, and the vote.

$S A S 2021$. Aldo Craievich outlined preparations for this meeting. Planning is underway for the meeting to be held at Campinas, São Paulo, Brazil. The Brazilian Synchrotron will be the official host. A range of accommodation options are being developed, and the organizers will be interested in building strong connections with the conference organizing expertise from previous SAS meeting hosts.

Report on canSAS meeting (Duncan McGillivray, Pete Jemian): canSAS (collective action for nomadic Small Angle Scatterers) is a loosely organized meeting involving users and instrument scientists from around the world - the 9th meeting was held in San Francisco in June. canSAS has several lines of activity: (1) reproducibility and reliability, (2) outreach, (3) grazing incidence measurements, and (4) data formats. The group has developed a prize for short videos illustrating SAS techniques to be awarded at SAS2018. It also maintains a website (http://www.cansas.org/) that can be accessed via the SAS portal (http://smallangle.org).

The CSAS web page is in urgent need of updating and ideas for content can be sent to U-Ser Jeng (usjeng@nsrrc.org.tw) and Duncan McGillivray (d.mcgillivray@auckland.ac.nz). Duncan would also be happy to receive suggestions for posting on the SAS portal (which has been updated gradually since February 2018).

$N X$ canSAS as a standard for reduced small-angle scattering data (Pete Jemian): A multidimensional data format for reduced small-angle scattering data has been developed using Nexus. This format is somewhat parallel to sasCIF (a format which has already been accepted for one-dimensional data and is utilized) that was developed to support biological users. Nexus may serve a wider range of scattering experiments including non-isotropic ones. Stronger connection between canSAS and the CSAS and possible work on interconversion protocols between Nexus and sasCIF were mentioned as being desirable.

2017 update of publication guidelines for biological structural modelling using $S A S$ data, the sasCIF, and future liaison with the PDB (Jill Trewhella, John Westbrook): A paper updating the guidelines for publication of biomolecular SAS data and models has been published in Acta Crystallographica Section D (see https://scripts.iucr.org/cgi-bin/paper?jc5010). It is open access and has a wide international authorship (including biomolecular SAS instrument scientists and users) including a number of CSAS members and consultants (see technical activities for further details). The paper recommends deposition of data in a public archive and utilization of the recently extended sasCIF, an infinitely extensible data format that can support interoperability with the wwPDB, by database and program developers. The sasCIF will require further extension to include the additional parameters recommended in the guidelines paper, to ensure the successful development of the sasCIF and its utilization to support deposition of NMR/ SAXS refined structures into the database SASBDB (in partnership with the Hamburg/EMBL). SASBDB has been greatly aided by the close working relationship between the CSAS and wwPDB that has been facilitated by the Chair of CSAS and the wwPDB Validation Task Force being the same person. With the end of Jill Trewhella's term as Chair, in order to continue to support this productive relationship, CSAS is pleased to have the wwPDB leadership nominate John Westbrook as the wwPDB representative/liaison on CSAS. 
The importance of the different efforts towards data formats to be harmonized was discussed, as well as the opportunity to ensure no duplication of effort and potentially harmonize efforts of canSAS and the SASBDB/wwPDB/sasCIF. It was also emphasized that it is critical for SAS measurements to have metadata about the sample and preparation in order to be able to validate the data.

The NIST SRM is now available commercially as a certified standard from NIST for SAXS intensity calibrations. Although the methodology is published, the certification only applies to official samples sourced from NIST.

A question was raised by an industry participant about any interactions between the CSAS and ISO around nanoparticle sizing standards. Andrew Allen indicated that he had some interactions with ISO in his non-Commission role, and was pleased that SAS data methods were being incorporated into ISO standards.

The incoming Chair, U-Ser Jeng, thanked the Commission for their support for his nomination, and spoke of the work for the next three years. He also thanked the outgoing Chair, Professor Trewhella, for her dedicated work on behalf of the Commission, which received unanimous applause.

Contributions to the 24th IUCr Congress, Hyderabad: As part of an ongoing effort by the Commission on data standards and model validation in biomolecular SAS, J. Mitchell Guss presented a joint paper co-authored with Jill Trewhella at a well attended CSAS-sponsored Microsymposium on SmallAngle Scattering Data Formats, Standards and Repositories (MS-125). The foundation for the talk was the Acta Crystallographica Section D paper referred to in the previous section (https://scripts.iucr.org/cgi-bin/paper?jc5010), which has since been among the most-read papers for the journal since publication, with downloads approaching 1800 (as of 25 February 2018). This paper is the culmination of ongoing efforts by CSAS and Journals Commission members that began at the Osaka IUCr Congress in 2008.

Jill Trewhella co-chaired a well attended Microsymposium co-sponsored by CSAS, the Commission on Biological Macromolecules and the Commission on Electron Crystallography, on Macromolecular Structures by Hybrid Methods.

Elliot Gilbert is organizer and Chair of Neutrons and Food 5, to be held 16-18 October 2018 in Sydney, which is a satellite to SAS2018. Elliot Gilbert also is serving on the Scientific Committee of the 11th World Conference on Neutron Radiography, to be held 2-7 September 2018 in Sydney.

Masaaki Sugiyama organized the following three international workshops concerning SAXS and SANS: Grand Challenges in Small-Angle Scattering, held in Okazaki, Japan, 18-20 March 2017 (as co-organizer), in which Dmitri Svergun and U-Ser Jeng gave invited talks; Neutron Biology for Next Generation, held in Tokai, Japan, 22-23 March 2017 (as principal organizer); Deuterated Materials Enhancing Neutron Science for Structure Function Applications held in Tokai, Japan, 19-20 October 2017 (as co-organizer). In addition, Masaaki Sugiyama gave a lecture in the 3rd X-ray Protein Solution Scattering School at the Photon Factory held in Tsukuba, Japan, 12-13 December 2017.
Andrew Allen conducted the business of the SAS Commission (CSAS) principally via e-mail and during personal meetings at national and international conferences. There was good engagement from many of the CSAS members and consultants, and most of the Commission met in person at the IUCr Congress in Hyderabad, India, in August 2017.

Dmitri Svergun is a member of the Advisory Committee of the 7th Synchrotron Radiation in Polymer Science to be held in Gyeongju, Korea on 4-7 September 2018, as a satellite meeting of SAS2018.

U-Ser Jeng gave an invited talk to promote bioSAXS in a local meeting for Advances in Structural Biology and Beyond, 11 May 2017; organized a session to promote bioSAXS in the annual meeting of Biophysics Society in Taiwan, 17-18 May 2017; gave an invited talk in a meeting of the Society of Fibre Science and Technology, Japan, Autumn Meeting, 29 October 2017; organized an international bioSAS workshop (180 people) and bioSAXS instrumentation 6-7 September 2017; co-organized the Eighth Taiwan-Japan Joint Meeting on Neutron and X-ray Scattering: Applications to Polymers, Nanomaterials and Biomolecules on 14-17 March 2018; chaired a Microsymposium with Professor Gregory Warr on Functional Materials on the Nanoscale during the the IUCr Congress in Hyderabad, India, 21-28 August 2017; and gave an invited talk on SAXS applications at IIT, Dehli, India, 27 August 2017.

Educational activities: EMBO continues to be a strong supporter in growing the SAS community with good support from Commission members and consultants. In 2017 an EMBO Global Exchange Lecture Course was held in Singapore (6-14 December 2017) entitled Structural and Biophysical Methods for Biological Macromolecules in Solution, organized by Dmitri Svergun with Gerhard Gruber and participants Jill Trewhella and Kristina Djinovic Carugo.

Jan Ilvasky is the main organizer of SAXS courses (teaching by Jan Ilvasky, Pete Jemia and other APS staff). In 2017 they had two five-day-long SAXS courses (one on bioSAXS and the second on materials SAXS) and three two-day-long courses on SAXS software. Organized by Jan Ilavsky and Pete Jemian, the Advanced Photon Source has held five small-angle scattering courses on various subjects in 2017. These courses are intended to grow the expertise of the SAS community and together had about 100 participants.

Eleonora Shtykova runs a weekly seminar on processing and interpretation of small-angle X-ray scattering data at the Federal Scientific Research Centre Crystallography and Photonics of the Russian Academy of Sciences for students, graduate students and employees from Moscow educational and research institutions, and, along with Vladimir Volkov, lectures and conducts training courses for students of the physical and biological faculties of the Moscow State University on the application of small-angle scattering in the study of biological objects and modern nanomaterials.

Dmitri Svergun gave: a Plenary talk Modern Small-Angle Scattering from Biomacromolecular Solutions at the Okazaki Conference Molecular System Sciences: Grand Challenges in 
Small-Angle Scattering, 18-21 March 2017, Nagoya, Japan; a Keynote Lecture Small-Angle X-ray Scattering for Biological Macromolecules on 24 August 2017 at the 24th Congress of the IUCr (Hyderabad, India); an invited lecture State-of-theArt of SAS Data Analysis at the EMBO SAXS/SANS Course, 15 September 2017, Grenoble, France; an invited talk SmallAngle X-ray Scattering on Biomacromolecular Solutions: Current Progress and Perspectives at the SAXS eXcites meeting in Graz, Austria, 26-27 September 2017; and a lecture Small-Angle X-ray Scattering and Bioinformatics at the European Bioinformatics Institute, Wellcome Genome Campus, Hinxton, Cambridge, 3 October 2017. Dmitri was the main organizer of an EMBO-supported Global Exchange Lecture Course Structural and Biophysical Methods for Biological Macromolecules in Solution (6-13 December 2017, Singapore). The main local co-organizer was Professor Dr Gerhard Grueber (Nanyang Technological University, Singapore). At the course, SAXS and SANS were presented as part of a hybrid approach in structural studies; the programme also covered NMR, biochemical and biophysical methods. Fifty students were selected from a highly competitive list of 167 applicants. Of those, 28 were local Singaporean students, 11 were from the Asia-Pacific region, eight were based in Europe, two students came from North America and one from Africa. A total of 15 tutors (ten European/Australian, including J. Trewhella and K. Djinovich-Carugo, and eight domestic from Singapore) contributed lectures, hands-on tutorials and demonstrations. One of the highlights was the world's first remote WAXS data collection conducted by the course participants at the EMBL P12 synchrotron beamline in Hamburg.

Community-building activities: CSAS members and consultants served on various SAS-related committees and panels, and on editorial boards.

Jill Trewhella serves as a Co-editor (biology and medicine) for $I U C r J$, and as an Editorial Board member of the Cell Press journals Biophysical Journal (Proteins) and Structure.

Elliot Gilbert continues as a Co-editor for the Journal of Applied Crystallography.

Eleonora Shtykova serves as the organizer, coordinator and designer of the Russian website on small-angle scattering. The Russian-language version of the site can be found at https:// www.saxs.space/. The site is in development. Currently, work is also underway to create an English-language version of the site for the development of international contacts on smallangle scattering. Eleonora Shtykova with Maxim Petoukhov, Petr Konarev and Vladimir Volkov (leading Russian SAS specialists from Federal Scientific Research Centre Crystallography and Photonics RAS) serve as the initiators of the further development of the Russian community on smallangle scattering in 2017. Several biological, chemical and physical academic institutes in Moscow are currently actively studying biological objects and modern nanomaterials using small-angle scattering. Eleonora Shtykova, along with other members of the Russian SAXS community, is in constant contact through regular visits and via e-mail with the bioSAXS group in Hamburg (group leader Dmitri Svergun) to carry out joint research and for further development of the method of small-angle scattering.

Dmitri Svergun continued as a Co-editor of the Journal of Applied Crystallography and as a member of the Associate Editorial Board of Frontiers in Molecular Biosciences, section Structural Biology. Dmitri Svergun also continued to act as a Management Committee member and Work Leader responsible for a Pan-European and AUM iNEXT meeting, 21-25 May 2017, Brno.

Members and consultants of CSAS were prominent contributors to meetings around the world supporting the dissemination of research using small-angle scattering. Jill Trewhella presented an invited paper at the Biophysical Discussions: Conformational Ensembles from Experimental Data and Computer Simulations (Berlin, Germany, 25-29 August 2017) highlighting the role SAS can play in this developing field. Jill Trewhella and Dmitri Svergun presented Keynote talks at the International SAXS Symposium - SAXS eXcites (Graz, Austria, 25-27 September 2017). This meeting honoured the contributions of Otto Kratky to SAS on the occasion of the 60th anniversary of the first commercial SAXS instrument designed by Otto Kratky and manufactured by Anton Paar.

U-Ser Jeng formed a bioSAS community in Taiwan (BioSWAN) and established contact with Professor Trusha Petal, who has a SAXS group in Canada. Professor Petal showed his keen interest in participating in the SAS Commission during the Open Meeting of the Commission at the IUCr Congress in Hyderabad. He has been recommended by the Canadian National Committee for Crystallography to join the SAS Commission after the Congress.

Consultant activities: CSAS has provided recommendations on SAS-related programmes and supporting letters for $\mathrm{IUCr}$ funding support for the following conferences:

(1) 50 Years of Synchrotron Radiation in the UK and its Global Impact, 26-29 June 2018, University of Liverpool, UK.

(2) XVII International Small Angle Scattering Conference (SAS2018), 7-12 October 2018, Traverse City, Michigan, USA, and the two satellite meetings: Neutrons and Food: Sydney, Australia, 16-19 October 2018, organized by Elliot Gilbert (CSAS member), and Grazing-Incidence SAS 2018 and 7th Synchrotron Radiation in Polymer Science, both held at Gyeongju, Korea, 4-7 September 2018.

CSAS members continue to support the worldwide Protein Data Bank (wwPDB) through the wwPDB SAS Task Force. The Task Force continues its work on requirements for validation of biomolecular SAS data and modelling (chaired by Jill Trewhella with Dmitri Svergun and Masaaki Sugiyama). Major technical outcomes from this consulting work are the 2017 publication guidelines for biomolecular SAS, the SASBDB and PDB-Dev (see Technical activities below).

David Babonneau continues to serve as Co-chair (technical activity) of the Peer Review Committee 3: Matter and Material Properties: Structure, Organization and Characterization, Elaboration for beam-time allocation at the SOLEIL synchrotron, France. 
Eleonora Shtykova with Maxim Petoukhov and Vladimir Volkov (Federal Scientific Research Centre Crystallography and Photonics of the Russian Academy of Sciences) are consultants for studies of biological objects and composite nanosystems by small-angle scattering, giving lectures to staff of several research institutes throughout Russia. Eleonora Shtykova serves as an expert of the Russian Academy of Sciences (identification number RAS 2016-01-5438-3259) to evaluate SAS-oriented projects.

Dmitri Svergun served on the Scientific Advisory Committee of the National Synchrotron Radiation Research Center, Taiwan, and on the French Academy (ANR) Scientific Evaluation Committee - Structural Biology and Molecular Biology (14-16 June 2017, Paris).

Technical activities: A number of CSAS members and consultants (Masaaki Sugiyama, Javier Pérez, Dmitri Svergun, Jill Trewhella), as part of a 22-member international team, co-authored the paper entitled 2017 publication guidelines for structural modelling of small-angle scattering data from biomolecules in solution: an update (also referred to above in the section about the CSAS Open Meeting at the Hyderabad Congress). The paper provides context and recommendations for reporting guidelines with regard to samples, data acquisition and reduction, analysis and interpretation, and modelling. It also recommends the deposition of data in a public archive and the utilization of the sasCIF to enable seamless data exchange with the worldwide Protein Data Bank. To this end, Dmitri Svergun's group in Hamburg continues to maintain and curate the publicly available Small Angle Scattering Biological Data Bank (SASBDB, https://www.sasbdb.org/; the main curators are A. Kikhney and C. Jeffries), which as of the time of this report contained 569 experimental data sets and 932 models, with 144 experimental data sets and 170 models on hold. The SASBDB uses the recently extended sasCIF. A new major release 2.8 of the ATSAS program package for SAS data analysis was published in 2017 (https://scripts.iucr. org/cgi-bin/paper?ge5042). As of 2017, ATSAS had been downloaded by over 15000 users and is utilized in over $50 \%$ of publications on biological SAS.

CSAS members strongly support the (wwPDB) initiative to establish a federated system of interconnected databases similar to what exists at present for the PDB (RSCB, PDBe, PDBj) but extended to include all data types that contribute to solving complex structures. In 2017, the public release of a prototype system for depositing integrative/hybrid structural models, PDB-Dev (https://pdb-dev.wwpdb.org), was announced; this is a major step toward the realization of the federated system [see Burley, Kurisu, Markley, Nakamura, Velankar, Berman, Sali, Schwede \& Trewhella (2017), PDBDev: a Prototype System for Depositing Integrative/Hybrid Structural Models. Structure, 25, 1317-1318 (https://www.ncbi. nlm.nih.gov/pmc/articles/PMC5821105/].

Eleonora Shtykova participates in the running of a highbrilliance biological SAXS/WAXS beamline at the new Russian SSRS-4 facility and in the related programme of the Russian Federation in the International Mega-class project European XFEL.
U-Ser Jeng continues to lead the construction of an advanced bioSAXS beamline at the Taiwan Photon Source, and established HPLC/SAXS/UV-Vis-absorption/refractiveindex integrated measurements at the 23A SAXS beamline of the Taiwan Light Source in 2017.

U.-S Jeng, Chair, and J. Trewhella, outgoing Chair

\subsection{Commission on Structural Chemistry}

The Commission on Structural Chemistry (CSC) encompasses a wide range of topics in the field of crystallography. There are extensive overlaps with other Commissions including the Commission on Inorganic and Mineral Structures and the Commission for Crystallographic Teaching, as well as with important external bodies such as the Cambridge Crystallographic Data Centre (CCDC).

The membership of the Commission on Structural Chemistry was updated extensively at the IUCr Congress in Hyderabad in 2017. Stuart Batten stood down as Chair, but remains a consultant and has helped to ensure continuity. Susan Bourne stepped into the role as Chair, with other new members Jun Harada, Katharina Fromm, Rahul Banerjee, Len MacGillivray and Alison Edwards. The composition of the consultants was also updated somewhat, bringing on board Pete Woods, Petra Bombicz, Ilia Guzei, A Bialonska and Nadezhda Bolotina, while Christer Aakeroy, Alessia Bacchi, Tony Linden and Patrick Mercier continue to provide wisdom stemming from experience in serving the Commission in different roles.

The members and consultants of the Commission provide liaison with other Commissions and important bodies: Patrick Mercier: Inorganic and Mineral Structures; Pete Wood: CCDC; Len MacGillivray: Co-editor of IUCrJ.

At its meeting in Hyderabad, the new CSC agreed to focus on (i) support for appropriate crystallographic conferences and schools, in particular those which aim to expand crystallography to under-represented regions such as South America and Africa; (ii) support for IUCr journals, through encouraging submission of excellent scientific results to $I U C r J$ and other journals; and (iii) building relations with other Commissions and external bodies such as IUPAC and the CCDC.

Since August 2017, the CSC has lent support to the following conferences and schools, which draw crystallographers in the structural chemistry sphere:

Indaba 9, Kruger Park, South Africa, September 2018. Organizing committee Chair: Demetrius Levendis.

Gordon Research Conference on Crystal Engineering, USA, June 2018. Organizing committee Chair: Len MacGillivray.

American Crystallographic Association annual meeting, Toronto, Canada, July 2018. Organizing committee Chair: Tiffany Kinnibrugh.

2nd Porous Molecular Materials (POMOS) conference, Vietri sul Mare, Italy, June 2018. Organizing committee Chair: Consiglia Tedesco. 
5th European Crystallography School, Stellenbosch, South Africa, July 2018. Organizing committee Chair: Catharine Esterhuysen.

In addition, the CSC has provided a list of nominations for the International Programme Committee for the IUCr Congress to be held in Prague, Czech Republic, in 2020.

S. Bourne, Chair

\subsection{Commission on Synchrotron and XFEL Radiation}

The mission of the Commission on Synchrotron and XFEL Radiation (CSXR) is to promote access and awareness of crystallographers worldwide to the world's synchrotron radiation (SR) and X-ray free-electron laser (XFEL) facilities. To this end, the Commission promotes the development of crystallographic instrumentation, technology and standards, and the synergies between storage-ring-based and LINACbased next-generation XFEL sources. The bulk of the Commission's work is carried out via e-mail, with occasional face-to-face meetings held at selected conferences attended by a sufficient number of Commission members.

Synchrotron radiation and free-electron laser facilities. Following the start of operation of the first fourth-generation storage ring, MAX IV in Sweden, most existing facilities, including the first three third-generation hard X-ray facilities, the ESRF, APS and Spring-8, are either undertaking or planning significant upgrade programmes based on these new designs. New facilities, such as the $6 \mathrm{GeV}$ High Energy Photon Source to be built near Beijing, China, and the $3 \mathrm{GeV}$ facilities SLiT-J (Tohoku, Japan) and SIRIUS (Campinas, Brazil) will also use the new high-brightness designs.

In 2017 several hard X-ray FEL facilities also started their user programmes. In the summer the PAL-XFEL (Pohang, Korea) had first users scheduled and by mid-September the first users of the European XFEL (Schenefeld, Germany) started their user experiments after only little more than eight months of commissioning of this facility. The first two instruments to receive users were the Femtosecond X-Ray Experiments (FXE) and the Single Particles, Clusters, and Biomolecules and Serial Femtosecond Crystallography (SPB/ SFX) instruments. By end of 2017, the SwissFEL (Villigen, Switzerland) had also started their user programs with test experiments.

SXR Commission membership. The current members and consultants are as follows. 2017-2020 members (with year appointed): P. Grochulski (Canada) (2008) Chair, M. A. Garcia-Aranda (Spain) (2011), Y. Murakami (KEK, Japan) (2011), S. Pascarelli (France) (2011), J. Smith (USA) (2011), T. Tschentscher (Germany) (2014), E. Granado (Brazil) (2014), M. Kozak (Poland) (2017), S. Ramaswamy (India) (2017) and T. Hatsui (Japan) (2017). 2017-2020 consultants: R. Garrett (Australia) past Chair, D. Fritz (USA), S.-I. Adachi (Japan), M. Suchomel (USA), M. K. Sanyal (India), N. Zatsepin (USA) and Lisa Keefe (USA).

Supported meetings, schools and workshops. The Commission organized and sponsored several sessions at the IUCr
Congress in Hyderabad as well three Keynote talks by Janet Smith, Sakura Pascarelli and Henry Chapman.

The CSXR provided letters of support and endorsement for the following meetings in 2017:

Italian Synchrotron Radiation 14th School on Synchrotron Radiation, organized by the Italian Society (SILS), Muggia, 18-29 September 2017.

The RapiData Course on Automated Data Collection, to support participation of Latin-American students. The CSXR has endorsed this annual event for many years, and did so again for the school held at the SLAC National Accelerator Laboratory in April 2017.

In general, the Commission has strongly supported IUCr sponsorship for the purpose of assisting attendance by young researchers and scientists from developing countries.

CSXR member activities. The members of the Commission are active in key synchrotron and crystallography communities and conferences. For example:

Thomas Tschentscher organized sessions of scientific applications and instrumentation of FEL facilities at the SPIE OPTICS conference in Prague in April 2017 and at the CLEO optics conference in Munich in July 2017. He also chairs the EUCALL (European Cluster of Advanced Laser Light Sources) project funded by the European Commission and grouping accelerator- and laser-driven X-ray user facilities. Within EUCALL, these infrastructures cooperate on common technical, scientific and strategic issues for the first time, with the goal of making the future operation of these facilities more efficient, and therefore more sustainable.

Maciej Kozak is President of the Polish Synchrotron Radiation Society and a member of Polish Synchrotron - a council supporting the construction of the Polish synchrotron SOLARIS.

Pawel Grochulski represented the Commission on the International Programme Committee of the 2017 IUCr Congress.

Eduardo Granado was Chairman of the Organizing Committee of the LNLS 27th Annual Users' Meeting (RAU), Campinas, 22-24 November 2017; was Co-chair of the Microsymposium Total Scattering in Hyderabad; and was a member of the organizing committee of the São Paulo School on Light, Neutrons and X-rays, São Paulo, 17-21 July 2017.

Sakura Pascarelli was involved in the organization of the following two workshops, both at the ESRF: the 2nd Workshop on Studies of Dynamically Compressed Matter with X-rays, 29-30 March 2017, which aimed to bring together the community of future users of the High Power Laser Facility; and the 2nd EUCALL Annual Meeting, 7-9 June 2017.

Asia Oceania Forum for Synchrotron Radiation Research (AOFSRR). The Asia Oceania Forum for Synchrotron Radiation Research is an international network whose mission is to foster collaboration among synchrotron-radiation facilities and user communities in Asia and Oceania, as well as promote collaborations with facilities and communities in America and Europe. The eight facility-operating nations in the region are full members of the AOFSRR, and the Forum's 
mission includes promotion of synchrotron-based science throughout the region.

One of the core activities of the AOFSRR has been the Cheiron School, a two-week international synchrotron school, which has been held annually at SPring-8 since 2007. The 2015 Cheiron School was the 9th and final year that SPring- 8 hosted this event. Following a review, it has been decided to change the format of the SPring-8 school to a shorter, higher-level workshop aimed more specifically at staff members of the AOFSRR synchrotron light source facilities. At its 2016 Council Meeting, the AOFSRR decided to establish the AOF Synchrotron Radiation School as an annual school rotating between the member countries. An initial rotation has been decided, with Australia hosting the first AOF School in 2017, to be followed by South Korea in 2018 and Thailand in 2019.

P. Grochulski, Chair

\subsection{Commission on XAFS (CXAFS)}

The satellite workshop to the IUCr Congress on data quality in XAFS spectroscopy (Q2XAFS2017: International Workshop on Improving Data Quality in XAFS Spectroscopy) held at Diamond, UK, 14-15 August 2017, was a great success for the XAFS community with 80 attendees. The workshop aimed to bring together experts in the field of X-ray absorption spectroscopy to discuss aspects of the technique that affect data quality in XAFS experiments, from the preparation of the experiment to data collection and data reduction. Methods were also considered that can help deliver robust means to assess data quality. Aside from data quality, the workshop also addressed the issue of data format standardization and storage. It was suggested that the International X-ray Absorption Society (IXAS) website could host a XAS database and also that the IUCr may be the best forum, including or in addition to specific IUCr and other journals (Journal of Synchrotron Radiation, Radiation Physics and Chemistry and so on). The issue of data format was also discussed. This topic is of particular interest as many funding agencies around the world as well as journals are requiring archival data. It is noteworthy that EXAFS beamlines in several facilities are keen to contribute to the XAS spectra database.

Speakers included C. T. Chantler, R. Boada-Romero, G. Aquilanti, R. Sarangi, M. Newville, D. Bowron, E. Welter, B. Bunker, S. Pascarelli, H. Abe, Y. Joly, T. Penfold, K. Asakura, S. Mangold, S. Figueroa, a video telecast from B. Ravel, S. Bartlett, P. Glatzel, G. Subias and M. Nachtegaal, and there was a strong poster session.

The outcomes of the meeting were discussed among the speakers on 16 August. A special issue in Journal of Synchrotron Radiation containing ten papers related to the Q2XAFS meeting (with Sofía Diaz-Moreno as guest editor) will be published.

The next Q2XAFS meeting will be held in three years' time at APS and will be organized by Matt Newville. It will be a bit over three months away from the IUCr Congress and it will be advertised on the IXAS website and on the CXAFS Commission website, but not on the IUCr Congress website, because it will not be described as a satellite meeting of the IUCr Congress.

The workshop on XAFS at the 24th IUCr Congress was organized by the IUCr XAFS Commission and the International X-ray Absorption Society, with the local support of the Board of Research in Nuclear Science (India). This workshop was held on 21 August in Hyderabad, India, with 80 attendees. This is comparable to the the number of attendees at the workshop held in Montreal within the 23rd IUCr Congress. The scope of this one-day, free tutorial workshop was to provide an overview of the physics and chemistry of X-ray absorption spectroscopy with a particular emphasis on its complementarity with diffraction techniques. The curriculum included introductions to beamline instrumentation, measurement methods, methods of data processing and analysis, and proposal writing. A software panel discussion discussed a wide variety of software packages. Workshop speakers: C. T. Chantler, F. Jalilehvand, S. Heald, B. Mishra, G. Aquilanti, R. Sarangi, H. Harris, Sohini Basu. Chairs of the workshop: Christopher Chantler, Farideh Jalilehvand and Bruce Ravel. Local organizer: Dibyendu Bhattacharyya.

A record number of eight Microsymposia at the 24th IUCr Congress were organized or co-organized by the XAFS Commission:

(1) MS-090 Spectroscopy Applications in Biologically Relevant Systems, Co-chairs Sofia Diaz-Moreno (UK) and Bhoopesh Mishra (USA).

(2) MS-051 Recent Developments in XAFS Spectroscopy: Theory, Instrumentation and Data Analysis, Co-chairs Hiroyuki Oyanagi (Japan) and Konstantin Klementiev (Sweden).

(3) MS-107 Synchrotron Measurement in Conservation and Cultural Heritage, Co-chairs Bruce Ravel (USA) and Eric Dooryhèe (USA), shared with the Commission on Crystallography in Art and Cultural Heritage (Chair: Gilberto Artioli, Italy).

(4) MS-060 XAS at Extreme Conditions, Co-chairs Giuliana Aquilanti (Italy) and Daniel Haskel (USA), shared with the Commission on High Pressure (Chair: Andrzej Katrusiak, Poland).

(5) MS-096 XAFS of Materials for Clean Energy, Co-chairs Pieter Glatzer (France) and Steve M. Heald (USA), shared with the Commission on Crystallography of Materials (Chair: Artem Oganov, USA).

(6) MS-121 Synchrotron-Based X-ray Techniques and the Environment, Co-chairs Richard Garrett (Australia) and Hugh Harris (Australia), shared with the Commission on Synchrotron and XFEL Radiation (Chair: Richard Garrett, Australia).

(7) MS-042 High Resolution Spectroscopy, Co-chairs Dimosthenis Sokaras (SSRL, USA) and Hamid Reza Khavasi.

(8) MS-074 Porous Framework for Catalysis and Renewable Energy, Co-chairs Christian Doonan and Gustav Van Tendeloo. 
The abstract submissions in these Microsymposia were excellent.

A Keynote Lecture was given by Sakura Pascarelli (ESRF, France) with the title Science at High-Pressure: the Emerging Role of X-ray Absorption Spectroscopies. Another excellent Keynote was given by Farideh Jalilehvand (Canada) with the title X-ray Absorption Spectroscopy and Chemical Speciation: from Archaeology to Biology. A third excellent Keynote was given by Vittal Yachandra on Taking Snapshots of Photosynthetic Water Oxidation with an X-ray Laser.

About half of attendees of the Keynotes were young and new to the field. In fact, this is the first Congress where the Commission has nominated three Keynote speakers and all were accepted and provided outstanding Keynotes. In discussions with the Executive Committee and others at the Congress it was perhaps remarkable that we as a Commission provided an average of $66 \%$ female nominations and successes for the Keynote etc. process. We note that our Commission and Microsymposia are fairly balanced in gender but that all nominations and speakers were nominated by the Commission on purely scientific grounds.

Conference support and proposals. Since the IUCr's Calendar Committee has a limited amount of funds to distribute to different meetings, it is vital that the CXAFS prioritizes those meetings, workshops etc. for which we wish to receive support (and not only endorsement) from the IUCr. Support to IXAS should be our main priority and Q2XAFS should be our next highest priority; therefore the Calendar Committee will be informed that next IXAS meeting, which will be held in Krakow (Poland) in 2018, will be our priority.

International Tables for Crystallography, Volume I, X-ray Absorption Spectroscopy and Related Techniques. The editors have received most of the initial submissions for roughly 150 chapters; most are reviewed or under revision and some $20 \%$ are now accepted. They are still working on quite a few important chapters, e.g. those which the original authors are no longer able to complete, but the progress is steady and they are typically getting one chapter reviewed per week.

$C X A F S$ web page. The website contains useful information including files from the workshop at the last IUCr Congress and the XAFS dictionary definitions.

IXAFS Newsletter. IXAS encourages CXAFS to communicate any initiative of the Commission that can be advertised in their newsletter.

Links to IUCr journals. As mentioned previously, the outcomes of the Q2XAFS meeting will be published in the Journal of Synchrotron Radiation. The proceedings of XAFS17 conference, which will be held in Krakow (Poland) in July 2018, will be published in Radiation Physics and Chemistry. Approximately 50 EXAFS papers per year are published in the Journal of Synchrotron Radiation. Most are about applications.

CXAFS membership for 2017-2020. The following were proposed to IUCr Executive Committee after being contacted to ask whether they agreed to be a member and whether they were happy to take on their proposed roles. These have all been approved.
Membership and portfolios 2017-2020: Christopher T. Chantler (Australia) (member since 2008), Chair; Valérie Briois (France) (2017), Secretary; Sofia Diaz-Moreno (UK) (2014), Secretary, website; Guiliana Aquilanti (Italy) (2014), liaison with the International Programme Committee; Dibyendu Bhattacharyya (India) (2017), coordinator of funding support including from the Executive Committee for critical missions (IUCr Congress, Workshop, Satellite, IXAS, Q2XAFS, other); Yasuhiro Inada (Japan) (2017), working group on databases and coordinator of summary from Japan XAFS Society; Narcizo M. Souza-Neto (Brazil) (2017), IUCr dictionary of XAFS terminology; Steve M. Heald (USA) (2014), liaison with International Tables for Crystallography and the IUCr journals; Krystyna Lawniczak-Jablonska (Poland) (2011), coordinator for Q2XAFS workshop (Poland), IXAS liaison; Carlo Lamberti (Italy) (2017), IUCr Congress workshop, liaison with International Tables for Crystallography.

Consultants 2017-2020: Federico Boscherini (Italy), Farideh Jalilehvand (Canada), Hiroyuki Oyanagi (Japan), Pieter Glatzel (France) and Richard Strange (UK).

C. Chantler, Chair, and V. Briois and S. Diaz-Moreno, Secretaries

\section{Sub-committee on the Union Calendar}

The Sub-committee receives and considers requests for IUCr sponsorship and nominal financial support, and makes recommendations to the Executive Committee. Acting on the recommendations made by the Sub-committee, during 2017 the Executive Committee approved sponsorship of various schools and meetings, mostly with financial support. Those held in 2017 are listed at the beginning of this Report of the Executive Committee. Those scheduled for 2018 and 2019, but approved in 2017, are listed below.

1st LACA School - Small Molecule Crystallography, Montevideo, Uruguay, 19-25 February 2018.

Powder Diffraction and Rietveld Refinement School, Durham, UK, 8- 12 April 2018.

RapiData 2018, Stanford, USA, 22-27 April 2018.

6th International School on Crystallization: Drugs, Foods, Agrochemicals, Minerals, New Materials (ISC2018), Granada, Spain, 20-26 May 2018.

Quantum Crystallography School (Erice 2018), Erice, Sicily, Italy, 1-10 June 2018.

The 4D Workshop: Deep-Time Data-Driven Discovery and the Evolution of the Earth, Carnegie Institution for Science, Washington DC, USA, 4-6 June 2018.

2nd Meeting on Porous Molecular Solids (POMOS 2018), Vietri sul Mare, Italy, 6-8 June 2018.

XXV Conference of Serbian Crystallographic Society, Bajina Basta, Serbia, 21-23 June 2018.

Gordon Research Conference 2018: Crystal Engineering, Jordan Hotel at Sunday River, Newry, Maine, USA, 24-29 June 2018. 
Aperiodic 2018, Ames, Iowa, USA, 8-13 July 2018.

Sagamore XIX 2018, Halifax, Nova Scotia, Canada, 8-13 July 2018.

5th European Crystallographic School (ECS5 2018), Stellenbosch, South Africa, 8-14 July 2018.

Annual Meeting of the American Crystallographic Association (ACA 2018), Toronto, Canada, 20-24 July 2018.

17th International Conference on X-ray Absorption Fine Structure (XAFS17), Krakow, Poland, 22-27 July 2018.

50 Years of Synchrotron Radiation in the UK and its Global Impact (UKSR50), Liverpool, UK, 26-29 July 2018.

31st European Crystallographic Meeting (ECM 2018), Oviedo, Spain, 22-27 August 2018.

Sixth SMARTER Crystallographic Conference, Ljubljana, Slovenia, 2-6 September 2018.

INDABA 2018 (Modelling of Structures and Properties), Skukuza Camp, Kruger National Park, South Africa, 2-7 September 2018.

14th Biennial Conference on High-Resolution X-ray Diffraction and Imaging (XTOP 2018), Bari, Italy, 3-7 September 2018.

Second European School on Crystal Growth (ESCG2) and Sixth European Conference on Crystal Growth (ECCG6), Riviera Holiday Club, Varna, Bulgaria, 13-16 and 16-20 September 2018.

Annual Meeting of the Latin-American Crystallographic Association (LACA3 2018), Valparaiso, Chile, 3-5 October 2018.

Annual Meeting of the Asian Crystallographic Association (AsCA 2018), Auckland, New Zealand, 2-5 December 2018.

19th International Conference on Crystal Growth and Epitaxy (Crystal Growth 2019), Keystone, Colorado, 28 July 2 August 2019.

Organizers of meetings wishing to seek IUCr sponsorship should submit applications at least nine months in advance of the meeting, writing to the Chair of the Sub-committee. For up-to-date contact information, application procedures and rules, see http://www.iucr.org/iucr/sponsorship/meetings.html.

Requests from satellite meetings may be submitted, and possible financial support requested, separately or through the Organizing Committee of the main meeting.

Meetings (other than satellite meetings) scheduled to be held within one month before or after an IUCr Congress will not be considered for sponsorship. For any meetings scheduled to be held between one and two months before or after a Congress, the application for sponsorship will be sent to the Chair of the Congress Programme Committee for approval, or otherwise. For meetings (other than satellite meetings) scheduled to be held, in the respective region, within one month before or after a meeting of a Regional Associate (American Crystallographic Association, Asian Crystallographic Association, European Crystallographic Association, Latin-American Crystallographic Association), the applicants for sponsorship must seek approval of the Chair of the Regional Associate Organizing Committee.

IUCr sponsorship can only be given to meetings that are international in character and open to participants from all countries. For international meetings, the membership of the Programme Committee is a good indication of this. National meetings are only supported if held in developing countries.

Explicit support from the relevant IUCr Commission(s) is required for any international meeting (except for the meetings of Regional Associates) and from the Commission on Crystallographic Teaching for any international schools (except for those organized by an IUCr Commission).

The IUCr continues to support and uphold ICSU's policy of non-discrimination and adheres to its decisions and procedures concerning the free circulation of scientists. Organizers of any meetings seeking IUCr sponsorship or support must assure the Sub-committee on the Union Calendar that the authorities of the country in which the meeting is to take place guarantee free entrance of bona fide scientists from all countries.

IUCr sponsorship should only be given to meetings that include a speaker policy and statistics relating to gender balance on the conference website. The policy should be consistent with the IUCr's policy on gender balance (https:// www.iucr.org/iucr/principles-and-policies/gender-balance).

Visiting Professorships. The IUCr Visiting Professorship Scheme aims to support some of the costs of having internationally recognized scientists as lecturers for short courses at workshops or schools organized in developing countries. These schools or workshops may have national or international character. Up to a maximum of three Visiting Professorships can be granted for a single event. Travel and insurance costs will be met by the IUCr, while the local organizers cover the accommodation/subsistence expenses. Visiting Professorships can be requested in conjunction with the application for IUCr funding of a meeting, or independently as a single action to obtain highly qualified international teaching support within a teaching programme of local character. Support from at least one IUCr Commission is required. Full details may be found at http://www.iucr.org/iucr/ sponsorship/vp.html.

8. Committee for the Maintenance of the Crystallographic Information File Standard (COMCIFS)

COMCIFS is responsible for maintaining and developing the suite of standards known as the Crystallographic Information Framework (CIF) on behalf of the IUCr. The Committee consists of five voting members and a broad collection of advisers and observers. The current voting members are James Hester (Chair), Brian McMahon (Secretary), Herbert Bernstein, John Westbrook and John Bollinger. No issues required a vote in 2017 .

New dictionaries. No new dictionaries were approved in 2017. Preliminary drafts of a high pressure dictionary and a topological dictionary were sighted.

Updating legacy dictionaries. COMCIFS is in the process of rewriting all legacy IUCr dictionaries to use a modern dictionary definition language (DDLm). This work is now essentially complete for the core, powder, twinning and constraint/restraint dictionaries. The modulated structure 
dictionary required development of further standards in order to properly describe data spread over multiple blocks; a recommendation was developed and formally proposed at the end of the year.

The legacy dictionaries are being gradually phased out, with a maintainer appointed to ensure that the legacy dictionaries remain compatible with the new dictionaries in the overlap period.

Macromolecular standards. The wwPDB is responsible for a large and rapidly expanding collection of CIF definitions that encompass concepts and techniques used in the macromolecular community. The wwPDB continues to develop powerful tools for easy deposition of, and access to, data in $\mathrm{mmCIF} / \mathrm{PDBx}$ form, and continues to encourage an active community of users. In 2017, the wwPDB PDBx/mmCIF Working Group has drafted extensions describing macromolecular coherent diffraction experiments including definitions for describing data collection on potentially vast numbers of crystal samples.

Interactions with other standards groups. Collaboration with the NeXus project on harmonizing standards took a major leap forward during the Hyderabad meeting, with the approval by NeXus representatives of a method for wholesale incorporation of CIF data into NeXus files. This is initially intended as a way for NeXus users to include experimental and sample information defined in mmCIF/PDBx dictionaries into raw data files, and is sufficiently flexible to allow any data names defined in CIF dictionaries to be included in a NeXus file. With the increasing adoption of Dectris Eiger detectors at macromolecular crystallographic synchrotron beamlines, it has become routine practice to use automatic software translation from the Eiger HDF5/Nexus data format to the imgCIF/CBF format both on-the-fly and via file systems.

COMCIFS is also closely involved with the new IUCr Committee on Data (CommDat). Chairs of both Committees attended the Committee meetings for COMCIFS and inaugural meeting for CommDat held during the Hyderabad Congress.

JSON. A standard for writing CIF data in the JSON format was approved by COMCIFS during 2017. It is expected that this will be useful when transferring structural data within web-based applications.

Hyderabad meeting. COMCIFS sponsored a one-day workshop devoted to creating CIF dictionaries prior to the IUCr Hyderabad Congress, with about 15 registered attendees. There was also a well attended Microsymposium discussing programming for CIF, NeXus and related file structures (MS107). A COMCIFS Committee meeting was also held during the Congress.

Looking forward. Over the last few years a considerable amount of work has fallen to a handful of people. This situation is not sustainable, particularly as the first generation of CIF experts move into retirement. The Chair plans to explore strategies to expand the community of people actively engaged with CIF development.

J. Hester, Chair

\section{IUCr Newsletter}

Two issues of Volume 24 and two issues of Volume 25 were produced in 2017. All four issues were 24 pages in length. The content covered the activities of the IUCr and of its Regional Associates and Commissions, news concerning crystallographers and crystallography in general, awards including the 11th Ewald Prize, and included obituaries, book reviews, meeting reports, future meeting announcements, a general meeting calendar, product advertisement features and adverts.

A President's column appeared in all four issues, the first three by Marvin Hackert and the fourth by new President Sven Lidin. Each issue devoted space to articles related to IUCr publications, such as those introducing new editors and special issues, and to outreach activities, for example reports on OpenLabs in Albania, Bolivia and Senegal and news of the IUCr crystal growing competition for schoolchildren. Important announcements were included, such as the retirement/ appointment of the IUCr Executive Secretary, publication of the 6th edition of International Tables Volume A and the launch of the IUCr Associates Programme; the IUCr-IUPAP Lightsources for Africa, the Americas and Middle East Project (LAAMP); and the W. H. and W. L. Bragg Prize for early career crystallographers.

A number of pages - and covers - were devoted to promoting the Hyderabad Congress, including publication of the Parallel and Special Activities Programmes; the final issue contained several Microsymposia reports. A report on the First Pan-African Conference on Crystallography in Cameroon was published, along with reports on meetings and workshops in Croatia, Cuba, Japan, Mexico, Nepal, Poland, South Korea, Switzerland and Vietnam.

Each issue was distributed electronically to approximately 13000 people. Print copies went to an average of 555 libraries and individuals, and were distributed at several meetings, including the Hyderabad Congress. In addition, 1000 reprints of the Crystallography in India section of Volume 15 Number 4 were made available at the Congress.

Bill Duax handled all editorial responsibilities, and Patti Potter was responsible for layout and all phases of production and distribution. Volume 25 Number 2 marked Bill and Patti's retirement from their roles as Editor and Production Manager, respectively, and the IUCr wishes to express its deep appreciation for their dedicated work in disseminating news to the crystallographic community for 25 years. It is planned to move the production of the Newsletter to the IUCr Office in Chester in 2018.

A. Sharpe, Managing Editor

\section{IUCr/Oxford University Press (OUP) Book Series}

In 2017 the highly esteemed Chair of the IUCr/OUP Book Series Committee, Professor Davide Viterbo, passed away whilst in office. Soon after the IUCr Congress in Hyderabad was held in August 2017, I was invited by the IUCr President, 
Sven Lidin, to become the new Chair. I agreed, and consulted the IUCr OUP Agreement (and its detailed Appendices in the Annex of the Agreement). This explained that collated reports from the Book Series Committee members on a specific book proposal are transmitted by the Chairman to the IUCr Executive Committee by the IUCr Executive Secretary and (presumably at the same time) to OUP, the contact person at OUP being Sonke Adlung. The decision to proceed with a proposal or not is finally that of OUP and its Delegates, and is outside the control of the IUCr.

In consultation with the IUCr President and the IUCr Executive Secretary, a diverse and highly experienced Book Series committee has been assembled: J. R. Helliwell (Chair, UK); G. Chapuis (Switzerland); J. Gulbis (Australia); R. Herbst-Irmer (Germany); H. Maynard-Casely (Australia); P. Mueller (USA); M. Nespolo (France); N. Yagi (Japan); X. Zou (Sweden); K. A. Kantardjieff (USA; ex officio as Chair of the Commission on Crystallographic Teaching); S. Adlung ( $e x$ officio representative of Oxford University Press).

The books published within the book series stretch back about 20 years and are now commissioned in two categories: Monographs on Crystallography and Texts on Crystallography.

I thank the members who have retired: Christian Baerlocher (Switzerland), Peter Colman (Australia), Yuji Ohashi (Japan), Thomas Mak (Hong Kong China) and Adam Pietraszko (Poland).

For the upcoming BCA Conference in March 2018 I submitted an abstract about the book series. This has been accepted as a poster, whose aim is to assist a community consultation especially towards new topics and our next authors. This consultation is planned to extend further via a presentation at the ECM31 in Oviedo, Spain.

The IUCr offices have also very nicely redesigned the books section of the IUCr website (https://www.iucr.org/publications/ iucr-oup).

My internal consultations with our Committee members thus far have led to several ideas for new topics for books and authors, which are being pursued.

J. R. Helliwell, Chair

\section{Regional Associates and Scientific Associates}

\subsection{American Crystallographic Association}

The American Crystallographic Association, Inc. (ACA; $\mathrm{http} / /$ www.amercrystalassn.org) is a nonprofit, scientific organization of under a 1000 registered members. The ACA was founded in 1949 through a merger of the American Society for X-Ray and Electron Diffraction (ASXRED) and the Crystallographic Society of America (CSA). The objective of the ACA is to promote interactions among scientists who study the structure of matter at atomic (or near atomic) resolution.
The 2017 ACA Council consisted of Amy Sarjeant (President), Lisa Keefe (Vice-President), Tom Terwilliger (PastPresident), S. N. Rao [Chief Financial Officer (CFO) and Interim Treasurer], Sue Byram (Treasurer), Diana Tomchick (Secretary) and George Lountos as Young Scientists Special Interest Group (YSSIG) representative to the Council (ex officio). Tomislav Friscic served as the Canadian National Committee for Crystallography (CNCC) representative, Bill Duax as Chief Executive Officer (CEO), Kristin Stevens as a new Executive Secretary (Marcia Colquhoun has accepted the offer to serve as a consultant for 2018) and Hanna Dabkowska as the IUCr representative (ex officio). The Council met three times in 2017.

The 2017 (67th) Annual Meeting (http://www.amercrystalassn. org/2017-meeting-homepage) was held at the Hyatt-Regency Hotel in New Orleans, 26-30 May. Yulia Sevryugina and Ilia Guzei co-chaired this meeting. 2016 Nobel Laureate in Chemistry, Sir James Fraser Stoddart, presented the captivating Special Plenary Lecture. 544 attendees took part in the meeting, $27 \%$ were female. Excellent meeting statistics are available at http://www.amercrystalassn.org/2017-meetinghomepage.

The 2017 ACA Award Winners are Christine Durham (Etter Early Career Award), Helen M. Berman (David Rognlie Award), James O'Brien (Elizabeth Wood Science Writing Award) and Zbigniew Dauter (Patterson Award). This meeting was supported by about 26 sponsors; this time, the IUCr did not support the young scientists as it was the Congress year.

The 2017 ACA Fellows were Marilyn Olmstead and Brian Toby. This title recognizes a high level of excellence in scientific research, teaching and professional duties, but also service, leadership and personal engagement in the ACA and the broader world of crystallography and science.

The 2018 (68th) Annual ACA Meeting will be held on 20-24 July, in Toronto, Ontario, Canada. The Chairs are Gerald Audette and Tiffany Kinninbrugh. The Keynote speaker will be John Polanyi, 1986 Nobel Prize winner in Chemistry.

The 2019 (69th) Annual ACA Meeting is planned in Covington, KY.

Structural Dynamics, an ACA/AIP journal (http://aca. scitation.org/sdy/info/focus), achieved an impact factor of 2.968 in 2017.

The CFO (Rao) reported to the Council stressing that the 2017 budgeted project losses and more ways to cut costs should be discussed.

The CEO (Bill Duax) provided recommendations for the CEO and Headquarters further transition in 2017-2018. He will also draft a succession plan in case of an unexpected departure from his position as CEO.

The new CryoEM Special Interest Group (SIG) is now active (http://www.amercrystalassn.org/main-sig-cryo-em), the Chair is Catherine Lawson, the Chair Elect is Rui Zhao and the Secretary is Dominika Borek.

The formation of the Best Practices for Data Analysis and Archiving SIG was approved and the Officers are Nicholas 
Sauter (Chair), John Rose (Chair-elect) and Suzanna Ward (Secretary).

The Council will suggest candidates via e-mail for the Charles Supper Award, to be awarded at the 2018 Toronto ACA Meeting.

The results of the ACA 2017 election are as follows: Joseph Ferrara was elected for Vice-President, Diana Tomchick reelected as the Council Secretary, David Rose is a new Canadian Representative, Krystle McLaughlin will chair the Communications Committee, Peter Wood the Education Committee and Paul Sanschagrin the Data, Standards \& Computing Committee.

Ed Stevens volunteered to take over from Tom Koetzle as one of the editors of the ACA Newsletter.

The ACA History Portal run by Virginia Pett was financially supported.

The ACA supports African Crystallography initiatives.

The ACA Summer Course for Chemical Crystallography will be held 10-17 June on campus at the University of Notre Dame. Further information can be obtained from info@acasummercourse.net. The organizers are Allen Olivier, Amy Serjeant, Charlotte Stern and Christos Malliakas.

The Canadian National Committee for Crystallography (CNCC; http://xtallography.ca/) is chaired by Patrick Mercier, the Vice Chair is Tomislav Friscic, the Secretary is Michel Fodje and the Treasurer is Brian Patrick.

H. A. Dabkowska, IUCr Representative

\subsection{Asian Crystallographic Association}

AsCA continues to play a leading role in the nurturing of collective crystallographic activities in the Asia-Pacific region with successful scientific meetings being held in those years in which there is no IUCr Congress and General Assembly. The most recent AsCA meeting was held in Hanoi (December 2016), and was close to breaking even.

AsCA Executive officers. In 2017 the office bearers of AsCA (elected in Hanoi December 2016) were Jennifer Martin (President, Australia), Xiao-Dong Su (Vice-President, China), Edward R. T. Tiekink (Secretary/Treasurer, Malaysia) and Pinak Chakrabarti (Immediate Past President, India).

AsCA scientific meetings in 2017. No AsCA scientific meeting was held in 2017, due to the IUCr Congress and General Assembly held in Hyderabad in August 2017. At the General Assembly, Bangladesh and Singapore became full members of the IUCr; the President of AsCA, Jennifer Martin, was elected onto the IUCr Executive Committee; and Melbourne, Australia, was selected as the venue for the IUCr 2023 Congress.

An AsCA Council Meeting was held in Hyderabad on 26 August 2017 (at the IUCr Congress). Cambodia was approved as a category $\mathrm{B}$ member (with the inability to pay the fee noted) and will be nominated to membership of the IUCr Regional Committee from Asia (along with Malaysia, Thailand and Vietnam) (with fees paid by AsCA).
Future AsCA meetings. The 15th AsCA Conference (AsCA 2018) will be held in Auckland, New Zealand, 2-5 December 2018. Professors Chris Squire and Kurt Krause lead the local organizing committee (LOC) and Professor Ted Baker is Programme Chair. There is potential competition for delegates with a MOF conference scheduled soon after. Workshops will be included in the programme. Six of the 15 members of the International Programme Committee (IPC) are women. The IUCr has strengthened its policy on representation and urges its member organizations to implement actions to address diversity - especially gender equity - in conferences. A first step is to define conference policy and make the policy public on the conference website, and report on the data, e.g. the number of women and men attendees, the number of women and men members of the LOC and IPC, the number of women and men invited as Keynote and Plenary speakers, Microsymposia Chairs and Microsymposia speakers. The Programme Chair of the New Zealand AsCA meeting has announced their policy on the website at http://asca2018.org/ conference-policy/.

The 16th AsCA conference will be held in 2019 in Singapore, with Professor J. J. Vittal as the Local Chair (http:// www.chemistry.nus.edu.sg/events/CommunityOutreach/asca2019/ asca19.htm).

Malaysia will host the 17th AsCA Conference at Sunway University, Petaling Jaya, Malaysia, in December 2021.

AsCA website. The AsCA website, https://asca.iucr.org/, is currently being updated (thanks to Edward Tiekink).

\section{J. L. Martin, IUCr Representative}

\subsection{European Crystallographic Association}

The ECA is a scientific association among national members and individual members and corporate affiliates. It has 13 SIGs (Special Interest Groups) and 3 GIGs (General Interest Groups). The ECA main event - the ECM (European Crystallographic Meeting) - was not organized in 2017 because of the IUCr Congress in Hyderabad. However, the ECA council meetings and ECA executive committee (EC) meetings took place in India. The EC also organized one meeting with the SIG representatives and was also invited to the IUCr EC meeting there. SIG-14 D3-Dynamics, Disorder, Diffuse scattering was approved during the Council Meeting. SIG-02 Charge, Spin and Momentum Density asked to change its name to Quantum Crystallography similarly to the corresponding Commission of the IUCr.

The EC regular winter meeting was held in February 2017 in Asturias in Spain because the 31st ECM will be organized by the Spanish Crystallographic Association in Ovideo (22-27 August 2018, Chair: Santiago Garcia Granda). The organizers will offer a programme for children in order to attract young crystallographers with families and might also stream some lectures so that remote conference access will be possible. Streaming of lectures was discussed by the committee, but a decision was not reached. Problems with permissions were mentioned. In connection with the ECM, the EC also 
discussed how to improve poster presentations and the procedure for poster prizes. It was suggested that posters should be displayed for at least two days. Whole SIGs should be involved in the ECM programme preparation and, while the choices of speakers and Chairs are based primarily on science, attention should also be paid to gender and regional balance, where possible. Election of a new EC will take place in Oviedo, where a new ECA President, Vice-President, Secretary and Treasurer will be elected.

The ECM-32 will take place in the University of Vienna, Austria, 18-23 August 2019 (Chair: Klaudia Hradil). The ECM-33 will be in Versailles in France organized together with synchrotron Soleil.

The two ECA prizes, the Max Perutz Prize and the Erwin Felix Lewy Bertaut Prize, awarded to young scientists, were not given in 2017. Both will be awarded in 2018 in Oviedo.

The ECA schools, European Schools of Crystallography (ECS), are already regular and are organized under detailed ECA guidelines. The new GIG-3 on education is now intensely involved in the preparation of the schools. The fourth ECS was held in Warsaw, Poland, 2-7 July 2017, and was well attended. The fifth ECS will be in Stellenbosch (South Africa) in July 2018 and there is interest in holding the next in Budapest. It was suggested that an ECS could be organized every second year.

The Second Pan-African Conference on Crystallography will take place in Ghana in February 2019. An African Crystallography Steering Committee has been established and defined six African regions. There is a plan to found the African Crystallographic Association (AfCA) during the IUCr Congress in Prague in 2020.

The ECA has now about 300 individual members (fee: EUR 10 per year), about 20 corporate members (fee: EUR 250 per year), 37 national members and three observers. The income allows some support of schools and conferences but it is not too high. Seven meetings were supported in 2017, two in Italy, then one in each of Bulgaria, Czech Republic, Slovenia, Croatia, Tunisia and Switzerland. The total amount of support was over EUR 12000.

There is a contining problem with Russian membership, since Russia considers the ECA to be part of the IUCr; since they pay a fee to the IUCr, they cannot also pay a fee to the ECA.

The ECA is a member of the ISE (Initiative for Science in Europe) that moved to Strasbourg and has 17 member organizations. ISE appears to have solved many of its organizational problems and is ready to make its voice heard in the European science arena again. It was therefore suggested that ECA maintain its ISE membership. The ISE meetings are usually attended by the ECA Vice-President.

The ECA has two internet domains, https://crystallography.eu and https://ecanews.org, and has a presence in the main social networks [@social_eca (Twitter) and ecanews (Facebook)].

Discussion continues on how to strengthen the position of the ECA as a really European association, which has some legal issues (at the moment it is registered in The Netherlands according to Dutch law) and the possibility of professional management. There is also an option to include the organization of the ECM there, for example to have a core professional conference organizer. Proposals will be discussed during the ECA council meeting during the ECM in Oviedo.

R. Kuzel, IUCr Representative

\subsection{Latin-American Crystallographic Association}

\section{(1) Regional meeting}

As the IUCr Congress and General Assembly took place in 2017, there was no meeting of this Regional Associate in 2017. The III-LACA meeting will take place at Pontificia Universidad Católica de Valparaíso, in Valparaíso, Chile, on 10-12 October 2018, organized by Asociación Chilena de Cristalografía (AChCr).

Several workshops will be held before the meeting:

Curso de Difracción de rayos X y Base de datos PDF-4 ICDD, 9 October 2018, Universidad Federico Santa María (UFSM), Departamento de Ingeniería Metalúrgica y de los Materiales, Valparaíso, Chile. Organizers and instructors: Dr Claudio Aguilar (UTFSM-Valparaíso) and Dr José Miguel Delgado (Universidad de los Andes-Venezuela).

Olex2 at LACA in Valparaíso, 8-9 October 2018. Instructors: Oleg Dolomanov and Horst Puschmann (OlexSys).

Protein Crystallography Course: from Theory to Practice, 16-20 October 2018, Universidad de Chile, Santiago, Chile. Organized by Laboratorio de Bioquímica y Biología Molecular, Universidad de Chile. https://sites.google.com/view/ mxcienciasuchile.

The place and dates for the IV-LACA meeting in 2019 will be decided at the Assembly during the III-LACA meeting in Chile. Colombia has prepared a bid for the IV-LACA with Professor José Antonio Henao from UIS, Bucaramanga, as the Chair of the Organizing Committee.

(2) Participation of Latin-American crystallographers in international events

Latin-American crystallographers participated in the 24th Congress and General Assembly of the IUCr, in Hyderabad, 21-28 August 2017, as invited speakers, Microsymposia Co-chairs, members of IUCr Commissions, delegates, and oral and poster presenters. All member countries from Latin America with a crystallography society or association were represented at the General Assembly. Several Commissions incorporated new members from Latin America. LACA hopes to increase its representation in all IUCr Commissions.

Participation in the International Crystal Growing Competition. Argentina and Uruguay were awarded the Gold, Silver and Bronze Medals in the 2017 edition of the competition (see below). We would like to highlight the efforts of these two associations in promoting science through crystallography at the elementary-, middle- and high-school levels.

IUCr Crystal Growing Competition: under 11 category (primary school) (source: https://www.iycr2014.org/participate/ competition-winners/2017-winners): 
Gold medal 134585 Authentic Argentinian Crystallographers, Escuela San José de Calasanz, San Juan, Argentina.

Silver medal 134424 Joyas cristalizadas, Escuela No. 65, Uruguay.

Bronze medal 134426 El mundo de los cristales, Escuela No. 65, Uruguay.

(3) Activities by country

The following countries have a crystallography association.

Argentina. The XIII Meeting of Asociación Argentina de Cristalografía (AACr) took place at Universidad del Sur, Bahía Blanca, Buenos Aires Province, 1-3 November 2017. The event was suported by CONICET, Ministerio de Ciencia, Tecnología e Innovación Productiva, Universidad del Sur, the IUCr and Bruker, among other institutions.

Satellite events: VI Taller de la Asociación Argentina de Cristalografía: Vinculación del Sector Científico Cristalográfico y el Sector Productivo Nacional, 31 October 2017 at UAT-CCT CONICET Bahía Blanca; IX Escuela de la Asociación Argentina de Cristalografía (6-10 November 2017), Course 1: Dispersión a Bajo Ángulo y Reflectometría de Rayos X. Teoría, Análisis de Datos y Aplicaciones, Course 2: Difracción de Rayos X en Polvo: Fundamentos y Aplicaciones, UAT-CCT CONICET Bahía Blanca.

The XIV Annual Meeting of the AACr will be from 31 October to 2 November 2018 at Centro Atómico Constituyentes of Comisión Nacional de Energía Atómica (CNEA) in San Martín, Buenos Aires Province. The theme of the school will be X-ray Diffraction in the Study of Phase Transitions. Professor Mike Glazer is among the instructors. The PreCongress Workshop for Operators and Users of X-ray Diffraction Laboratory Equipment will be on 30 October at the same venue.

Three hundred and fifty secondary schools registered for 4th edition of the Crystal Growth Competition for Secondary Schools of the Argentinian Crystallographic Association (AACr), and 265 entries (videos or written reports) were received. The jury selected 13 finalists for the final round, which took place at Facultad de Ciencias Exactas y Naturales de la Universidad de Buenos Aires, Buenos Aires, on 14 November 2017. At this event, the finalists presented their crystals and their work before the jury. Additionally, 21 groups received Special Distinctions and were invited to also present their work at this event. At the end of the day there was an award ceremony. This activity was funded by Consejo Nacional de Investigaciones Científicas y Técnicas (CONICET), Fundación José A. Balseiro, Facultad de Ciencias Exactas y Naturales of Universidad de Buenos Aires, Universidad Nacional de General San Martín and Comisión Nacional de Energía Atómica (CNEA). The 2018 edition of the Crystal Growth Competition is already open, and entries will be received until 1 September 2018.

The AACr conducted 44 Crystallography and Crystal Growth Workshops for Teachers in preparation for the Argentinian Crystal Growth Competition for Secondary Schools and the International Crystal Growing Competition of the IUCr. The workshops were taught in the 24 provinces of the country by members of the AACr. These activities have taken place since 2014, the International Year of Crystallography, with partial support from CONICET.

The course Cristalografía en Biología Estructural - Cómo y para qué Obtener el Cristal de una Proteína? (Crystallography in Structural Biology - How to Grow Protein Crystals and Why it is Important?) took place in Ciudad Autónoma de Buenos Aires, Argentina, 17-28 July 2017. This is a LatinAmerican course supported by Centro Latinoamericano de Formación Interdisciplinaria, CELFI.

The course Método de Rietveld Aplicado a Difracción de Rayos X de Polvos took place in Ciudad de La Plata, Provincia de Buenos Aires, Argentina, 28 August - 1 September 2017.

IUCr Crystal Growing Competition: We are pleased to report that the Argentinian Team Authentic Argentinian Crystallographers from Escuela San José de Calasanz, San Juan, obtained the Gold Medal in the 2017 edition of IUCr's Crystal Growing Competition in the primary-school category (under 11).

Brazil. Two major events took place in 2017 as part of the activities of Associação Brasileira de Cristalografia (ABCr):

Twenty-Third Meeting of the Brazilian Crystallographic Association (ABCr), 5-9 September 2017, at Universidade Federal do Espírito Santo (UFES), Vitória, ES. This meeting takes place every two years. This time 121 participants attended the meeting from all over Brazil. Simon Billinge (Columbia University, USA) and Adriana Serquis (Centro Atómico Bariloche CNEA, Argentina) were invited speakers at this event. Financial support was provided by CAPES, CNPQ, CREA-ES, ArcelorMittal, Bruker, Rigaku-DAIRIX, Malvern-Panalytical, Facto, Instituto Federal do Espírito Santo, Universidade Federal do Espírito Santo, VALE, Grupo de Física Aplicada-UFES, Prefeitura de Vitória, Planetário de Vitória and others.

Satellite event: 7o Workshop de Cristalografia Aplicada a Engenharia de Materiais (7th Workshop on Crystallography Applied to Materials Science), 5-7 September, preceded the $\mathrm{ABCr}$ meeting. This was a very successful event with 53 participants, including graduate students, engineers and young researchers from different Brazilian institutions.

The course Método de Rietveld 2017 at the Santo André campus of UFABC, 11-15 December 2017, was organized by Dr Fabio Furlán Ferreira and members of Laboratório de Cristalografia e Caracterização Estrutural de Materiais (LCCEM) of Universidade Federal do ABC and Dr Selma Gutiérrez Antonio of Instituto de Química-UNESP. Financial support was provided by LCCEM-UFABC, Bruker and NOX, among other sources.

Professor Yvonne Mascarenhas received the IUPAC-2017 Distinguished Women in Chemistry or Chemical Engineering Award during the 46th World Chemistry Congress of the International Union of Pure and Applied Chemistry, in Sao Paulo, Brazil, 9-14 July 2017. Professor Mascarenhas is one of the most highly respected Latin-American crystallographers and this distinction was certainly well deserved.

At the 69th Annual Meeting of the Brazilian Society for the Progress of Science (SBPC), 16-22 July 2017, Belo Horizonte, 
MG, a short course Crystallography and Innovation was taught by Carlos Basílio Pinheiro (UFMG) and Nivaldo Lúcio Speziali (UFMG).

The 1st SPSLNX (São Paulo School on Scattering: Diffraction and Imaging using Light, Neutrons and X-rays) was organized by Cristiano L. P. Oliveira (IF-USP), Márcia C. A. Fantini (IF-USP), Eduardo M. S. Granado (IF-UNICAMP) and Heloísa N. Bordallo (Niels Bohr Institute, University of Copenhagen, Denmark), 17-21 July 2017 at IF-USP, São Paulo, SP. The invited instructors included Professor Otto Glatter (University of Graz, Austria), Professor Frank Scheffold (University of Fribourg, Switzerland), Professor Leopoldo Suescun (Universidad de la Republica, Uruguay) and Dr Nikolay Kardjilov (HZB - Helmholtz Zentrum Berlin, Germany).

Chile. Asociación Chilena de Cristalografía is organizing the III-LACA meeting for 2018. No information on activities for 2017 was received.

Costa Rica. The IUCr-UNESCO-LAAMP OpenLab took place 4-9 December 2017. This was a very important event for Costa Rica and Central America, as well as for our region. For this OpenLab, courses in single-crystal and powder diffraction were held. The venues were LANOTEC-CeNAT-CONARE (Opening Ceremony, first-day lectures and closing lectures and ceremony), Escuela de Química of Universidad de Costa Rica (single-crystal course) and Escuela de Ciencias e Ingeniería de los Materiales of Tecnológico de Costa Rica (powder diffraction course). A total of 114 people applied but, owing to space and equipment limitations and the hands-on character of the OpenLab, the number of participants for each course was limited to 25 . However, members of several institutions in Costa Rica were allowed to attend the lectures. The participants were graduate students, young researchers and industry personnel from Colombia (4\%), El Salvador (6\%), Guatemala (10\%), Mexico (6\%), Nicaragua (2\%), Panama (8\%), Peru (2\%) and Costa Rica (62\%). The organizers were José Roberto Vega (LANOTEC, UCCr) and Andrea Araya (Tecnológico de Costa Rica) and the sponsors and hosting institutions were CONARE, TEC, CeNAT, LANOTEC, Universidades Públicas, MICITT, CONICIT, IUCr, UNESCO, LAAMP, CCDC, ICDD, OPTIMED S.A., Bruker, PANalytical and Rigaku.

At the Opening Ceremony, participants were welcomed and and opening remarks were delivered by José Roberto Vega (LANOTEC/UCCr/Adjunct Secretary of LACA), Michele Zema (IUCr Executive Outreach Officer/IUCr-UNESCO OpenLab/LAAMP), Diego Lamas (President of LACA), Guiselle Tamayo (President of CONICIT), Cristian Campos (Director Escuela de Química-UCR), Federico Torres Carballo (Director of R\&D, MICITT), Jorge Cubero (Representing TEC) and Graciela Díaz de Delgado (Secretary of LACA and member of the IUCr Executive Committee).

The instructors for the single-crystal course were Graciela Díaz de Delgado (ULA, Venezuela), Vojtech Jancik (UNAM, Mexico), Pierre Le Maguere (Rigaku, USA), Bruce Noll (Bruker, USA), Leslie W. Pineda (University de Costa Rica, Costa Rica), Leopoldo Suescun (University de la República,
Uruguay), Serena C. Tarantino (University Pavia, Italy) and Michele Zema (IUCr and University Pavia, Italy).

The instructors for the powder diffraction course were John Faber (Marquette University, USA), Diego G. Lamas (CONICET and UNG-San Martín, Argentina), José Miguel Delgado (ULA, Venezuela/ICDD Regional Co-chair), Jorge Cubero (TEC, Costa Rica), Teodolito Guillén (TEC, Costa Rica), Tom McNaulty (Rigaku, USA), Ronald Mauricio García (PANalytical) and Felipe Torres (PANalytical).

This OpenLab helped to strengthen the collaboration among crystallographers from Central America and with other crystallographers in the LACA region. One very positive and encouraging outcome of this OpenLab was the subsequent course taught in Guatemala last May, as highlighted in the section for Guatemala below.

Mexico. The First International Meeting on Diffraction was organized in conjunction with the $\mathrm{V}$ National Meeting on Diffractometry and the National Meeting of Synchrotron Users in Mexico, 21-26 October 2017, in Mérida, Yucatán. As is traditional, several pre-Congress courses took place on 21-22 October. Plenary and Semi-Plenary Lectures and oral contributions were delivered by invited speakers from Argentina, Belgium, Brazil, France, Greece, Germany, Italy, the USA and Mexico. The topics covered in the pre-Congress courses and the instructors were as follows.

Electron Diffraction: Alfredo Gómez and David Romeu, Instituto de Física, UNAM, Mexico.

Synchrotron Light Diffraction: Abel Moreno (IQ-UNAM), Matías Moreno (IF-UNAM), Mayra Cuéllar, Gustavo Cruz, Guadalupe de la Rosa (U. de Guanajuato), Eric Juárez (U. Papaloapan), Daniel Hernández (U.A. Chiapas), Maria Elena Montero and Luis Fuentes (CIMAV), Jean Jakoncic (NSLS-2, USA), and René Loredo (IG-UNAM Unidad Noroeste).

X-ray Diffraction: Xim Bokhimi (Instituto de Física, UNAM, Mexico).

Diffraction: José Reyes-Gasga, Instituto de Física, UNAM, Mexico.

SAXS, a Technique to Analyse Nanomaterials: Rosario Espinosa (Anton Paar, Mexico).

7th Reunión de Usuarios de Luz de Radiación Sincrotrón, León, Guanajuato, Mexico, 3-6 October, 2017.

It is worth noting that Sociedad Mexicana de Materiales (SMM) organizes the International Materials Research Conference (IMRC) in collaboration with the Materials Research Society (MRS). This meeting takes place in Cancún every year in August, attracting close to 2000 participants from all over the world. The programme includes plenary lectures, workshops, tutorials, symposia, poster sessions and a commercial exhibit, all in a beautiful beach setting. Members of Sociedad Mexicana de Cristalografía frequently participate as Symposia Chairs and/or workshop organizers. In 2017, the programme included the Symposium Structural and Chemical Characterization of Metals and Alloys organized by, among others, Jesús Arenas (SMCr). Some members of the SMCr participated as speakers in this and other symposia.

Uruguay. The Macromolecular Crystallography School Structural Biology to Enhance High-Impact Research in 
Health and Disease took place 13-23 November 2017 at Institut Pasteur de Montevideo, Uruguay. It was organized by Alejandro Buschiazzo (Institut Pasteur, Uruguay), Ronan Keegan (CC4 Group, UK) and Richard Garrat (Universidade de Sao Paulo, Brazil). This school was the sixth edition of a series which started in 2010 in Uruguay. It is now run every year and the location alternates with Instituto de Física de Sao Carlos (U. Sao Paulo, Brazil). The collaboration with the $\mathrm{CCP} 4$ project has been very fruitful. The school was supported by Centro de Biología Estructural del Mercosur (CeBEM), the IUCr and Institut Pasteur. In this school, 15 instructors from the USA, UK, Germany, Spain, Brazil and Uruguay taught the 23 students selected from nine countries (the total number of applications was 45). The participants were advanced PhD students, postdocs and young researchers from Argentina, Brazil, Chile, Mexico, The Netherlands, Peru, Spain, the USA and Uruguay. The topics covered included data processing, phasing, molecular replacement, experimental phasing, macromolecular model refinement, data and model validation. Some time was also dedicated to cryoelectron microscopy. Two 'Burning Questions' sessions were held, along with poster presentations and short talks by the students at the end of the course. This school has certainly become a reference point in Latin America and has gained an excellent reputation.

The group from Facultad de Química, Universidad de la República, Uruguay, organized the Third Edition of the National Crystal Growing Competition (CNCC, Concurso Nacional de Crecimiento de Cristales). The organizers, N. Alvarez, I. Aguiar, M. Barros, I. Galain, R. Keuchkerian, M. Mombrú, I. Núñez, G. Peinado, M. Rodríguez and L. Suescun, are scientists from different research areas. As part of the preparations, the tutors receive training in workshops on growing crystals, growing an actual single crystal, keeping detailed records of the experiment and presenting the work as a video at the end to be judged. Participants were judged by the weight and quality of the crystal grown as well as their records of the experiment in terms of creativity and scientific rigour. More than 800 people, aged 7 to 30, have participated in the three editions of the CNCC. Their effort was rewarded with Silver and Bronze Medals for two teams (in the category for under 11 years old) at the last Crystal Growing Competition of the IUCr. A very interesting major prize, called 'Chemist for a Day', is awarded in the high-school category of the competition. Winners in this category are invited to the Facultad de Química to carry out simple inorganic and organic synthesis and to characterize their products by means of infrared spectroscopy, powder and single-crystal X-ray diffraction. During the day, teenagers work in research labs, operate equipment and discuss their results. It has become an activity that students and teachers look forward to.

Venezuela. Given the difficult economic situation in Venezuela, it has not been possible to organize as many meetings, workshops or other activities that require mobility within the country as were previously organized. Additionally, the presence of Venezuelan scientists at international meetings has decreased significantly owing to the impossibility of obtaining foreign currency to cover expenses abroad. As a Venezuelan, I have to say that, in spite of many adversities, we continue to work with the resources available. We have an excellent group of students interested in crystallography in our institutions. We have strengthened collaborations between research groups in the country and with research groups abroad, particularly with the X-ray Laboratory at Universidad Industrial de Santander in Bucaramanga, Colombia. We appreciate the support and solidarity of the crystallographic community around the world. In spite of these difficulties, there are some positive notes:

Lic. Analio J. Dugarte from the Crystallography Laboratory of Universidad de Los Andes (ULA), Mérida, Venezuela, received one of the Ludo Frevel Crystallography Scholarships awarded by the International Centre for Diffraction Data (ICDD). A. Dugarte is a PhD student working on incommensurate modulated structures of pharmaceutical compounds. The scholarship, USD 2500, will allow Lic. Dugarte to attend a meeting and to attend a school or workshop to get additional training in the solution and refinement of these interesting structures.

Access to the Cambridge Structural Database (CSD) for the Crystallography Laboratory at Universidad de Los Andes in Mérida and Instituto Venezolano de Investigaciones Científicas (IVIC) in Caracas was made possible through the Frank H. Allen International Research \& Education Programme (FAIRE) from the Cambridge Crystallographic Data Centre (CCDC). We are grateful to Dr Amy Sarjeant (CCDC) for her help.

The Venezuelan Catalysis Society held the XXI Congress at Universidad de Los Andes in Mérida, 13-15 November 2017. The theme of the Congress, Catalysis: a Bridge to Innovation and Development, provided an excellent opportunity to discuss new directions in the design of new catalysts for sustainable chemical processes. Several oral and poster presentations included characterization by powder-diffraction techniques by members of the X-ray Laboratory of IVIC, Caracas, and of ULA, Mérida. A School followed the Congress from 16 to 17 November and focused on Treatment of Heavy Crude Oil.

The traditional minerals exhibit was again presented at Encuentro con la Física, Química, Matemática y Biología, 2022 November 2017. This is an outreach activity of the School of Sciences at Universidad de Los Andes, Mérida, aimed at encouraging elementary- and secondary-school students to pursue undergraduate studies in science. Students from the Crystallography Laboratory, supervised by Professors J. M. Delgado and G. Díaz de Delgado, showed the students mineral samples from the laboratory's collection.

The following countries are without an established crystallography association.

Colombia. Colombia is one of the Latin-American countries with more financial resources dedicated to science than most. One important activity which took place in 2017 was the XVII Congreso Colombiano de Química, 25-27 October 2017, at Universidad Industrial de Santander (UIS), Bucaramanga. Crystallography had a very prominent place at this event. 
Several pre-Congress courses in chromatography, infrared spectroscopy, NMR, electron microscopy, thermal methods of analysis and a three-day course on X-ray diffraction preceded the main event. The X-ray diffraction workshop was organized by Professor José Antonio Henao of UIS-Colombia and Professor José Miguel Delgado of ULA-Venezuela. Professor Henao, Professor Delgado, along with Tom Blanton (ICDD, USA), Amy Sarjeant (CCDC, USA), Eric Reinheimer (Rigaku), G. Díaz de Delgado (ULA), Robert Toro (UIS), Hernando Camargo (UST, Colombia) and John Bonilla were the instructors. Fifty participants from academia and the industrial sector in Colombia and three Venezuelan students attended the pre-Congress course. The invited instructors gave semi-plenary lectures at the Congress, where they had additional time to present different advanced applications of X-ray diffraction techniques to the study of materials. Professor Henao is preparing a bid for the IV LACA meeting for Colombia in 2019. It is expected that the Colombian Crystallographic Society, which was formed about 20 years ago, could be revitalized for the IV LACA meeting.

Ecuador. The LACA Council was approached by the organizers of the I Congreso Internacional de Química, which will take place in Riobamba, Ecuador, 31 July - 2 August, to participate in the event. Ada Yonath, winner of the Nobel Prize in Chemistry in 2009, is the main invited speaker. Prior to the event, the workshop Introduction to Crystallographic Techniques will be taught by Diego Lamas (U. Nacional de San Martín, Argentina), José Miguel Delgado and Graciela Díaz de Delgado (ULA, Venezuela). This is a positive sign and we hope that there will be more crystallography-oriented events in Ecuador and that a crystallography society will be formed soon.

Guatemala. As a result of the success of the Costa Rica OpenLab, Guatemalan participants at the OpenLab started to explore the idea of establishing a Guatemalan Society for Crystallography. Professor José Miguel Delgado (Venezuela) and Professor Diego Lamas (Argentina) were invited to teach a workshop from 7 to 9 May 2018 at Universidad de San Carlos de Guatemala. Not only was the workshop a great success but the Asociación Guatemalteca de Cristalografía was also formed. We hope Guatemala will soon be incorporated in LACA and in take part in IUCr activities.

Other countries. Efforts are being made to incorporate Panama, Paraguay, Peru and Puerto Rico in LACA.

G. Diaz de Delgado, IUCr Representative

\subsection{International Organization for Crystal Growth}

No formal meeting of the IOCG (http://www.iocg.org/) was planned or organized in 2017.

The IOCG President for 2016-2019 is K. Kakimoto (Japan). Co-Vice-Presidents are T. F. Kuech (USA) and E. Vlieg (The Netherlands), the Secretary is H. Dabkowska (Canada), and the Treasurer is J. Derby (USA). The members of the EC are J. M. Garcia-Ruiz (Spain), Y. Mori (Japan), S. L. Baldochi
(Brazil), M. Heuken (Germany), S. Krukowski (Poland), A. Voloshin (Russia), J. Y. Wang (China) and J. De Yoreo (USA).

The connection with the Commission on Crystal Growth and Characterization of Materials (CCGCM) is obvious, as T. F. Kuech, K. Kakimoto, E. Vlieg, J. M. García-Ruiz, S. L. Baldochi and H. Dabkowska are also (or have been) members or consultants of the CCGCM.

The 19th International Conference on Crystal Growth and Epitaxy (ICCGE-19) will be held in Keystone, Colorado, USA, 28 July - 2 August 2019, and will be chaired by J. Derby and V. Fratell. The week before it will take place is the International Summer School on Crystal Growth ISSCG17, chaired by Joan Redwing and Tom Kuech, member of the CCGCM. Members and consultants of the CCGCM are strongly involved in the work of the Programme and Advisory Committees of this meeting. Moreover, we are also discussing the chance (as was done in the case of ICCGE-17 and ICCGE18) that some sessions could be officially co-organized by the IUCr.

Other important events for the crystal-growth community in 2017 were:

7th Asian Conference on Crystal Growth and Crystal Technology (CGCT-7), Changchun, Jilin, China, 15-18 October 2017.

IWGO 2017 2nd International Workshop on Gallium Oxide and Related Materials, Parma, Italy, 13-15 September 2017.

21st American Conference on Crystal Growth and Epitaxy (ACCGE-21) and 18th US Workshop on Organometallic Vapour Phase Epitaxy (OMVPE-18) and 3rd Symposium on Two-Dimensional Electronic Materials and Symposium on Epitaxy of Complex Oxides, Santa Fe, New Mexico, USA, 30 July - 4 August 2017.

The 9th International Conference on Advanced Materials, ROCAM 2017, and the 2nd International Symposium on Dielectric Materials and Applications, ISYDMA 2017, 11-14 July 2017, Bucharest, Romania.

International Summer School on Crystal Growth and Advanced Materials for Energy, Bucharest, Romania, 10-15 July 2017.

7th International Workshop on Crystal Growth Technology, Potsdam (near Berlin), Germany, 2-6 July 2017.

Gordon Research Conference on Crystal Growth and Assembly, University of New England, Biddeford, ME, USA, 25-30 June 2017.

A. Zappettini, IUCr Representative

\subsection{International Center for Diffraction Data}

The Commission on Powder Diffraction maintains close links with the ICDD and also with the International X-ray Absorption Society (IXAS) (http://www.ixasportal.net/ixas/).

D. Billing, IUCr Representative 


\subsection{Worldwide Protein Data Bank (wwPDB)}

The Worldwide Protein Data Bank (wwPDB) maintains the single global archive of experimentally determined structural data for biological macromolecules. It provides expert deposition, validation and biocuration services for depositors and ensures open public access at no cost, managing the PDB archive as a public good.

The wwPDB is structured as a consortium of partners in the USA (RCSB), Europe (PDBe) and Japan (PDBj) together with the specialist NMR data bank (BMRB). The wwPDB has a formal relationship with the IUCr as a Scientific Associate, reflecting the ongoing importance of crystallography to the deposited data and the long relationship with the IUCr in development of policies around deposition, validation and dissemination of data.

The structural archive continues to grow rapidly. At the end of 2017, the number of macromolecular crystallography entries was $>120000$, with an increase also in the size and complexity of the structures. The number of NMR entries has levelled off, but a steep rise is now occurring in the number of structures determined by cryoEM, driven by the recent technical advances. The number of new cryoEM entries in 2017 was $>500$, approximately equal to the number of new NMR structures. New deposition software (OneDep) is being implemented and is already seeing major advances in efficiency.

Validation of the deposited structures continues to be an extremely important role of the wwPDB. Validation policies and tools are developed by expert Task Forces. More rigorous validation of protein-ligand complexes has become an urgent issue recently, and the X-ray Validation Task Force, led by Professor Randy Read, is due to report on upgraded methods in the coming year. Much effort is also being expended to provide a validation framework for cryoEM structures.

A key feature of the wwPDB is that the experimental data on which the structures are based should also be deposited and available to users. Crystallographic data are archived by the wwPDB; these data, which traditionally have been structure-factor data only, can now include the unmerged data (but not yet the original raw data images). NMR experimental data are collected by the BMRB.

Electron microscopy maps are archived by the EM Data Bank (EMDB), which also carries out limited validation of these maps. With the dramatic growth of cryoEM that is now occurring, a decision was made at the October 2017 meeting of the wwPDB Advisory Committee to invite the EMDB to become a full partner in the wwPDB. This has now been approved.

Other current activities of the PDB include efforts to establish principles for deposition of small-angle scattering data, being developed by a Task Force led by Professor Jill Trewhella, and continued remediation of the existing database, focusing on carbohydrates

Edward N. Baker, IUCr Representative

\section{Representatives on Other Bodies}

12.1. IUPAC Interdivisional Committee on Terminology, Nomenclature and Symbols (ICTNS)

During 2017 I reviewed a manuscript for the journal Pure and Applied Chemistry titled Definition of the Mole. The only other activity related to crystallography was a memo describing a project to backup, maintain and redevelop the IUPAC's Gold Book website and asking for ideas about how the project might be made successful. There are clear parallels between the Gold Book and the Online Dictionary of Crystallography.

C. P. Brock, IUCr Representative

\subsection{International Council for Scientific and Technical Information}

The IUCr has been a member of the International Council for Scientific and Technical Information (ICSTI), as an affiliate of the International Council for Science (ICSU), for several years. This is an international not-for-profit membership organization engaged in the scientific communication process with the aim of improving the effectiveness of scientific research. Meetings of ICSTI take place twice a year in different international locations, during which talks are given by experts on a large range of topics related to scientific communication. Valuable though this can be, at the Finance Committee meeting in March 2018 the cost to the IUCr was discussed. While membership of ICSTI is relatively inexpensive, the addition of travel and subsistence costs for attendance in different parts of the world was considered to be very high, and given the current state of IUCr funds it was decided to withdraw from ICSTI.

\section{Glazer, IUCr Representative}

\subsection{International Council for Science (ICSU)}

The International Council for Science (ICSU) is a nongovernmental organization with a global membership that includes 30 international scientific unions and 122 national scientific bodies representing 142 countries. ICSU was founded in 1931 to promote international scientific activity in the different branches of physical sciences and its application for the benefit of humanity. It is one of the oldest nongovernmental organizations in the world and represents the evolution and expansion of two earlier bodies known as the International Association of Academies (IAA; 1899-1914) and the International Research Council (IRC; 1919-1931).

In 1998, its members agreed that the organization's activities would be better reflected by modifying the name from the International Council of Scientific Unions to the International Council for Science, while retaining the rich history of its existing acronym, ICSU. ICSU's strength and uniqueness lie in its membership consisting of both national scientific members and international scientific unions. This wide spec- 
trum of interdisciplinary expertise allows ICSU to address major international scientific issues. Heide Hackmann has been the Executive Director for ICSU since March 2015 and works with a staff of about 18 in Paris. ICSU has three regional offices, serving Africa (Pretoria, South Africa), Asia and the Pacific (Kuala Lumpur, Malaysia), and Latin America and the Caribbean (San Salvador, El Salvador).

The General Assembly (GA) of ICSU meets every three years and is responsible for setting the general direction, policies and priorities for the next triennium. The 32nd General Assembly of the International Council for Science was held in Taipei from 23 to 24 October 2017, followed by a joint meeting with the International Social Science Council (ISSC) on 25 to 26 October 2017. A priority of ICSU is to seek ways to strengthen the voice of global science in international policy. One example of an outcome of this initiative was the accord on Open Data in a Big Data World. The IUCr has been deeply involved in discussions on best practices to achieve the goals of open access which is also sustainable and 'FAIR' [Findable/Assessable (Accessible)/Interoperable/ Reusable] data.

However, the historic news of 2017 for ICSU happened during the joint meeting in Taipei. After two days of separate GA meetings by ICSU and ISSC, the Councils representing the natural and social sciences met jointly for two days to consider a merger of ICSU and ISSC. After reviewing statutes and rules of procedure, a vote was taken that overwhelmingly supported the merger of the two organizations. By French law this will involve a process whereby ISSC will first dissolve and then be adsorbed by ICSU. Assets and liabilities will be combined and then the merged ICSU will be renamed as ISC (International Science Council). Thus, an additional GA meeting is needed to complete the merger process and elect new officers. This meeting will take place in Paris from 3 to 5 July 2018.

The goal of ISC will be to emphasize that the importance of scientific understanding to society has never been greater, as humanity grapples with the problems of living sustainably and equitably on planet Earth. According to its mission statement, the new Council will act as the global voice of science. That voice will:

(i) speak for the value of all science and the need for evidence, informed understanding and decision-making;

(ii) stimulate and support international scientific research and scholarship on major issues of global concern;

(iii) articulate scientific knowledge on such issues in the public domain;

(iv) promote the continued and equal advancement of scientific rigour, creativity and relevance in all parts of the world; and

(v) defend the free and responsible practice of science.

Looking back, the relationship between the IUCr and ICSU has been long-standing and mutually beneficial. Through its Grants Programme, ICSU funded our efforts related to Building Science Capacity in Africa via Crystallography. More recently, Michele Zema led a successful effort whereby IUCr partnered with IUPAP on a larger, joint proposal supported by organizations such as UNESCO, TWAS etc. and a number of large-scale facilities to obtain a grant for EUR 300000 over three years. Initially, this project was called LAAMP (Lightsources for Africa, the Americas and the Middle East Project) but has since been expanded to include SE Asia and is now LAAAMP (Lightsources for Africa, the Americas, Asia and the Middle East Project). The full title of the project is Utilization of Light Source and Crystallographic Sciences to Facilitate the Enhancement of Knowledge and Improve the Economic and Social Conditions in Targeted Regions of the World. With this project, the IUCr partners with IUPAP and ICSU to enhance advanced light sources and crystallographic sciences in Africa, the Middle East, SE Asia, Mexico and Caribbean. The LAAAMP website has information about the activities of this project (https://laaamp.iucr.org/). We look forward to working with the new Council. At this time we do not expect the merger to change the funding obligation for our IUPAP/IUCr joint grant.

\section{L. Hackert, IUCr Representative}

\subsection{ICSU Committee on Data for Science and Technology (CODATA)}

CODATA is the interdisciplinary Committee on Data for Science and Technology of the International Council for Science (ICSU). Full details of CODATA activities are available from its website at http://www.codata.org.

Planning for CODATA's biannual conference and General Assembly is underway and is to be held in November 2018 in Gaberone, Botswana. This will again form part of an International Data Week, i.e. organized jointly by CODATA, the Research Data Alliance and the ICSU World Data System (see http://www.internationaldataweek.org/). For this event IUCr has joined in a proposal with IUPAC for a session there entitled Data Interoperability in Chemistry, Biology, and Crystallography: Enabling Multidisciplinary Solutions to Societal Challenges.

CODATA organized two workshops in 2017 on the theme of interoperability of scientific data in which IUCr took part, making oral presentations at each, firstly in Paris by John R. Helliwell and then in London by Simon Coles (as JRH alternate). IUCr is regarded as one of the disciplinary groups that have made considerable advances in exploiting modern data resources and thereby can provide examples and advice. CODATA's objectives with this obviously important initiative are stated as follows: 'A major potential (of science) remains unrealized: to merge and integrate the data from different disciplines in order to reveal deep patterns in the multifacetted complexity that underlies most of the major global challenges that humanity currently faces. This failing arises from the varying and incompatible standards that have been used across the disciplines of science to codify data, and, in some, inadequate definition of the vocabularies needed to categorize them, with the result that the integration of diverse data can generally only be achieved between closely allied fields. Characterizing, understanding, and dealing with the 
Table 1

Income and expenditure account (in USD) for the year ended 31 December 2017.

All the income and expenditure related to continuing activities. Historic cost results would only differ from above by the profit or loss on sale of investments. Separate Statements of Total Recognized Gains and Losses and Reconciliation of Movements in the Fund Account are not given, as the information is incorporated in the above.

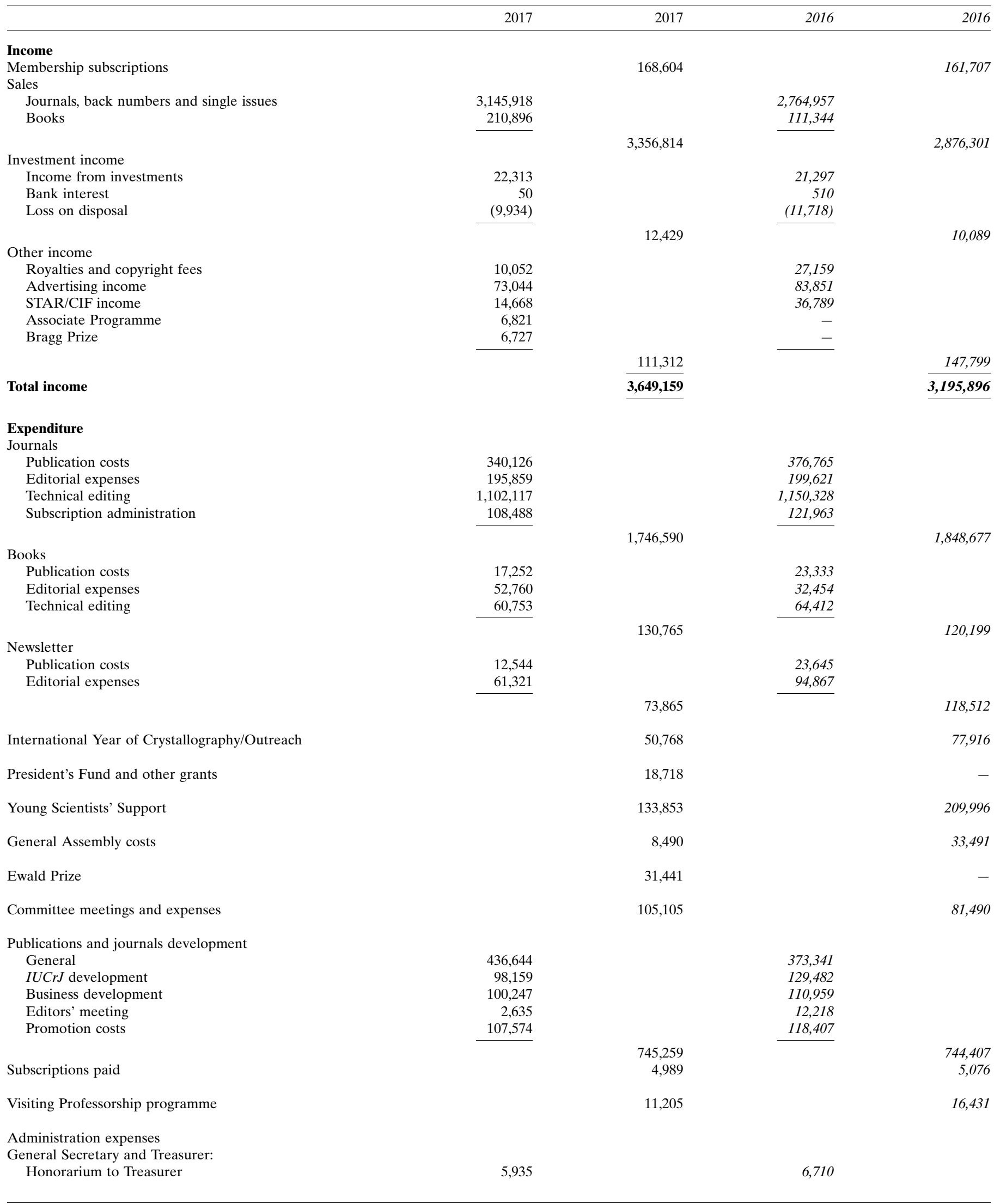


Table 1 (continued)

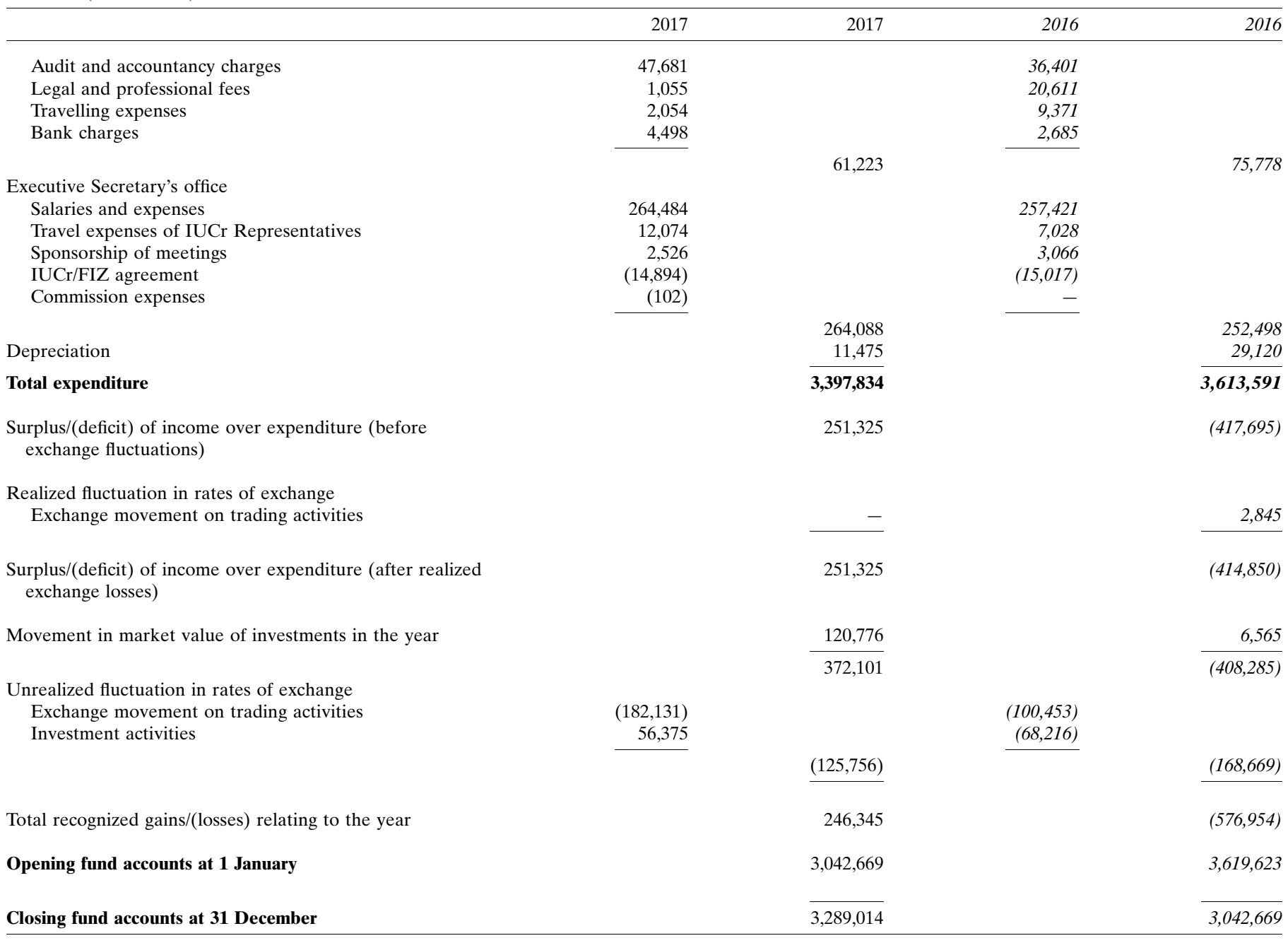

complexity inherent in major global challenges will be integral to the mission of the new International Science Council that will come into being in July 2018 ... The plan is to develop proposals for major cross-disciplinary data integration projects to advance solutions for important global challenges aligned with the United Nations Sustainable Development goals such as in infectious diseases, sustainable cities, and disaster risk reduction.'

\section{J. R. Helliwell, IUCr Representative}

\subsection{ICSU Committee on Space Research (COSPAR)}

COSPAR's (http://cosparhq.cnes.fr/) main objective is to promote international collaboration in scientific research in Space, with an emphasis on the exchange of results, information and opinions. It is responsible for developing world standards for the space environment and its protection.

COSPAR's highest body is the Council. The Council comprises the Committee's President, representatives of member national scientific institutions and international scientific unions, the Chairs of COSPAR scientific commis- sions, and the Chair of the Finance Committee. The Council meets at the Committee's biennial Scientific Assembly. Between Assemblies on a day-to-day basis COSPAR is run by the Bureau.

COSPAR President for the period 2014-2018 is Lennard A. Fisk (USA) and the Vice-Presidents are J. Wu (People's Republic of China) and A. Jayaraman (India). Members of he Bureau are: Ines S. Batista (Brazil), C. Cesarsky (France), K.-H. Glassmeier (Germany), M. I. Panasyuk (Russia), S. Sasaki (Japan) and J.-P. St Maurice (Canada).

The most recent 40th COSPAR Assembly was held in Moscow, Russia, in August 2014.

The 41st Assembly planned in Istanbul, Turkey for 2016, was cancelled because of the military coup. This was unfortunate, as the opportunity for scientific dialogue essential to the operation of COSPAR was lost.

COSPAR 2018 will be held in Pasadena, California, USA, 14-22 July 2018, whereas COSPAR-2020 was voted to take place in Sydney, Australia, on 15-23 August 2020.

During the Pasadena Congress there will be a session COSPAR Capacity Building Initiative: a Review of the Last 15 Years and How to Face the Next 10, which will be addressing 
Table 2

Balance sheet (in USD) as at 31 December 2017.

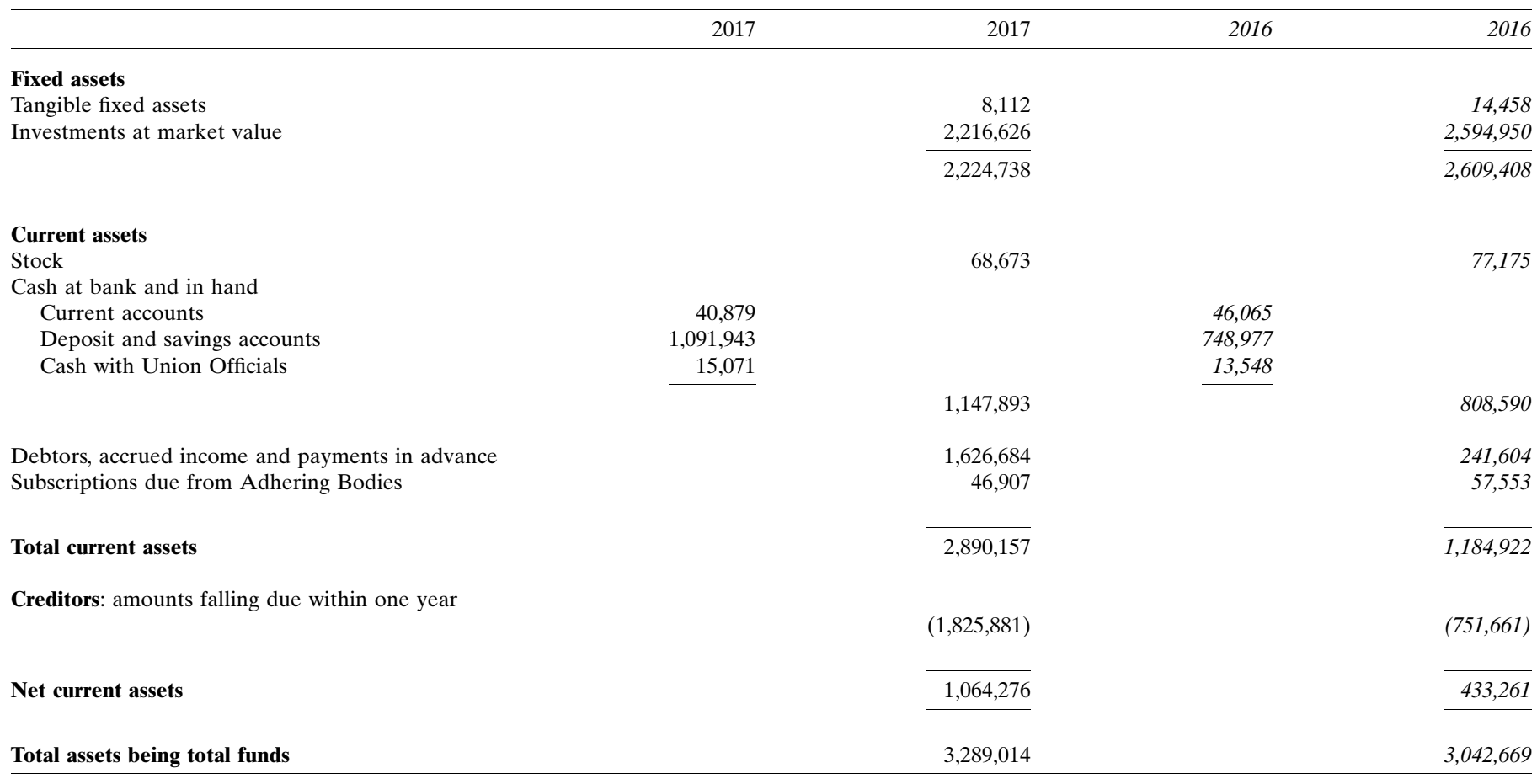

the question of whether the very successful capacity building programme should be continued and in what format. The IUCr was invited to take part in this discussion as a follow-up to the very well received Capacity Building Workshop on Crystallography for Space Science organized by Juan M. Garcia-Ruiz, Hanna A. Dabkowska, Maria Eugenia Mendoza, Guillermo T. Tagle and Mariano Mendez in the INAOE site in Puebla, Mexico in April 2016 (http://www.inaoep.mx). If time permits I would like to participate in the discussion, making a statement about possible similar future collaborations between the IUCr and COSPAR.

Advances in Space Research (ASR), http://ees.elsevier.com/ asr/, which had an impact factor of 1.40 in 2016, is the official journal of COSPAR. ASR also includes COSPAR's information bulletin, Space Research Today. The newest COSPAR journal, Life Sciences in Space Research, is a quarterly peerreviewed scientific journal covering astrobiology, origins of life, habitability, life in extreme environments, effects of spaceflight on the human body, radiation risks, and other aspects of life sciences relevant in space research.

In 2017 COSPAR organized four capacity-building workshops, covering a large variety of new areas:

International Reference Ionosphere 2017 Workshop: Improved Real-Time Ionospheric Predictions with COSMIC and Other GNSS Data, 6-17 November 2017, Taoyuan City, Taiwan, China.

Small Satellites, Big Sciences, 10-17 September 2017, Daejeon, South Korea.

Interdisciplinary Remote Sensing, Modelling and Validation of Environmental Processes, 12-23 June 2017, Kumasi, Ghana.
Latin American X-ray School for Different Astrophysical Scenarios, 20 February - 3 March 2017, Viedma, Argentina.

COSPAR also co-organizes/co-sponsors a limited number of meetings and colloquia each year that are of interest to its Associates. More information about this initiative can be found at https://cosparhq.cnes.fr/events/co-sponsoredmeetings.

\section{H. A. Dabkowska, IUCr Representative}

\subsection{International Organization for Standardization}

There were no activities in 2017 that related to crystallography.

C. P. Brock, IUCr Representative

\section{Finances}

Extracts from the full financial statements, namely the income and expenditure account and balance sheet, are given in Tables 1 and 2, respectively. For comparison, the figures for 2016 are provided in italics. The accounts are presented in USD.

Transactions denominated in foreign currencies are translated into US dollars at the rates ruling at the dates of the transactions. Monetary assets and liabilities denominated in foreign currencies at the balance sheet date are retranslated at the rates ruling at that date. 


\section{international union of crystallography}

Investments are stated at market value. Changes in market value are taken through the income and expenditure account.

The virtual fund model that has been used in previous years has been discontinued as it created unnecessary complexity, increased accountancy costs and will make the eventual movement to electronic accounting software more difficult.

The balance sheet shows that the assets of the Union have increased during the year, from USD 3,042,669 to USD $3,289,014$. The movement in market value of the investments was USD 120,776 in 2017 (USD 6,565 in 2016).

The administrative expenses were USD 325,311 in 2017 as compared with USD 328,276 in 2016.

The expenses of the Union Representatives on other bodies were USD 12,074. The cost of the Finance Committee meetings held in 2017 was USD 16,410, while the Executive Committee meetings cost USD 88,695. The income from the IUCr/Fachinformationszentrum agreement (to provide lowcost copies of the Inorganic Crystal Structure Database) was USD 14,894. The subscriptions from Adhering Bodies were USD 168,604. Interest on bank accounts and investments credited to the General Fund was USD 22,363.

The journals for 2017 show a surplus of USD 1,399,328, as compared with a surplus of USD 916,280 in 2016. The majority of this increase is due to the weakness of the pound sterling when the income from Wiley was being converted from USD for payment.

The cost of the technical-editing office has been divided between the journals and International Tables in percentages based on the staff time spent on each publication. The technical-editing costs for the journals were USD 1,102,117 as compared with USD 1,150,328 in 2016.

Books showed a profit of USD 80,131, as compared with a deficit of USD 8,855 in 2016. The net sales income was USD 210,896 in 2017 as compared with USD 111,344 in 2016.

The cost for the Union in producing the IUCr Newsletter in 2017 was USD 73,865.

USD 133,853 was provided for financial support to young scientists, to enable them to attend scientific meetings sponsored by the Union. Visiting Professorships (USD 11,205), outreach and education costs (USD 50,768), and grants totalling USD 18,718 paid from the President's Fund in 2017 also contributed to the IUCr's good works.

The unusually large values in the Creditors and Debtors sections relate to an underpayment of UK VAT on journal income for four years. As this had not been passed to the Union by Wiley, the two amounts offset each other.

An Outreach and Education Fund has been established. In 2017 donations totalling USD 27,522 were received. 